\title{
Methodology to determine post yield material mechanical properties from spherical indentation
}

\author{
Bharath Konda \\ West Virginia University
}

Follow this and additional works at: https://researchrepository.wvu.edu/etd

\section{Recommended Citation}

Konda, Bharath, "Methodology to determine post yield material mechanical properties from spherical indentation" (2005). Graduate Theses, Dissertations, and Problem Reports. 1603.

https://researchrepository.wvu.edu/etd/1603

This Thesis is protected by copyright and/or related rights. It has been brought to you by the The Research Repository @ WVU with permission from the rights-holder(s). You are free to use this Thesis in any way that is permitted by the copyright and related rights legislation that applies to your use. For other uses you must obtain permission from the rights-holder(s) directly, unless additional rights are indicated by a Creative Commons license in the record and/ or on the work itself. This Thesis has been accepted for inclusion in WVU Graduate Theses, Dissertations, and Problem Reports collection by an authorized administrator of The Research Repository @ WVU. For more information, please contact researchrepository@mail.wvu.edu. 


\title{
Methodology to Determine Post Yield Material Mechanical Properties from Spherical Indentation
}

\author{
Bharath Konda \\ Thesis submitted to the \\ College of Engineering and Mineral Resources \\ at West Virginia University \\ in partial fulfillment of the requirements \\ for the degree of \\ Master of Science \\ In \\ Mechanical Engineering \\ Bruce S. Kang, Ph.D., Chair \\ Jacky C. Prucz, Ph.D. \\ Charles F. Stanley, Ph.D. \\ Department of Mechanical and Aerospace Engineering \\ Morgantown, West Virginia \\ 2005
}

Keywords: Spherical indentation, Finite element method, mechanical properties Copyright 2005 Bharath Konda 


\section{Abstract \\ Methodology to Determine Post Yield Material Mechanical Properties from Spherical Indentation}

\section{Bharath Konda}

Conventional material testing methods, such as tensile tests require the preparation of specimens and is not applicable for small-size coupons or on-site, in-situ testing. In this research, a method of determining material stress-strain curve based on spherical indentation is studied. Spherical-indentation process is analyzed by finite element (FE) method and a systematic analysis of relationships between indentation parameters and true stress/plasticstrain $\left(\sigma_{\mathrm{t}}-\varepsilon_{\mathrm{p}}\right)$ curve is performed for a range of material properties. A detailed methodology based on Tabor's empirical formula and Meyer's law is developed to determine the material strain hardening properties, Young's modulus and yield strength. It is noticed that Tabor's empirical formula is valid in the plastic region (deep indentation) with a small percentage error in the calculated values of yield strength. Based on the FE results, strain values have been predicted corresponding to which indentation gives satisfactory output. Steel and aluminum alloys, with same Young's modulus and yield strength but with different strain hardening coefficients, were selected for the simulation. FE simulation of 20 material models was performed. It is observed that the Tabor's constant is not equal to the value of 2.8 but takes different values for different materials. From the results it is concluded that the value of Tabor's constant decreases as the strain hardening value increases. 


\section{Acknowledgements}

I would like to thank Dr.Bruce Kang for providing me with an opportunity to work with him, and for his guidance and technical advice. His support and patience during the course of

my research work deserve a special mention. I would also like to thank Dr.Jacky C.Prucz, and Dr.Charles F.Stanley, for their technical guidance and advice.

I wish to express my sincere thanks to Ziheng Yao. Without his help it would have been very difficult to accomplish the amount of work that I have been able to in the last few years. Ziheng Yao had provided me invaluable analysis knowledge and for this I thank him.

Finally, I would like to thank my parents and brother for their moral support and encouragement throughout my graduate studies. I dedicate my research thesis to them. 


\section{Table of Contents}

Abstract $\quad$ ii

Acknowledgements $\quad$ iii

Table of contents $\quad$ iv

List of figures vii

List of tables

List of symbols $\quad$ xii

Chapter 1. Introduction

1.1 Indentation hardness 1

1.2 Static indentation hardness 2

1.2.1 Brinell hardness test 2

1.2.2 Meyer Hardness 3

1.2.3 Vickers hardness 3

1.2.4 Rockwell hardness test 4

1.3 Research Objective 6

Chapter 2. Literature Review

2.1 Instrumented Indentation for Hardness and Material Properties 7

2.2 Analysis Techniques $\quad 8$

$\begin{array}{ll}2.3 \text { Use of instrumented indentation testing } & 10\end{array}$

2.4 Previous FEM analyses 11

2.5 Meyer's Law 12

Chapter 3. Methodology

3.1 Methodology proposed in the current research 14

3.1.1 Determining strain hardening exponent 14 


\section{Chapter 4. Finite Element Modeling}

$\begin{array}{ll}\text { 4.1 ABAQUS software } & 17\end{array}$

$\begin{array}{ll}\text { 4.2 Solving the problem using ABAQUS } & 18\end{array}$

$\begin{array}{ll}\text { 4.2.1 Solver used } & 19\end{array}$

4.3 Indentation modeling $\quad 19$

$\begin{array}{ll}4.4 \text { Element used } & 20\end{array}$

$\begin{array}{ll}4.5 \text { Indenter modeling } & 20\end{array}$

4.6 Specimen modeling $\quad 21$

4.7 Boundary condition and load 25

$\begin{array}{ll}4.8 \text { Interaction between indenter and specimen } & 26\end{array}$

$\begin{array}{ll}4.8 .1 \text { choosing the master and slave surfaces of a contact pair } & 27\end{array}$

4.9 Simulation of the Indentation process 28

\section{Chapter 5. Results}

$\begin{array}{lr}\text { 5.1 Materials analyzed } & 29\end{array}$

5.2 Application of the methodology 30

5.3 Variation in Error percentage with increase of strain hardening Coefficient in a given material $\quad 56$

5.4 Results from Modified Tabor's Constant $\quad 57$

5.4.1 Comparison of the yield stress values obtained with Tabor's Constant 2.8 and modified Tabor's Constant for Aluminum E $=69 \mathrm{GPa}, \mathrm{S}_{y}=275 \mathrm{MPa} \quad 60$

5.4.2 Comparison of the yield stress values obtained with Tabor's Constant 2.8 and modified Tabor's Constant for Aluminum E $=69 \mathrm{GPa}, \mathrm{S}_{y}=500 \mathrm{MPa} \quad 62$

5.4.3 Comparison of the yield stress values obtained with Tabor's Constant 2.8 and modified Tabor's Constant for Steel E=200 GPa, $\mathrm{S}_{y}=500 \mathrm{MPa}$ 
5.4.4 Comparison of the yield stress values obtained with Tabor's Constant 2.8 and modified Tabor's Constant for Steel E=200 GPa, $\mathrm{S}_{y}=750 \mathrm{MPa}$

5.4.5 Comparison of the yield stress values obtained with Tabor's Constant 2.8 and modified Tabor's Constant for Steel E=200 GPa, $\mathrm{S}_{y}=1000 \mathrm{MPa}$

5.5 Simulation results for Ramberg-Osgood model

5.6 Simulation results for Power Law hardening model

References

Data Sheets 


\section{List of Figures}

Figure 1.1 Schematic diagram of brinell hardness test 3

Figure 1.2 Schematic diagram of vickers hardness test. 4

Figure 1.3 Schematic diagram of Rockwell hardness test. 5

Figure 2.1 Instrumented indentations assembly $\quad 8$

$\begin{array}{ll}\text { Figure 2.2 Indentation force-displacement curve } & 10\end{array}$

Figure 4.1 CAX4R element with one gaussian integration point 20

$\begin{array}{ll}\text { Figure 4.2 Indenter with biased meshed } & 21\end{array}$

Figure 4.3 Specimen with bias meshed $\quad 23$

Figure 4.4 Trapezoidal element used in transition region $\quad 24$

Figure 4.5 Boundary conditions applied on the specimen 25

Figure 4.6 Boundary conditions applied on the deformable indenter 26

Figure 4.7 Demonstrating the master and the slave surface 27

Figure 4.8 Pileup of the material with $n=0.18 \quad 28$

Figure 4.9 Sink in of the material with $\mathrm{n}=0.36$

Figure 5.1 Load Versus Contact Radius for Aluminum, E=69 GPa, $\mathrm{S}_{y}=275 \mathrm{MPa}$, $\mathrm{n}=0.09 \quad 31$

Figure 5.2 Stress Versus Strain for Aluminum, E=69 GPa, $\mathrm{S}_{y}=275 \mathrm{MPa}, \mathrm{n}=0.09$

Figure 5.3 Load Versus Contact Radius for Aluminum, E=69 GPa, $\mathrm{S}_{y}=275 \mathrm{MPa}$, $\mathrm{n}=0.18$

Figure 5.4 Stress Versus Strain for Aluminum, E=69 GPa, $\mathrm{S}_{y}=275 \mathrm{MPa}, \mathrm{n}=0.18$

Figure 5.5 Load Versus Contact Radius for Aluminum, E=69 GPa, $\mathrm{S}_{y}=275 \mathrm{MPa}$, $\mathrm{n}=0.27$

Figure 5.6 Stress Versus Strain for Aluminum, E=69 GPa, $\mathrm{S}_{y}=275 \mathrm{MPa}, \mathrm{n}=0.27$

Figure 5.7 Load Versus Contact Radius for Aluminum, E=69 GPa, $\mathrm{S}_{y}=275 \mathrm{MPa}$, $\mathrm{n}=0.36 \quad 34$

Figure 5.8 Stress Versus Strain for Aluminum, E=69 GPa, $\mathrm{S}_{y}=275 \mathrm{MPa}, \mathrm{n}=0.36$

Figure 5.9 Load Versus Contact Radius for Aluminum, E=69 GPa, $\mathrm{S}_{y}=500 \mathrm{MPa}$, $\mathrm{n}=0.09$

Figure 5.10 Stress Versus Strain for Aluminum, E=69 GPa, $\mathrm{S}_{y}=500 \mathrm{MPa}, \mathrm{n}=0.09$ 
Figure 5.11 Load Versus Contact Radius for Aluminum, E=69 GPa, $\mathrm{S}_{y}=500 \mathrm{MPa}$, $\mathrm{n}=0.18$

Figure 5.12 Stress Versus Strain for Aluminum, E=69 GPa, $\mathrm{S}_{y}=500 \mathrm{MPa}, \mathrm{n}=0.18$

Figure 5.13 Load Versus Contact Radius for Aluminum, E=69 GPa, $\mathrm{S}_{y}=500 \mathrm{MPa}$, $\mathrm{n}=0.27$

Figure 5.14 Stress Versus Strain for Aluminum, E=69 GPa, $\mathrm{S}_{y}=500 \mathrm{MPa}, \mathrm{n}=0.27$

Figure 5.15 Load Versus Contact Radius for Aluminum, E=69 GPa, $\mathrm{S}_{y}=500 \mathrm{MPa}$, $\mathrm{n}=0.36$

Figure 5.16 Stress Versus Strain for Aluminum, $\mathrm{E}=69 \mathrm{GPa}, \mathrm{S}_{y}=500 \mathrm{MPa}, \mathrm{n}=0.36$

Figure 5.17 Load Versus Contact Radius for Steel, E=200 GPa, $\mathrm{S}_{y}=500 \mathrm{MPa}, \mathrm{n}=0.1$

Figure 5.18 Stress Versus Strain for Steel, E=200 GPa, $\mathrm{S}_{y}=500 \mathrm{MPa}, \mathrm{n}=0.1$

Figure 5.19 Load Versus Contact Radius for Steel, E=200 GPa, $\mathrm{S}_{y}=500 \mathrm{MPa}, \mathrm{n}=0.2$

Figure 5.20 Stress Versus Strain for Steel, E=200 GPa, $\mathrm{S}_{y}=500 \mathrm{MPa}, \mathrm{n}=0.2$

Figure 5.21 Load Versus Contact Radius for Steel, E=200 GPa, $\mathrm{S}_{y}=500 \mathrm{MPa}, \mathrm{n}=0.3$

Figure 5.22 Stress Versus Strain for Steel, E=200 GPa, $\mathrm{S}_{y}=500 \mathrm{MPa}, \mathrm{n}=0.3$

Figure 5.23 Load Versus Contact Radius for Steel, E=200 GPa, $\mathrm{S}_{y}=500 \mathrm{MPa}, \mathrm{n}=0.4$

Figure 5.24 Stress Versus Strain for Steel, E=200 GPa, $\mathrm{S}_{y}=500 \mathrm{MPa}, \mathrm{n}=0.4$

Figure 5.25 Load Versus Contact Radius for Steel, E=200 GPa, $\mathrm{S}_{y}=750 \mathrm{MPa}, \mathrm{n}=0.1$

Figure 5.26 Stress Versus Strain for Steel, E=200 GPa, $\mathrm{S}_{y}=750 \mathrm{MPa}, \mathrm{n}=0.1$

Figure 5.27 Load Versus Contact Radius for Steel, E=200 GPa, $\mathrm{S}_{y}=750 \mathrm{MPa}, \mathrm{n}=0.2$

Figure 5.28 Stress Versus Strain for Steel, E=200 GPa, $\mathrm{S}_{y}=750 \mathrm{MPa}, \mathrm{n}=0.2$

Figure 5.29 Load Versus Contact Radius for Steel, E=200 GPa, $\mathrm{S}_{y}=750 \mathrm{MPa}, \mathrm{n}=0.3$

Figure 5.30 Stress Versus Strain for Steel, E=200 GPa, $\mathrm{S}_{y}=750 \mathrm{MPa}, \mathrm{n}=0.3$

Figure 5.31 Load Versus Contact Radius for Steel, E=200 GPa, $\mathrm{S}_{y}=750 \mathrm{MPa}, \mathrm{n}=0.4$

Figure 5.32 Stress Versus Strain for Steel, E=200 GPa, $\mathrm{S}_{y}=750 \mathrm{MPa}, \mathrm{n}=0.4$

Figure 5.33 Load Versus Contact Radius for Steel, E=200 GPa, $\mathrm{S}_{y}=1000 \mathrm{MPa}, \mathrm{n}=0.1$

Figure 5.34 Stress Versus Strain for Steel, E=200 GPa, $\mathrm{S}_{y}=1000 \mathrm{MPa}, \mathrm{n}=0.1$

Figure 5.35 Load Versus Contact Radius for Steel, E=200 GPa, $\mathrm{S}_{y}=1000 \mathrm{MPa}, \mathrm{n}=0.2 \quad 52$

Figure 5.36 Stress Versus Strain for Steel, E=200 GPa, $\mathrm{S}_{y}=1000 \mathrm{MPa}, \mathrm{n}=0.2$

Figure 5.37 Load Versus Contact Radius for Steel, E=200 GPa, $\mathrm{S}_{y}=1000 \mathrm{MPa}, \mathrm{n}=0.3 \quad 53$

Figure 5.38 Stress Versus Strain for Steel, E=200 GPa, $\mathrm{S}_{y}=1000 \mathrm{MPa}, \mathrm{n}=0.3$

Figure 5.39 Load Versus Contact Radius for Steel, E=200 GPa, $\mathrm{S}_{y}=1000 \mathrm{MPa}, \mathrm{n}=0.4 \quad 54$

Figure 5.40 Stress Versus Strain for Steel, E=200 GPa, S $y_{y}=1000 \mathrm{MPa}, \mathrm{n}=0.4$

Figure 5.41 Percentage error variations with strain hardening coefficient in aluminum alloys 
Figure 5.42 Percentage error variations with strain hardening coefficient in steel alloys

Figure 5.43 Effect of Tabor's constant on stress strain curve

Figure 5.44 Comparison of Stress Versus Strain Curves for Aluminum, E=69 GPa, $\mathrm{S}_{y}=275 \mathrm{MPa}, \mathrm{n}=0.09$

Figure 5.45 Comparison of Stress Versus Strain Curves for Aluminum, E=69 GPa, $\mathrm{S}_{y}=275 \mathrm{MPa}, \mathrm{n}=0.18$

Figure 5.46 Comparison of Stress Versus Strain Curves for Aluminum, E=69 GPa, $\mathrm{S}_{y}=275 \mathrm{MPa}, \mathrm{n}=0.27$

Figure 5.47 Comparison of Stress Versus Strain Curves for Aluminum, E=69 GPa, $\mathrm{S}_{y}=275 \mathrm{MPa}, \mathrm{n}=0.36$

Figure 5.48 Strain hardening exponent Versus modified constant for aluminum, $\mathrm{E}=69 \mathrm{GPa}, \mathrm{S}_{y}=275 \mathrm{MPa}$

Figure 5.49 Comparison of Stress Versus Strain Curves for Aluminum, E=69 GPa, $\mathrm{S}_{y}=500 \mathrm{MPa}, \mathrm{n}=0.09$

Figure 5.50 Comparison of Stress Versus Strain Curves for Aluminum, E=69 GPa, $\mathrm{S}_{y}=500 \mathrm{MPa}, \mathrm{n}=0.18$

Figure 5.51 Comparison of Stress Versus Strain Curves for Aluminum, E=69 GPa, $\mathrm{S}_{y}=500 \mathrm{MPa}, \mathrm{n}=0.27$

Figure 5.52 Comparison of Stress Versus Strain Curves for Aluminum, E=69 GPa, $\mathrm{S}_{y}=500 \mathrm{MPa}, \mathrm{n}=0.36$

Figure 5.53 Strain hardening exponent Versus modified constant for aluminum, $\mathrm{E}=69 \mathrm{GPa}, \mathrm{S}_{y}=500 \mathrm{MPa}$

Figure 5.54 Comparison of Stress Versus Strain Curves for Steel, E=200 GPa, $\mathrm{S}_{y}=500 \mathrm{MPa}, \mathrm{n}=0.1$

Figure 5.55 Comparison of Stress Versus Strain Curves for Steel, E=200 GPa, $\mathrm{S}_{y}=500 \mathrm{MPa}, \mathrm{n}=0.2$

Figure 5.56 Comparison of Stress Versus Strain Curves for Steel, E=200 GPa, $\mathrm{S}_{y}=500 \mathrm{MPa}, \mathrm{n}=0.3$

Figure 5.57 Comparison of Stress Versus Strain Curves for Steel, E=200 GPa, $\mathrm{S}_{y}=500 \mathrm{MPa}, \mathrm{n}=0.4$

Figure 5.58 Strain hardening exponent Versus modified constant for steel,

$\mathrm{E}=200 \mathrm{GPa}, \mathrm{S}_{y}=500 \mathrm{MPa}$

Figure 5.59 Comparison of Stress Versus Strain Curves for Steel, E=200 GPa, $\mathrm{S}_{y}=750 \mathrm{MPa}, \mathrm{n}=0.1$

Figure 5.60 Comparison of Stress Versus Strain Curves for Steel, E=200 GPa, $\mathrm{S}_{y}=750 \mathrm{MPa}, \mathrm{n}=0.2$

Figure 5.61 Comparison of Stress Versus Strain Curves for Steel, E=200 GPa, $\mathrm{S}_{y}=750 \mathrm{MPa}, \mathrm{n}=0.3$ 
Figure 5.62 Comparison of Stress Versus Strain Curves for Steel, E=200 GPa, $\mathrm{S}_{y}=750 \mathrm{MPa}, \mathrm{n}=0.4$

Figure 5.63 Strain hardening exponent Versus modified constant for steel,

$\mathrm{E}=200 \mathrm{GPa}, \mathrm{S}_{y}=750 \mathrm{MPa}$

Figure 5.64 Comparison of Stress Versus Strain Curves for Steel, E=200 GPa, $\mathrm{S}_{y}=1000 \mathrm{MPa}, \mathrm{n}=0.1$

Figure 5.65 Comparison of Stress Versus Strain Curves for Steel, E=200 GPa, $\mathrm{S}_{y}=1000 \mathrm{MPa}, \mathrm{n}=0.2$

Figure 5.66 Comparison of Stress Versus Strain Curves for Steel, E=200 GPa, $\mathrm{S}_{y}=1000 \mathrm{MPa}, \mathrm{n}=0.3$

Figure 5.67 Comparison of Stress Versus Strain Curves for Steel, E=200 GPa, $\mathrm{S}_{y}=1000 \mathrm{MPa}, \mathrm{n}=0.4$

Figure 5.68 Strain hardening exponent Versus modified constant for steel,

$\mathrm{E}=200 \mathrm{GPa}, \mathrm{S}_{y}=1000 \mathrm{MPa}$

Figure 5.69 Strain hardening exponent Versus modified Tabors constant

Figure 5.70 Variation of Tabor constant, B.Taljat [12]

Figure 5.71 Load Versus Contact Radius obtained for Ramberg-Osgood model

Figure 5.72 Stress Versus Strain obtained for Ramberg-Osgood model

Figure 5.73 Input Stress Versus Strain curve describing power law model

Figure 5.74 Stress Versus Strain curve obtained from simulation for Power law model 


\section{List of Tables}

Table 4.1 List of materials being analyzed

Table 5.1 List of material properties

Table 5.2 Comparison of the results obtained for Aluminum, E=69 GPa,

$$
\mathrm{S}_{y}=275 \mathrm{MPa}
$$

Table 5.3 Comparison of the results obtained for Aluminum, E=69 GPa,

$$
\mathrm{S}_{y}=500 \mathrm{MPa}
$$

Table 5.4 Comparison of the results obtained for Steel, E=200 GPa,

$$
\mathrm{S}_{y}=500 \mathrm{MPa}
$$

Table 5.5 Comparison of the results obtained for Steel, E=200 GPa,

$$
\mathrm{S}_{y}=750 \mathrm{MPa}
$$

Table 5.6 Comparison of the results obtained for Steel, E=200 GPa,

$$
\mathrm{S}_{y}=1000 \mathrm{MPa}
$$

Table 5.7 Comparison of the results obtained before and after the change in

Tabor's Constant for Aluminum, E=69 GPa, $\mathrm{S}_{y}=275 \mathrm{MPa}$

Table 5.8 Comparison of the results obtained before and after the change in

Tabor's Constant for Aluminum, E=69 GPa, $\mathrm{S}_{y}=500 \mathrm{MPa}$

Table 5.9 Comparison of the results obtained before and after the change in Tabor's Constant for Steel, E=200 GPa, $\mathrm{S}_{y}=500 \mathrm{MPa}$

Table 5.10 Comparison of the results obtained before and after the change in Tabor's Constant for Steel, E=200 GPa, $\mathrm{S}_{y}=750 \mathrm{MPa}$

Table 5.11 Comparison of the results obtained before and after the change in Tabor's Constant for Steel, E=200 GPa, $\mathrm{S}_{y}=1000 \mathrm{MPa}$ 


\section{List of Symbols}

\begin{tabular}{ll}
$\mathrm{F}$ & Load \\
$\mathrm{d}$ & Contact diameter of spherical indenter \\
$\mathrm{D}$ & Diameter of spherical indenter \\
$\mathrm{E}$ & Young's modulus \\
$\mathrm{HV}$ & Vickers hardness \\
$\mathrm{P}$ & Force applied on the indenter \\
$\mathrm{h}$ & contact depth \\
$\mathrm{S}$ & indentation stiffness \\
$\mathrm{E}_{r}$ & reduced modulus \\
$\mathrm{u}$ & Poisson's ratio \\
$p_{m}$ & Meyer hardness \\
$\varepsilon$ & Strain \\
$\varepsilon_{i}$ & Indentation strain (Tabor's relation) \\
$\varepsilon_{p}$ & plastic strain \\
$\sigma$ & Stress \\
$\sigma_{i}$ & Indentation stress (Tabor's relation) \\
$\mathrm{n}$ & Strain hardening coefficient \\
$\mathrm{m}_{y}$ & Linear strain hardening coefficient \\
$\mathrm{S}_{y}$ & Micro \\
\hline &
\end{tabular}




\section{Chapter 1}

\section{Introduction}

\subsection{Indentation hardness}

In general hardness implies the resistance to deformation. Hardness has conventionally been defined as the resistance of a material to permanent penetration by another harder material with measurement being made after the applied force has been removed, such that elastic deformation is ignored. Today the indentation hardness test is used in practically every metal working plant as a means of checking the quality and uniformity of metals and metal parts. The test serves as a control or designation of the heat-treating or processing of the metals, or is used in estimating the tensile strength. Because of the simplicity of the indentation hardness test as carried out by modern hardness testers, and relatively small cost, it is probably the most commonly employed test in industry. Hardness measurements usually fall into three main categories: scratch hardness, static indentation hardness, and rebound or dynamic hardness. With the exception of the Brinell tester, most modern testers use diamond penetrators or indenters. Diamond is the hardest of the all known materials. The indentation hardness is calculated from the test force, F, divided by the projected area of the indenter in contact with the test piece at maximum load.

\subsection{Static indentation hardness}

The methods most widely used in determining the hardness of the metals are static indentation methods. Primarily used in engineering and metallurgy, indentation 
hardness seeks to characterise a material's resistance to permanent, and in particular plastic deformation. It is usually measured by loading an indenter of specified geometry onto the material and measuring the dimensions of the resulting indentation. The most commonly used methods are:

Brinell hardness test,

Vickers hardness test and

Rockwell hardness test.

\subsubsection{Brinell hardness test}

The first widely accepted and standardized indentation hardness test was proposed by J. A. Brinell in 1900. The Brinell hardness test consists of indenting the metal surface with a 10-mm-diameter steel ball at a load of 3,000 kg mass (29400 N). For soft metals the load is reduced to $500 \mathrm{~kg}$ to avoid deep impression, and for very hard metals a tungsten carbide ball is used to minimize distortion of the indenter. The load is applied for a standard time, usually $30 \mathrm{~s}$, and the diameter of the indentation is measured with a low-power microscope after removal of the load. The Brinell hardness number is calculated by dividing the load applied by the surface area of the indentation.

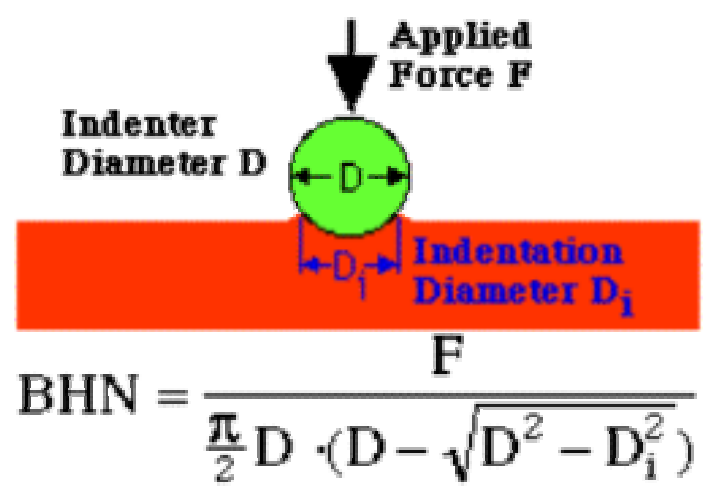

Figure 1.1 Schematic diagram of brinell hardness test [23] 
Where,

$\mathrm{BHN}=$ the Brinell hardness number

$\mathrm{F}=$ the imposed load in $\mathrm{kg}$

$\mathrm{D}=$ the diameter of the spherical indenter in $\mathrm{mm}$

$\mathrm{D}_{\mathrm{i}}=$ diameter of the resulting indenter impression in $\mathrm{mm}$

\subsubsection{Meyer Hardness}

Meyer suggested that a more rational definition of hardness than that proposed by Brinell would be one based on the projected area of the impression rather than the surface area. The mean pressure between the surface of the indenter and the indentation is equal to the load divided by the projected area of the indentation. Meyer proposed that this mean pressure should be taken as the measure of hardness. It is referred to as the Meyer hardness.

\subsubsection{Vickers hardness}

The Vickers hardness test method consists of indenting the test material with a diamond indenter, in the form of a right pyramid with a square base and an angle of 136 degrees between opposite faces subjected to a load of 1 to $100 \mathrm{kgf}$. The full load is normally applied for 10 to 15 seconds. The two diagonals of the indentation left in the surface of the material after removal of the load are measured using a microscope and their average calculated. The area of the sloping surface of the indentation is calculated. The Vickers hardness is the quotient obtained by dividing the kgf load by the square $\mathrm{mm}$ area of indentation. 


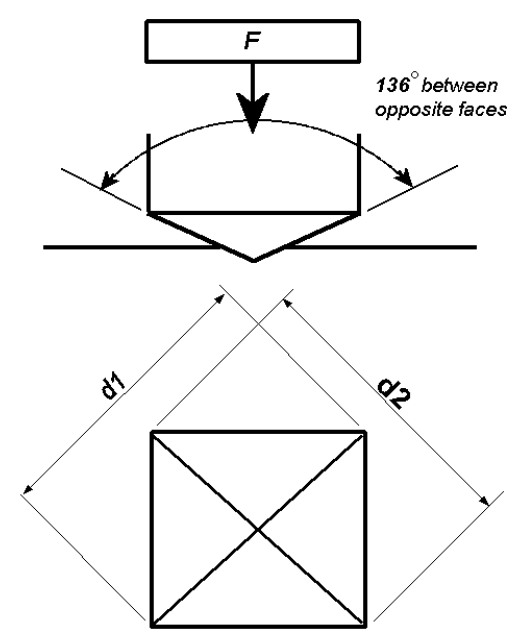

Figure 1.2 Schematic diagram of Vickers hardness test [24]

$H=\frac{2 F \sin \frac{136^{\circ}}{2}}{d^{2}} \quad H N=1.354 \frac{F}{d^{2}}$ approximately

Where,

$\mathrm{F}=$ Load in $\mathrm{kgf}$

$\mathrm{d}=$ Arithmetic mean of the two diagonals, $\mathrm{d} 1$ and $\mathrm{d} 2 \mathrm{in} \mathrm{mm}$

$\mathrm{HV}=$ Vickers hardness

\subsubsection{Rockwell hardness test}

Stanley P. Rockwell invented the Rockwell hardness test. The most widely used hardness test is the Rockwell hardness test. Its general acceptance is due to its speed, freedom from personal error, ability to distinguish small hardness differences in hardened steel, and the small size of the indentation, so that finished heat-treated parts can be tested without damage. This test utilizes the depth of indentation, under constant load, as a measure of hardness. A minor load of $10 \mathrm{~kg}$ is first applied to seat the specimen. This 
minimizes the amount of surface preparation needed and reduces the tendency for ridging or sinking in by the indenter. The major load is then applied, and the depth of indentation is automatically recorded on a dial gage in terms of arbitrary hardness numbers.

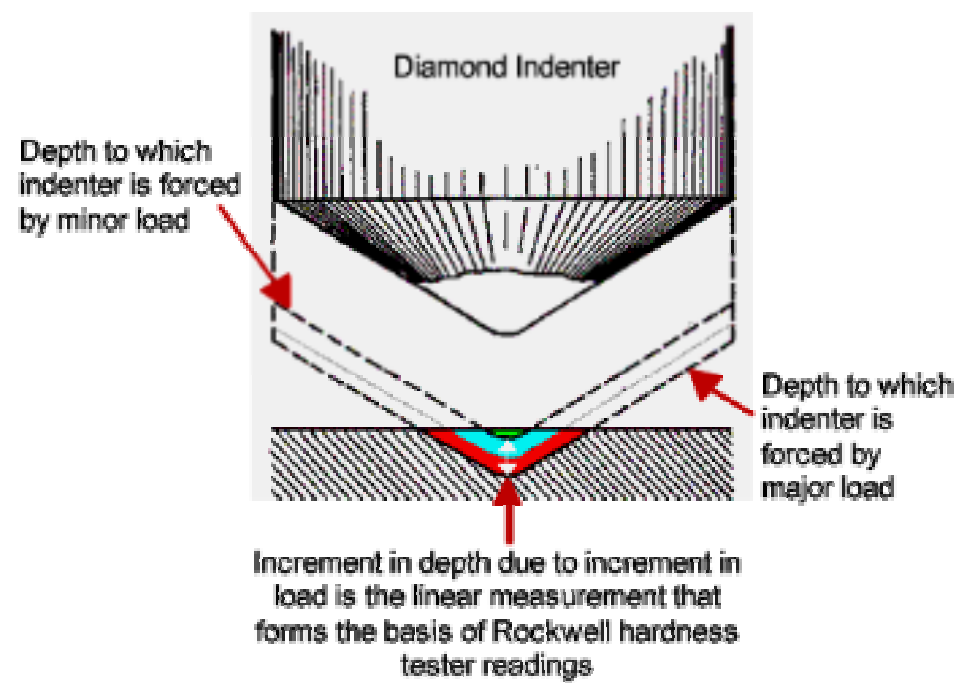

Figure 1.3 Schematic diagram of Rockwell hardness test [25]

The resulting Rockwell number represents the difference in depth from the zero reference position as a result of the application of the major load.

\subsection{Research Objective}

The objective of this research is to develop a methodology to determine material mechanical properties like Young's modulus, yield stress and strain hardening coefficient based on Meyer's law and Tabor's empirical equation using indentation technique. Numerical finite element simulations of spherical indentation will be carried out on various metallic alloys and a detailed methodology will be proposed based on the results obtained. 
Indentation technique is very promising and convenient for evaluating mechanical properties of materials at micro or nano scale level, for thin surface layers, coatings, ion implanted layer, corroded surface layer, irradiated materials etc. Empirical equation relating the applied load, the radius of the sphere and the radius of the indentation, known as Meyer's law is available. Tabor's empirical equation provides the necessary relationships between stress, strain and the load-induced contact radius. Focus will be placed on determining the material mechanical properties based on the data obtained from two outputs: the applied load (N) and contact diameter (d). Special attention will be placed to determine the range of strain corresponding to which the results obtained are in good agreement with the input values. Recent studies at different research institutes and laboratories have proved that the Tabors constant is not a fixed value and varies with materials. Here, we will work to determine the correct Tabors constant for the present set of materials in order to obtain the yield stress with less error percentage. 


\section{Chapter 2}

\section{Literature Review}

\subsection{Instrumented Indentation for Hardness and Material Properties}

Instrumented indentation, also known as depth-sensing indentation is increasingly being used to probe the mechanical response of materials from metals and ceramics to polymeric and biological materials. It is used to determine the properties of materials by putting an indentation in the surface of a material sample. Instrumented indentation hardness provides the ability to measure the indenter penetration (h) under the applied force $(\mathrm{F})$ throughout the testing cycle and is therefore capable of measuring both the plastic and elastic deformation of the material under test.

Like a hardness test, an indenter with a well-defined geometry is indented onto the sample surface. Unlike a hardness test, where only the indent size or depth is measured after the total force has been removed, instrumented indentation testing utilizes high-precision instrumentation to continuously monitor and control the displacement of the indenter as it penetrates and then is withdrawn from the sample. The data points generated during the indentation process are stored for post data analysis. A visual load/unload curve as shown in Figure 2.2, is normally generated from the data. Below Figure 2.1 shows the assembly of an instrumented indentation system. 


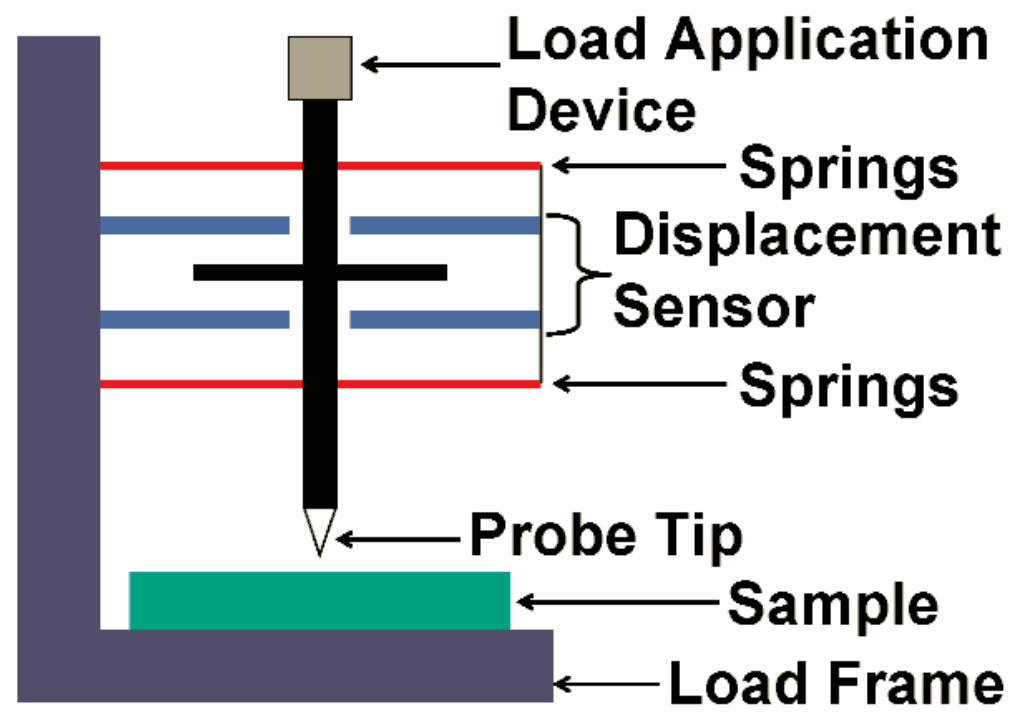

Figure 2.1 Instrumented indentations assembly

\subsection{Analysis Techniques}

The analysis of force-displacement curves produced by instrumented indentation systems is based on work by Doerner and Nix [1] and Oliver and Pharr [2]. Their analyses were in turn based upon relationships developed by Sneddon [3] for the penetration of a flat elastic half space by different probes with particular axisymmetric shapes (e.g., a flat-ended cylindrical punch, a paraboloid of revolution, and a cone). These elasticity-based analyses are normally applied to the unloading data of an indentation measurement, assuming the unloading behavior of the material is characterized by elastic recovery only. In general, the relationships between penetration depth, $h$, and force, $P$, during unloading is be represented in the form

$$
\mathrm{P}=\alpha\left(\mathrm{h}_{f}\right)^{m}
$$


The parameter $\alpha$ contains geometric constants, the sample elastic modulus, E, the sample Poisson's ratio, v, the indenter elastic modulus, $\mathrm{E}_{i}$, and the indenter Poisson's ratio, $v_{i}$; the parameter $\mathrm{h}_{f}$ is the final unloading depth; and $\mathrm{m}$ is a power law exponent that is related to the geometry of the indenter. A nonlinear power law fit to the unloading data, where $\alpha, \mathrm{h}_{f}$ and $m$ are fitting parameters, yields a good estimate of the data. Once an appropriate fit is obtained, a derivative, $\mathrm{d} P / \mathrm{d} h$, applied at the maximum loading point ( $h$ max, $P$ max) yields information about the state of contact at that point. This derivative is termed the contact stiffness, $\mathrm{S}^{*}$, and is given analytically by

$$
\mathrm{S}^{*}=2 \mathrm{aE}_{r}=\frac{2}{\sqrt{\Pi}} E_{r} \sqrt{A}
$$

The reduced modulus, $\mathrm{E}_{r}$, accounts for elastic deformation of both the indenter and the sample and is given by

$$
\frac{1}{E_{r}}=\frac{\left(1-v^{2}\right)}{E}+\frac{\left(1-v_{i}^{2}\right)}{E_{i}}
$$

An indentation force-displacement curve is illustrated in Figure 2.2 along with several important parameters used in the Oliver and Pharr analysis. The measured stiffness, $S^{*}$, is the slope of the tangent line to the unloading curve at the maximum loading point $\left(\mathrm{P}_{\max }\right)$ and is given by

$$
S^{*}=\left[\frac{d P}{d H}\right]_{p_{\max }}=\operatorname{am}\left(h_{\max }-h_{f}\right)^{m-1}
$$




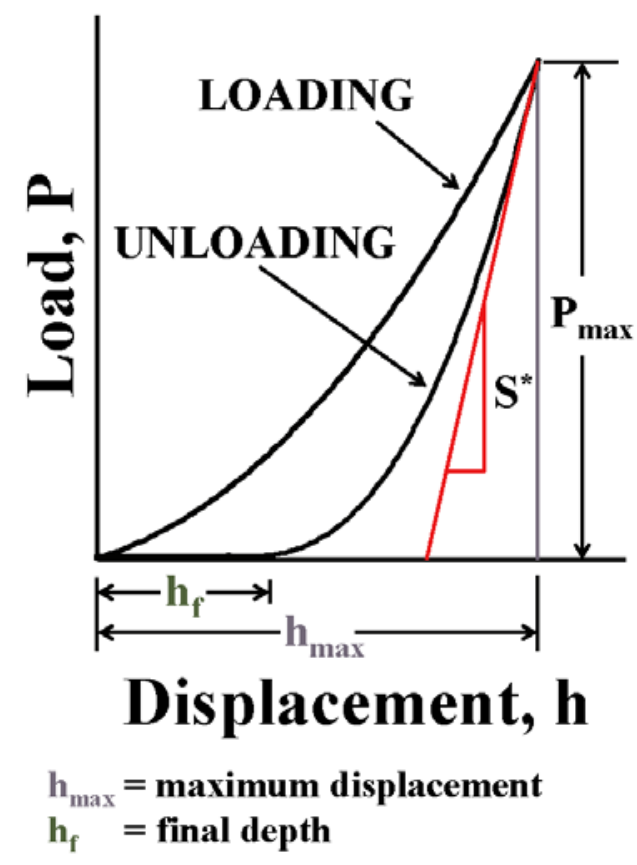

Figure 2.2 Indentation force-displacement curve [26]

\subsection{Use of instrumented indentation testing}

Instrumented indentation testing was developed to determine the properties of materials that, due to their configuration, could not be tested using other conventional methods. After approximately 20 years of development, instrumented indentation testing has become the primary technique to examine the properties of thin films and coatings as well as surfaces that have been specially treated such as laser heat-treated or ion implanted. Ceramics and other hard coatings and materials are also frequently tested using instrumented indentation testing. Hardness values can be determined from instrumented indentation testing test data, however, a major objective for doing instrumented indentation testing is to determine additional mechanical properties of the subject materials. 
The most universally accepted property determined from instrumented indentation testing is elastic modulus E and Poisson's ratio v. The material's modulus can be easily determined from the slope of the unload curve (see Figure 2.2). Almost any property that can be measured by uniaxial tension or compression testing can be measured or estimated using instrumented indentation testing. In addition, coating separation can be detected by observing discontinuities in the load curve, and fracture toughness may be estimated by optically measuring the cracks created by the indenter.

\subsection{Previous FEM analyses}

Giannakopoulos, et al. [4] investigated in detail the influence of mechanical properties, Young's modulus, yield stress, and hardening coefficient, on the deformation of materials under a Vickers indenter by using FEM analyses. The same method was applied to creep materials by Bower et al. and Storakers et al., using results from Hill. In all these cases, the indentation problem for the entire loading history is reduced to the solution of a single non-linear boundary value problem. This greatly facilitates the numerical solution of the reduced problem, since the finite element mesh can be chosen appropriately to the extent of the contact area and discretization errors as the contact area expands over the mesh are eliminated.

Field and Swain [5] focused on the behavior of pilling up and sinking in to characterize mechanical properties. Based on the FEM results, Cheng, et al. [6] addressed the limitation for the determination of the stress-strain relationship from the load-depth curve measured using the depth sensing indentation technique with conical and pyramidal indenters. 
Spherical indentation overcomes many of the limitations associated with pyramidal indenters and allows mechanical properties to be evaluated by following the transition from elastic to plastic behavior. This also enables the yield stress to be calculated. Indentation behavior depends on the ratio between the actual strain and the yield strain of the material; low ratios produce elastic behavior whereas high ratios produce plastic behavior. Here, Spherical-indentation technique is analyzed by finite element (FE) method using ABAQUS ${ }^{\mathrm{TM}}$.

\subsection{Meyer's Law}

Professor Eugene Meyer of the material testing laboratory at the imperial school of technology, charlottenburg, made an intensive study of the Brinell ball indentation hardness test and published his results in 1908. Meyer's work showed that resistance to penetration by a ball penetrator varies with the degree of penetration of the ball and follows the relation

$$
P=a d^{n}
$$

Where,

$P=$ load

$d=$ diameter of indentation

$a$ and $n$ are constants of the material under test.

The above relation is known as Meyer's law.

The mean pressure between the surface of the indenter and the indentation is equal to the ratio of the load to the projected area of the indentation. This quantity, as a measure of the hardness, was first proposed by Meyer in 1908 and is referred to as the Meyer hardness. 


$$
p_{m}=\text { Meyer hardness }=\frac{4 P}{\pi d^{2}}
$$

Meyer's work, carried out using a ball indenter, has been instrumental in giving a much clearer picture of the mechanics of the ball indentation test, especially the role of work-hardening capacity or strain-hardening ability of a metal.

Direct relation between the hardness number, the amount of deformation or strain, and the yield stress of any metal was given by Tabor (1948). In Tabor's empirical work, it was pointed out that for spherical indentation; the Meyer's hardness has a close agreement with the uniaxial stress-strain curve. He came up with the following stress and strain relations:

$\varepsilon_{i}=0.2 \frac{d}{D}$

$\sigma_{i}=\frac{p_{m}}{2.8}$

Where, $\mathrm{d}$ is the diameter of indentation, $\mathrm{D}$ is the ball indenter diameter and $\mathrm{p}_{m}$ is mean contact pressure. 


\section{Chapter 3}

\section{Methodology}

\subsection{Methodology proposed in the current research}

We aim to determine the material properties using the indentation technique. We will discuss the methodology to determine these using two available outputs from the Finite element analysis. Applied load which is calculated from the reaction forces at the bottom of the specimen and the contact diameter of the indenter are used in this process. This data is extracted from multiple frames available in the same step of the analysis. Then, we will be using the Meyer's and Tabors empirical equations to obtain the complete stress strain curve in order determine the material properties.

The relation between contact radius (a), indenter diameter (D) and the applied load (P) was proposed by Meyer, which governs spherical indentation, namely:

$$
P=K \frac{a^{n+2}}{D^{n}}
$$

Where $\mathrm{n}$ and $\mathrm{K}$ being material constants. The work of O'Neill and Tabor [27] showed that the value of $\mathrm{n}$ from indentation was equal to the strain hardening exponent of the material.

\subsubsection{Determining strain hardening exponent}

Graph is plotted between the applied load (P) and contact radius (a) of the indenter. Then the points obtained in the plane are curve fitted based on Equation (3.1) whose exponent is of the form $n+2$, where $n$ is material's strain hardening. Thus, the 
value of the power minus 2 gives the strain hardening coefficient of the material being analyzed. Let the curve-fitted equation obtained is of the form:

$p=y a^{n}$

Where, $\mathrm{y}$ is some constant.

This is followed by the use of Tabor's empirical equations of stress and strain:

$\varepsilon_{i}=0.2 \frac{d}{D}$

$\sigma_{i}=\frac{P_{m}}{2.8}$

Where,

$\mathrm{d}=$ Contact diameter

$\mathrm{D}=$ Diameter of the ball indenter and

$p_{m}=\frac{4 p}{\pi d^{2}}$

$p=$ Curve represented by Equation (3.2)

\subsubsection{Determining yield stress from stress-strain curve}

Graph is plotted between stress and strain. The resultant points obtained are the post yielding region of the stress strain curve. The points obtained are power curve fitted. The resultant equation is of the form:

$$
\sigma_{i}=\delta . \varepsilon_{i}{ }^{n}
$$

Where, $\delta$ is a constant and $\mathrm{n}$ is strain hardening coefficient.

The material follows Hook's law before yielding i.e. it behaves linearly before the yield point.

$$
\sigma=\text { E. } \varepsilon
$$


In order to obtain the yield stress, the point of intersection of the linear and non linear part of the stress strain curve is to be found. Solving the above Equations (3.5) and (3.6) we obtain

$\mathrm{S}_{y}=\left(\frac{\delta}{E^{n}}\right)^{\frac{1}{1-n}}$

Where,

$\mathrm{S}_{y}=$ Yield Stress

$\delta=$ Constant obtained from Equation (3.5)

$\mathrm{E}=$ Young's Modulus

$\mathrm{n}=$ Strain hardening coefficient.

The value obtained by using Equation (3.7) is the material yield stress. Thus by employing the above methodology, the material mechanical properties: yield stress and strain hardening exponent are found from the finite element simulation of the indentation technique. 


\section{Chapter 4}

\section{Finite Element Modeling}

\subsection{ABAQUS ${ }^{\mathrm{TM}}$ software}

ABAQUS $^{\mathrm{TM}}$ was founded in 1978 by David Hibbitt, Bengt Karlsson, and Paul Sorensen. Commercial FEM simulation software ABAQUS ${ }^{\mathrm{TM}} 6.4$ is used to carry out the indentation simulation. The ABAQUS ${ }^{\mathrm{TM}}$ suite of software for finite element analysis (FEA) is known for its high performance, quality and ability to solve challenging simulations ranging from simple linear to complex nonlinear simulations.

The ABAQUS ${ }^{\mathrm{TM}}$ suite consists of three core products - ABAQUS ${ }^{\mathrm{TM}} /$ Standard, ABAQUS $^{\mathrm{TM}} /$ Explicit and ABAQUS ${ }^{\mathrm{TM}} / \mathrm{CAE}$.

ABAQUS $^{\text {TM }} /$ Standard is a general-purpose, finite-element program designed to simulate large scale, complex linear problems and highly nonlinear problems.

ABAQUS $^{\mathrm{TM}} /$ Explicit provides $^{\mathrm{ABAQUS}}{ }^{\mathrm{TM}}$ analysis technology focused on transient dynamics and quasi-static analyses using an explicit approach appropriate in many applications such as drop test, crushing and many manufacturing processes.

ABAQUS $^{\text {TM}} /$ CAE provides a complete modeling and visualization environment for ABAQUS analysis products. With direct access to CAD models, advanced meshing and visualization, and with an exclusive view towards ABAQUS ${ }^{\mathrm{TM}}$ analysis products, $\mathrm{ABAQUS}^{\mathrm{TM}} / \mathrm{CAE}$ is the modeling environment of choice for many ABAQUS ${ }^{\mathrm{TM}}$ users.

In our present simulation ABAQUS ${ }^{\mathrm{TM}} /$ Standard and ABAQUS ${ }^{\mathrm{TM}} / \mathrm{CAE}$ has been used. 
ABAQUS $^{\mathrm{TM}} / \mathrm{CAE}$ is used as the preprocessor for the creation of the part, inputting the property of the materials, assembly of the model, for defining the interaction, applying the load and meshing the model. It is also used as the postprocessor for viewing the results.

\subsection{Solving the problem using ABAQUS ${ }^{\mathrm{TM}}$}

The present analysis is a nonlinear simulation. There are basically two types of nonlinearity involved in this simulation: material nonlinearity and the other being geometrical in nature.

Many metals display material nonlinearity at high strain values. At high strains, the materials yield and thus stress/strain relation is no longer linear. The plastic behavior of a material is described by its yield point and yield hardening. In general, the yield stress of the material is 0.05 to $0.1 \%$ of the materials yield's modulus. Many metals show work hardening. Work hardening is when a metal is strained beyond the yield point. An increasing stress is required to produce additional plastic deformation and the metal apparently becomes stronger and more difficult to deform. Indentation process is a highly localized phenomenon. There is high deformation in the area just beneath the indenter and the specimen, thus giving rise to geometrical nonlinearity. Geometric nonlinearity needs to be accounted for when the structure deforms to such an extent that the original geometry and/or position and direction of the loads significantly affect the structural behavior. 


\subsubsection{Solver used}

ABAQUS $^{\mathrm{TM}}$ uses Newton-Raphson method to obtain solution for nonlinear simulations. In a nonlinear analysis the solution cannot be calculated by solving a single system of linear equations. Instead, the solution is found by specifying the loading as a function of time and incrementing time to obtain the nonlinear response. Therefore, $\mathrm{ABAQUS}^{\mathrm{TM}} /$ Standard breaks the simulation into a number of time increments and finds the approximate equilibrium configuration at the end of each time increment.

An increment is part of a step. In nonlinear analyses each step is broken into increments so that the nonlinear solution path can be followed. The user suggests the size of the first increment, and ABAQUS ${ }^{\mathrm{TM}}$ /Standard automatically chooses the size of the subsequent increments. At the end of each increment the structure is in (approximate) equilibrium and results are available for writing to the restart, data, results, or output database files. Iteration is an attempt at finding an equilibrium solution in an increment. If the model is not in equilibrium at the end of the iteration, ABAQUS ${ }^{\mathrm{TM}} /$ Standard tries another iteration.

\subsection{Indentation modeling}

It is generally known that an axisymmetric two- dimensional finite element model can be used to capture the result of a full three-dimensional model as long as the projected area/depth of the two models are equivalent. This is done to take calculative efficiency into account. Computations were performed using the general purpose finite element package ABAQUS ${ }^{\mathrm{TM}}$. The complete set in the indentation model consists of a deformable Spherical indenter and specimen. The spherical indenter in the analysis is 
made up of tungsten material and the specimens are steel and aluminum alloys. Since, most of the practical indenters are made up of Tungsten, here the indenter material is chosen as tungsten. The radius of the indenter being $80 \mu \mathrm{m}$ and the length and height of the specimen are $1000 \mu \mathrm{m}$ each. Thus in reality, it being a spherical indenter of diameter $160 \mu \mathrm{m}$ and a cylindrical specimen of dimensions $1000 \mu \mathrm{m}$ radius and $1000 \mu \mathrm{m}$ in height.

\subsection{Element}

4-node linear axisymmetric quadrilateral, reduced integration, hourglass control 'CAX4R' element was used. Reduced integration signifies that there is only one Gauss integration point in the element as shown by $\mathrm{x} 1$ below.

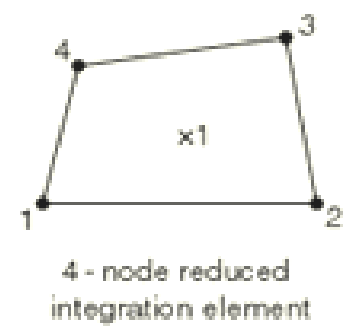

Figure 4.1 CAX4R element with one gaussian integration point

\subsection{Indenter modeling}

Deformable indenter of Tungsten material and radius of $800 \mu \mathrm{m}$ is modeled. The indenter model consists of 1600 elements and 1671 nodes in total. The indenter is bias meshed with high mesh density at the bottom (point of contact). The element size is lowest at the bottom with a measure of $3.91 \mu \mathrm{m}$ and highest at the top with measure of $19.63 \mu \mathrm{m}$. Indentation being a highly localized phenomena, very high stresses and high 
deformation are produced at the point of contact. Therefore, our main focus is at the area around the point of contact. Elastic property of Tungsten with Young's modulus E=750 GPa and Poisson's ratio $v=0.33$ is considered. The Young's modulus of indenter is 3 to 5 times the Young's modulus of the specimen.

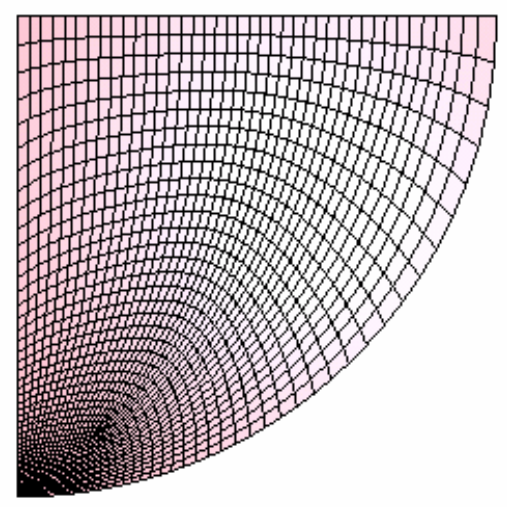

Figure 4.2 Indenter with biased meshed

\subsection{Specimen modeling}

Elastic power hardening plastic material property is assumed for the deformable specimen. Steel and Aluminum alloy with different yield stress and strain hardening coefficient are chosen. In total, analysis on 20 such different materials has been performed. The materials in a given set have same Young's modulus and yield strength but with different stain hardening coefficients. The list of materials chosen is listed below.

\begin{tabular}{|l|l|l|l|l|l|l|l|}
\hline \multicolumn{7}{|c|}{ Aluminum alloys (E=69 GPa, $v=0.33)$} \\
\hline $\mathrm{n}=0.09$ & $\mathrm{n}=0.18$ & $\mathrm{n}=0.27$ & $\mathrm{n}=0.36$ & $\mathrm{n}=0.09$ & $\mathrm{n}=0.18$ & $\mathrm{n}=0.27$ & $\mathrm{n}=0.36$ \\
\hline
\end{tabular}




\begin{tabular}{|c|c|c|c|c|c|c|c|c|c|c|c|}
\hline \multicolumn{12}{|c|}{ Steel alloys $(E=200 \mathrm{GPa}, v=0.3)$} \\
\hline \multicolumn{4}{|c|}{$S_{y}=500 M P a$} & \multicolumn{4}{|c|}{$S_{y}=750 M P a$} & \multicolumn{4}{|c|}{$S_{y}=1000 M P a$} \\
\hline $\mathrm{n}=0.1$ & $\mathrm{n}=0.2$ & $\mathrm{n}=0.3$ & $\mathrm{n}=0.4$ & $\mathrm{n}=0.1$ & $\mathrm{n}=0.2$ & $\mathrm{n}=0.3$ & $\mathrm{n}=0.4$ & $\mathrm{n}=0$. & $\mathrm{n}=0.2$ & $\mathrm{n}=0.3$ & $\mathrm{n}=0.4$ \\
\hline
\end{tabular}

Table 4.1 List of materials being analyzed

For Plastic property, the uniaxial true stress $(\sigma)$ true strain $\left(\varepsilon_{p}\right)$ data is required to input. There are several math models which describe the true stress strain curve. Some among them are:

a) Ramberg-Osgood model

$$
\varepsilon=\left\{\begin{array}{l}
=\sigma / E ; \quad \sigma<\sigma_{Y} \\
=\varepsilon_{e}+\varepsilon_{p}=\frac{\sigma}{E}+a\left(\frac{\sigma}{b}\right)^{n} \text { otherwise }
\end{array}\right.
$$

b) Linear elastic - linear strain hardening plastic model

$$
\varepsilon=\left\{\begin{array}{l}
\sigma / E ; \quad \sigma<\sigma_{Y} \\
\left(\sigma-\sigma_{Y}\right) / m+\sigma_{Y} / E \text { otherwise }
\end{array}\right.
$$

Where, $\mathrm{m}$ is the linear strain hardening coefficient.

c) Some other available form is

$$
\sigma=\left\{\begin{array}{l}
E \varepsilon \quad \sigma<\sigma_{Y} \\
\sigma_{Y}+K\left(\varepsilon-\frac{\sigma}{E}\right)^{n} \quad \text { otherwise }
\end{array}\right.
$$


d) piecewise linear elastic - power-law plastic model

$$
\begin{gathered}
\varepsilon=\left\{\begin{array}{l}
\sigma / E ; \quad \sigma<\sigma_{Y} \\
\frac{\sigma_{Y}}{E}\left(\frac{\sigma}{\sigma_{Y}}\right)^{1 / n} \quad \text { otherwise }
\end{array}\right. \\
\sigma=\left\{\begin{array}{l}
E \varepsilon \quad \sigma<\sigma_{Y} \\
\sigma_{Y}\left(\frac{E}{\sigma_{Y}}\right)^{n} \varepsilon^{n} \text { otherwise }
\end{array}\right.
\end{gathered}
$$

Most widely used math model's are linear elastic - power-law plastic, Ramberg Osgood and power law hardening model.

In the present work, piecewise linear elastic - power-law plastic model represented by Equation (4.4) is used. Few simulations have been carried out for Ramberg-Osgood model represented by Equation (4.1) and power law hardening model.

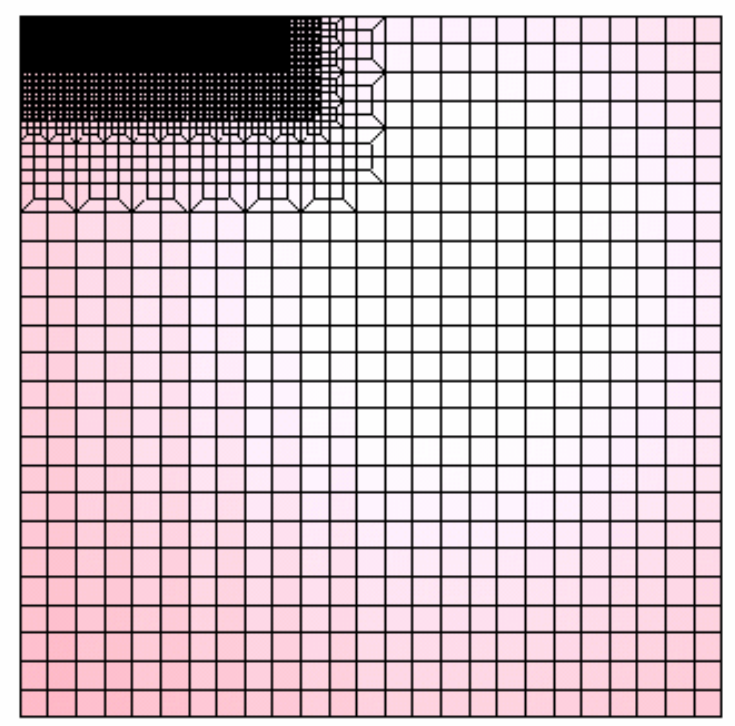

Figure 4.3 Specimen with bias meshed.

The specimen is also bias meshed in a similar way as the indenter. This approach is applied to reduce the computational time. Very fine mesh with a least size of $10 \mu \mathrm{m}$ is 
modeled at the top surface of the specimen and the size of the mesh gets coarser as we move away. The maximum size of the mesh used in the specimen is $640 \mu \mathrm{m}$. It is essential to have such a highly refined mesh in the contact area in order to calculate the contact radius accurately. It has been observed that a small error in the calculation of the contact radius results in high error in calculation of yield stress.

The trapezoidal shaped element is used in the transition area to connect the fine mesh with the coarse. Figure 4.4 below shows the transition area where trapezoidal elements are used to connect a finer with a coarser region. This process is employed through out the model giving rise to a stair case mesh model.

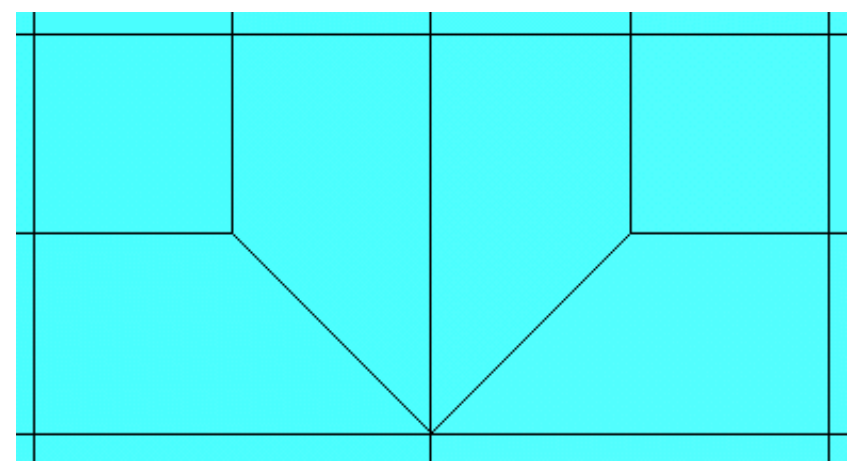

Figure 4.4 Trapezoidal element used in transition region

In total, 21573 elements and 21930 nodes are in the specimen model. Convergence of the present mesh was compared with the simulation of still finer mesh. Results showed no significant changes. Thus, the fineness of the present mesh is validated.

ABAQUS $^{\mathrm{TM}}$ has no designated unit system I.e. the unit system is arbitrary as long as there is a consistency in the entire unit being used in the analysis. Here, we will be inputting the force in Newton $(\mathrm{N})$ and the length is micrometer $(\mu \mathrm{m})$. 


\subsection{Boundary condition and load}

The specimen has fixed bottom and the side along the axis of symmetry is constrained in X-direction, as it is an axis-symmetry model. The specimen is free to move in Y-direction. The other two sides are left free. The specimen size is chosen large enough so that the results obtained are independent of the boundary conditions setup. The Figure 4.5 below shows the constrained specimen.
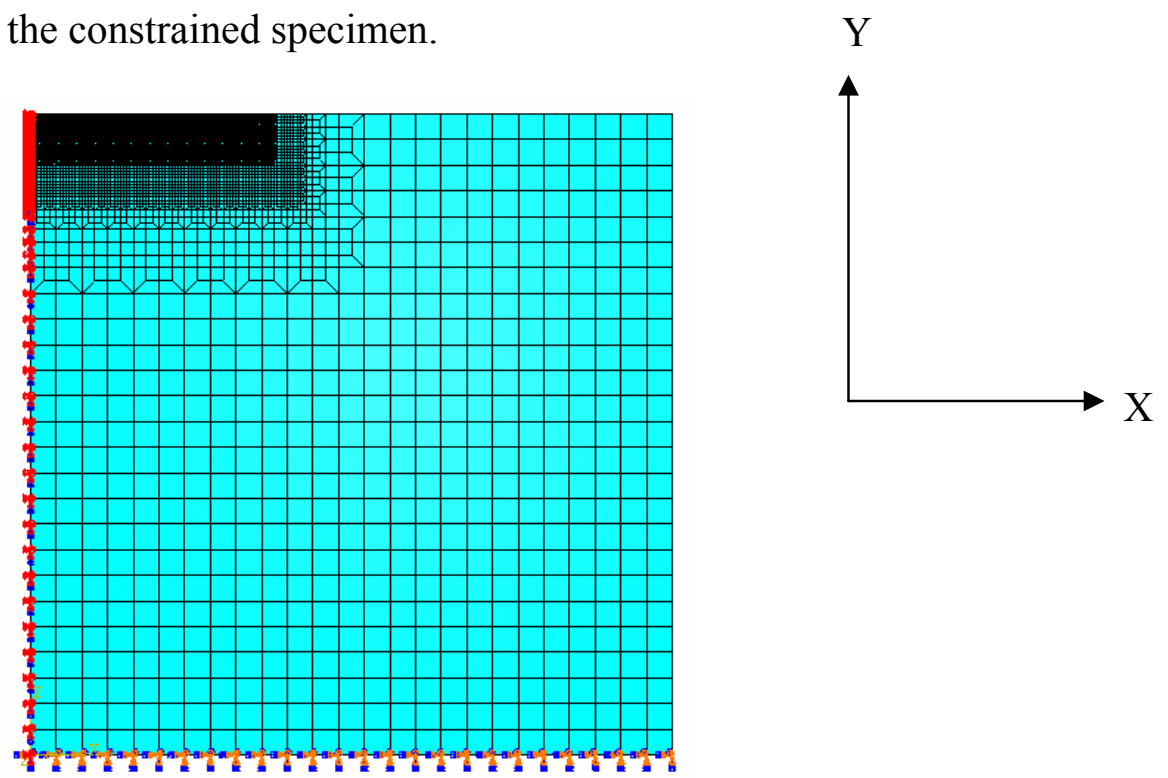

Figure 4.5 Boundary conditions applied on the specimen

The indenter is also constrained in X-direction along the axis of symmetry. The moment of the indenter is controlled along the Y-direction.

The load can be applied on the indenter in two methods: load controlled and displacement controlled. In the load controlled method, the desired load is applied at the top surface of the indenter. In displacement control, the moment of the indenter is controlled by inputting the desired displacement to the top surface nodes. Here we have used the displacement controlled method in order to control the moment of the indenter. Thus, all the nodes at the top surface are given a constant displacement value. It has been noticed 
that no matter which method is employed to input the load, the results obtained are the same. Arrows at the top surface, in the below Figure 4.6 shows the direction of the displacement of the indenter.
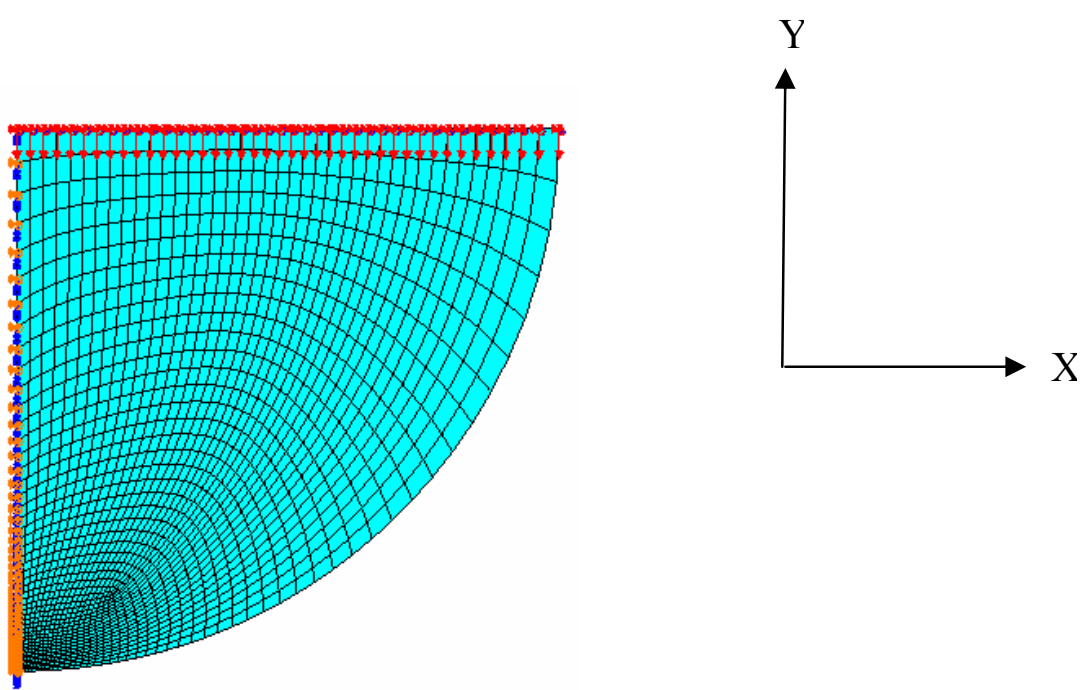

Figure 4.6 Boundary conditions applied on the deformable indenter

In this work, load applied on the indenter is calculated in an indirect method. For a given displacement of the indenter, the load applied is calculated by summing up the total reaction forces at the bottom of the specimen. The results are extracted from multiple frames for a given step. Thus, the Contact radius and the total force applied for a particular displacement of the indenter are extracted from all the frames.

\subsection{Interaction between indenter and specimen}

ABAQUS $^{\mathrm{TM}}$ defines contact between two bodies in terms of two surfaces that may interact: these surfaces are called 'contact pair'. Contact interaction occurs between two surfaces. However, in strict master-slave contact formulation in ABAQUS ${ }^{\mathrm{TM}}$ /Standard, only the master surface is used as a surface. The only data required by the 
ABAQUS $^{\mathrm{TM}}$ from the slave surface are the location of its nodes and the surface area associated with each node.

\subsubsection{Choosing the master and slave surfaces of a contact pair}

ABAQUS $^{\mathrm{TM}}$ defines that, slave surfaces must always be attached to deformable bodies. Rigid bodies must always be the master surfaces in the contact pair. When both the bodies are deformable, the stiffer body is chosen as the master surface.

In the present simulation, the interaction between the indenter and the specimen is modeled as contact pair. The indenter surface is defined as 'master' surface and the specimen surface as 'slave' surface because the indenter is stiffer than the specimen.

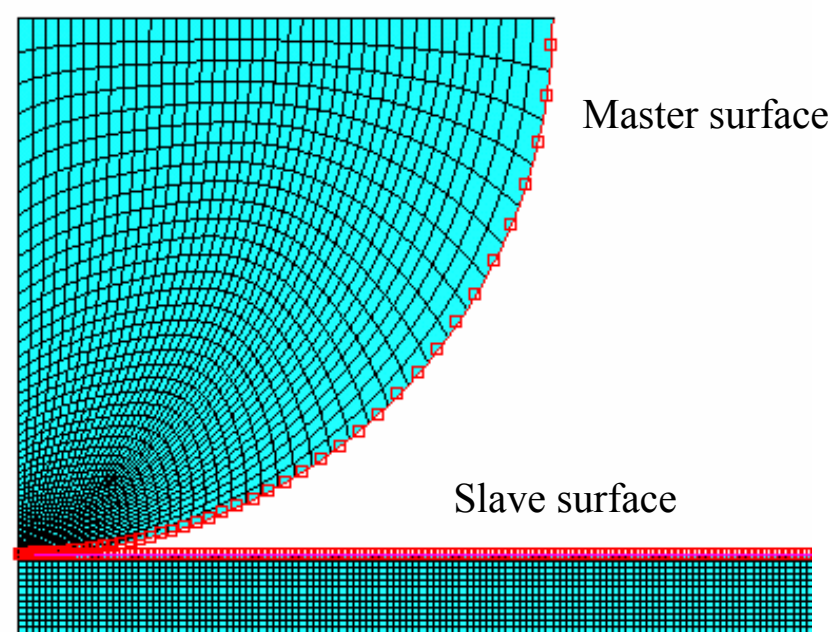

Figure 4.7 Demonstrating the master and the slave surface

Earlier work by Nix [22] was carried out under the assumption of frictionless conditions between the indenter and the specimen. He claimed no considerable change in load displacement response even with a friction coefficient of 1 . But this has been challenged by the subsequent work of Mesarovic and Fleck claiming that friction could 
decrease the contact area by $8 \%$. In the present work, we will be assuming the friction coefficient to be 0.1 in all the analysis models.

\subsection{Simulation of the Indentation process}

The finite element model is prepared by following the procedure discussed above. Maximum depth of the indentation is $320 \mu \mathrm{m}$ in all the models. Pile-up is observed for materials with strain hardening exponent less than 0.2 and sink-in for material with strain hardening exponent greater than 0.2 . Figures 4.8 and 4.9 below demonstrate the pile up and sink during the indentation process.

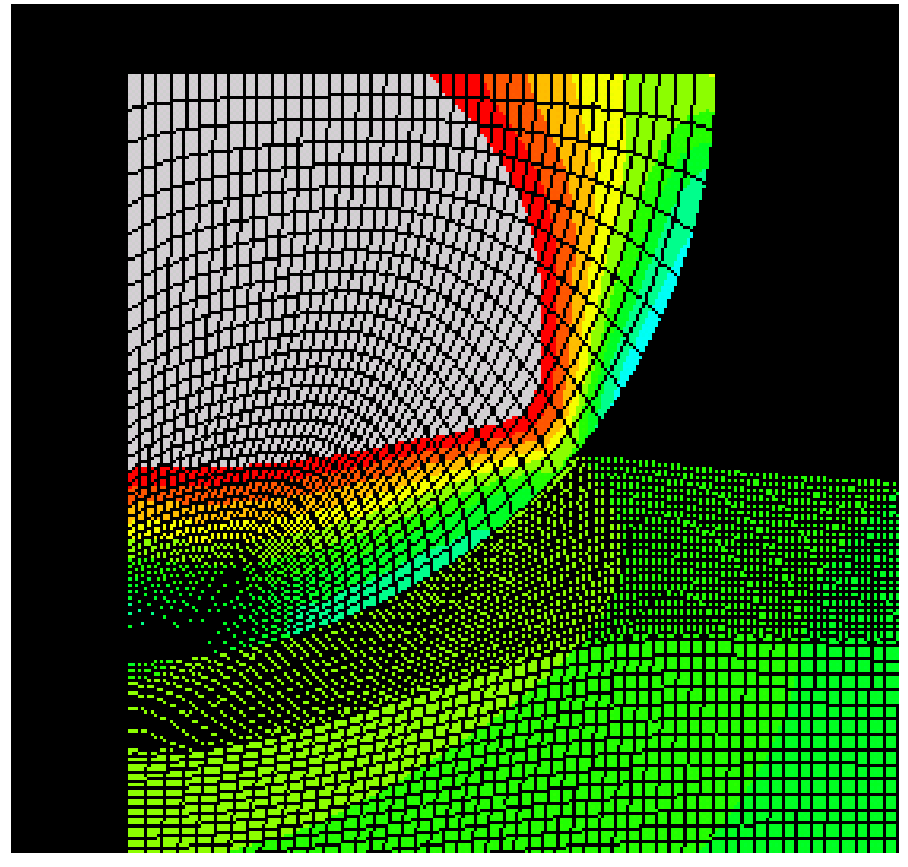

Figure 4.8 Pileup of the material with $\mathrm{n}=0.18$

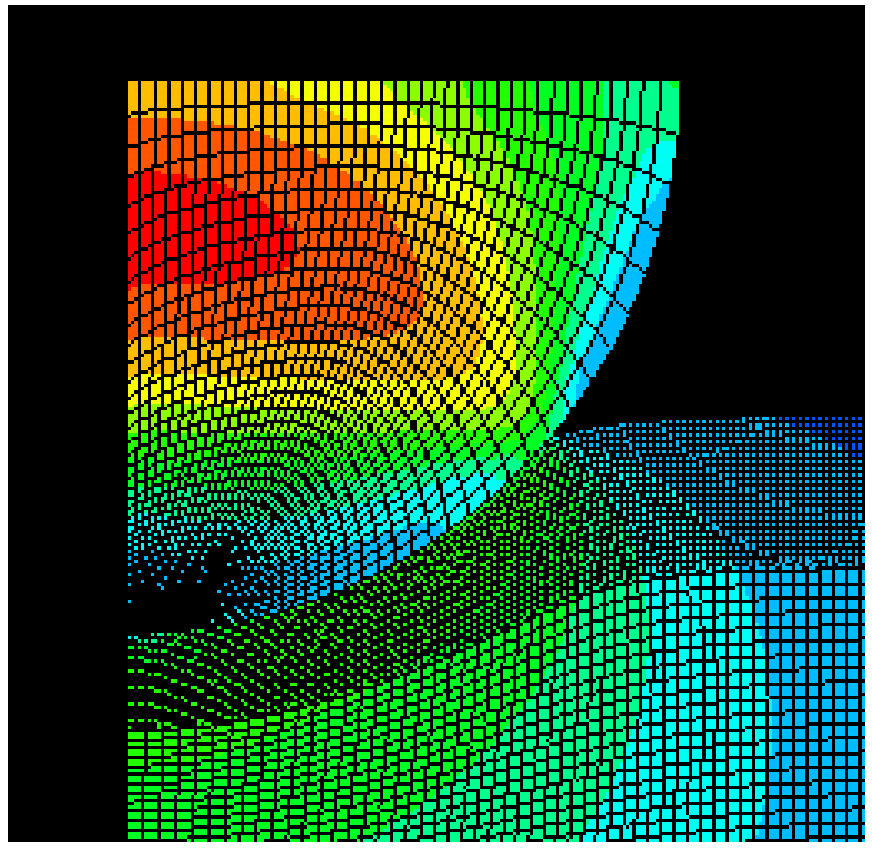

Figure 4.9 Sink in of the material with $\mathrm{n}=0.36$ 


\section{Chapter 5}

\section{Results}

\subsection{Materials analyzed}

Finite element simulation has been performed on wide variety of steel and aluminum alloys. The table below gives the list of material matrix.

\begin{tabular}{|c|c|c|c|c|c|c|c|c|c|c|c|}
\hline \multicolumn{12}{|c|}{ Aluminum alloys $(\mathrm{E}=69 \mathrm{GPa}, \mathrm{v}=0.33)$} \\
\hline \multicolumn{6}{|c|}{$S_{y}=275 M P a(6061-\mathrm{T} 6)$} & \multicolumn{6}{|c|}{$S_{y}=500 M P a(7075-\mathrm{T} 651)$} \\
\hline $\mathrm{n}=0.09$ & \multicolumn{2}{|c|}{$\mathrm{n}=0.18$} & $\mathrm{n}=0.27$ & \multicolumn{2}{|c|}{$\mathrm{n}=0.36$} & $\mathrm{n}=0.09$ & \multicolumn{2}{|c|}{$\mathrm{n}=0.18$} & $\mathrm{n}=0.27$ & \multicolumn{2}{|c|}{$\mathrm{n}=0.36$} \\
\hline \multicolumn{12}{|c|}{ Steel alloys $(E=200 \mathrm{GPa}, v=0.3)$} \\
\hline \multicolumn{4}{|c|}{$S_{y}=500 M P a$} & \multicolumn{4}{|c|}{$S_{y}=750 M P a$} & \multicolumn{4}{|c|}{$S_{y}=1000 M P a$} \\
\hline $\mathrm{n}=0.1$ & $\mathrm{n}=0.2$ & $\mathrm{n}=0.3$ & $\mathrm{n}=0.4$ & $\mathrm{n}=0.1$ & $\mathrm{n}=0.2$ & $\mathrm{n}=0.3$ & $\mathrm{n}=0.4$ & $\mathrm{n}=0.1$ & $\mathrm{n}=0.2$ & $\mathrm{n}=0.3$ & $\mathrm{n}=0.4$ \\
\hline
\end{tabular}

Table 5.1 List of material properties

As a result of various heat treatment processes, the materials in a given set of alloys may have same Young's modulus but different yield stress and strain hardening coefficient. Thus, we have chosen materials with same Young's modulus and yield stress but with different strain hardening coefficient to perform the indentation simulation.

Material of the indenter is tungsten with Young's modulus of $650 \mathrm{GPa}$ and Poisson's ratio 0.2. The indenter has much higher hardness value when compared with the materials being analyses. In practice, many commercially available indenters are made up of tungsten material. 


\subsection{Application of the methodology}

The indenter is indented to a depth of $320 \mu \mathrm{m}$. It has been applied in multiple steps. The purpose of this is to obtain sufficient number of frames within a step, so that the required output can be extracted from the frames. It is then followed by calculating the force applied and the contact diameter of the indenter for a given displacement of the indenter. The force is calculated by summing up the total reaction force at the bottom of the specimen and at the same time noting the contact diameter. These two are the only required outputs in order to obtain the complete stress-strain curve of a material by applying the present proposed methodology. This is then followed by applying the Tabor's stress strain Equation (5.1).

$\varepsilon_{i}=0.2 \frac{d}{D}$ and $\sigma_{i}=\frac{P_{m}}{2.8}$

Where,

$\mathrm{d}=$ Contact diameter

$\mathrm{D}=$ Diameter of the ball indenter and

$p_{m}=\frac{4 p}{\pi d^{2}}$

$p=$ Applied load

Now, the methodology explained in Chapter 5 is employed. The applied load versus the contact radius and stress versus strain graphs are plotted and the required material properties are calculated. The following results were obtained. 
Aluminum, E=69 GPa, $\mathbf{S}_{y}=275 \mathrm{MPa}$

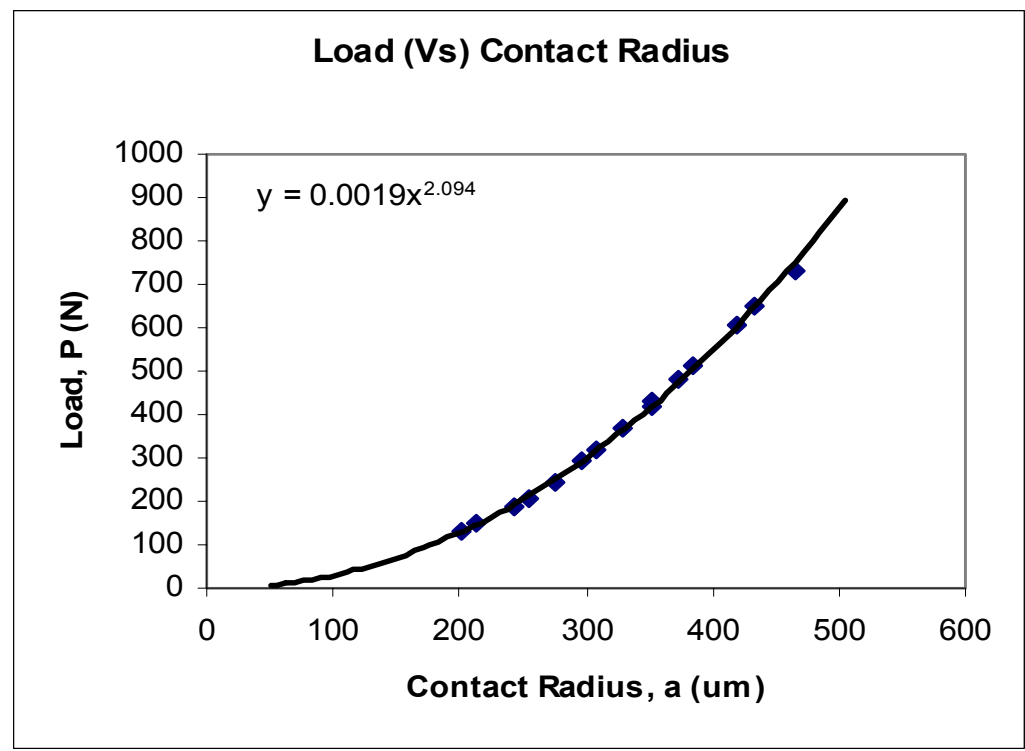

Figure 5.1 Load Versus contact radius for aluminum $\mathrm{E}=69 \mathrm{GPa}, \mathrm{S}_{y}=275 \mathrm{MPa}, \mathrm{n}=0.09$

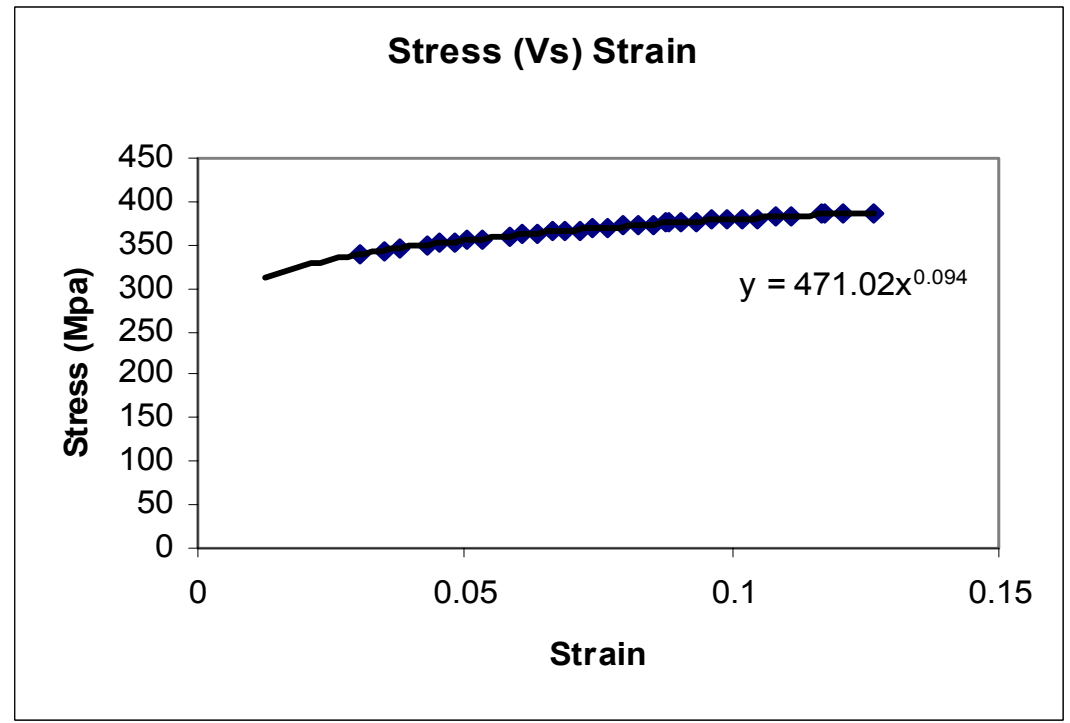

Figure 5.2 Stress Versus strain for aluminum

$$
\mathrm{E}=69 \mathrm{GPa}, \mathrm{S}_{y}=275 \mathrm{MPa}, \mathrm{n}=0.09
$$




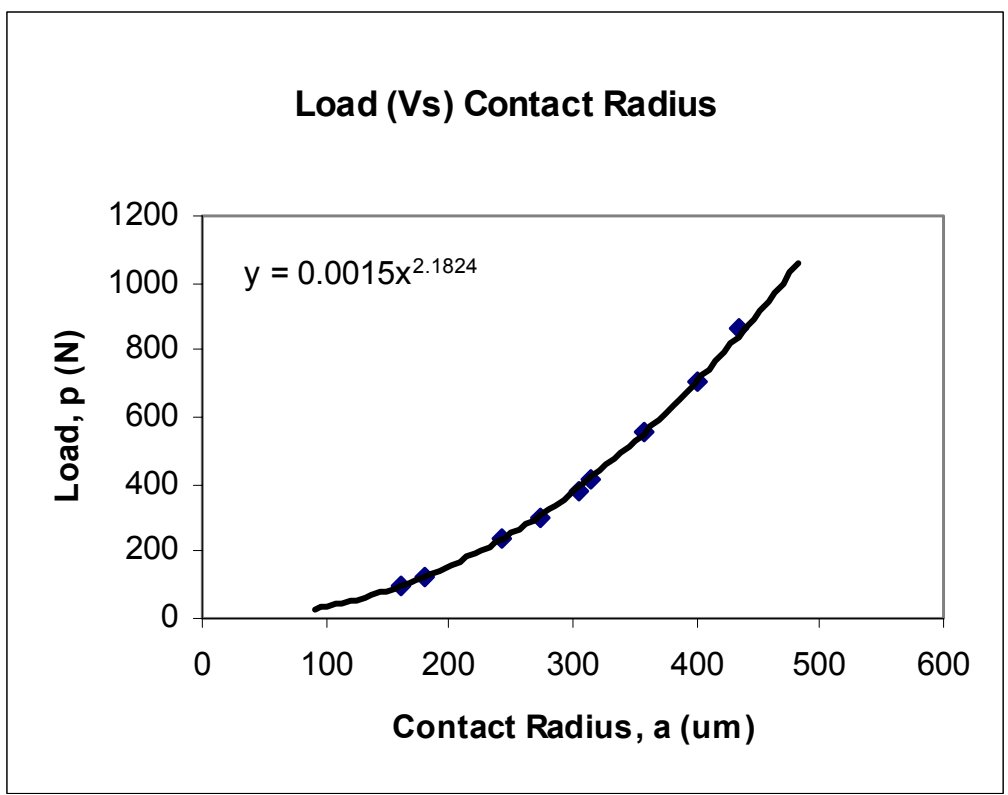

Figure 5.3 Load Versus contact radius for aluminum $\mathrm{E}=69 \mathrm{GPa}, \mathrm{S}_{y}=275 \mathrm{MPa}, \mathrm{n}=0.18$

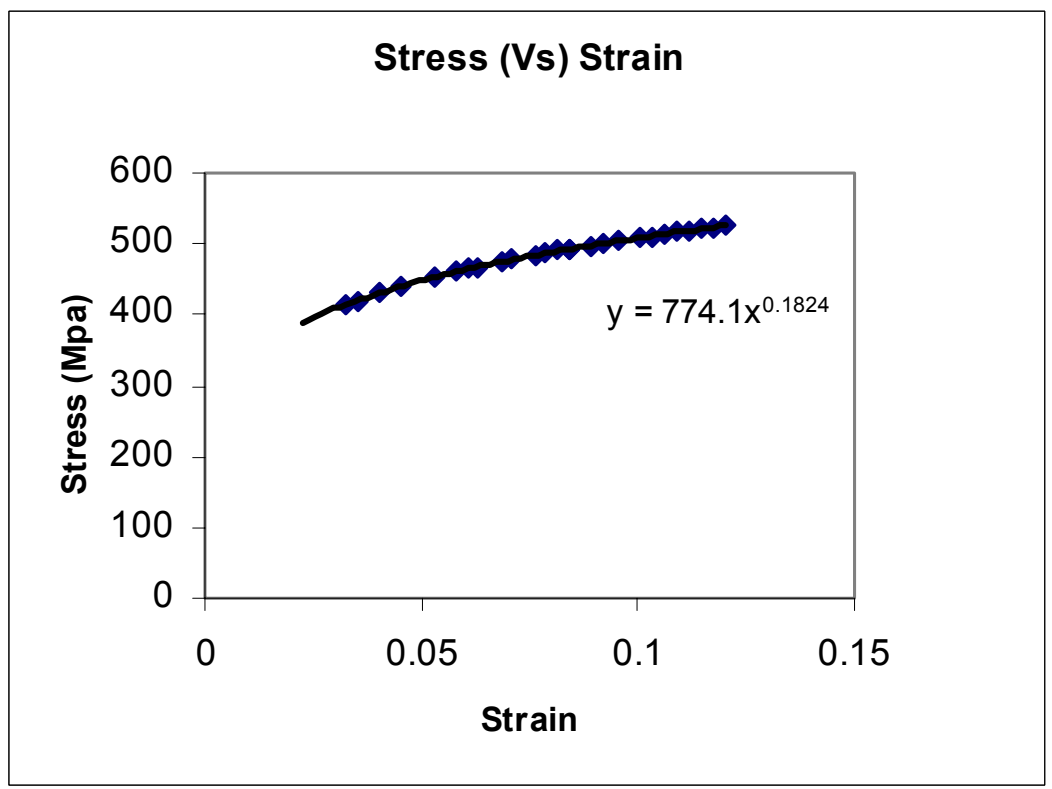

Figure 5.4 Stress Versus strain for aluminum

$\mathrm{E}=69 \mathrm{GPa}, \mathrm{S}_{y}=275 \mathrm{MPa}, \mathrm{n}=0.18$ 


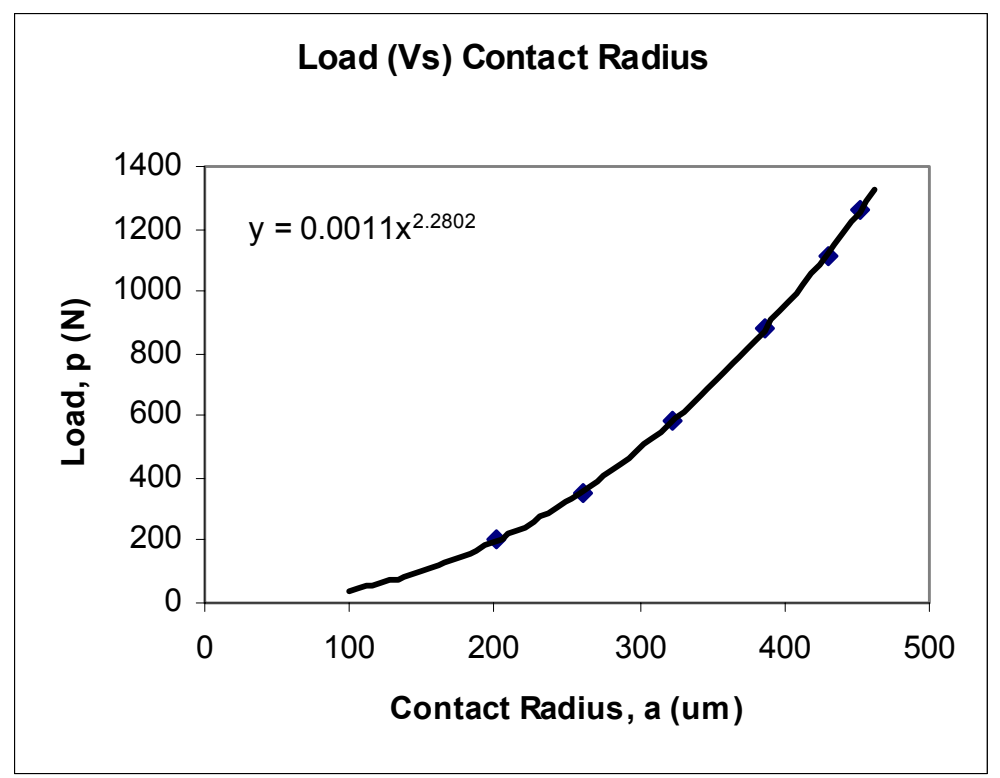

Figure 5.5 Load Versus contact radius for aluminum

$$
\mathrm{E}=69 \mathrm{GPa}, \mathrm{S}_{y}=275 \mathrm{MPa}, \mathrm{n}=0.27
$$

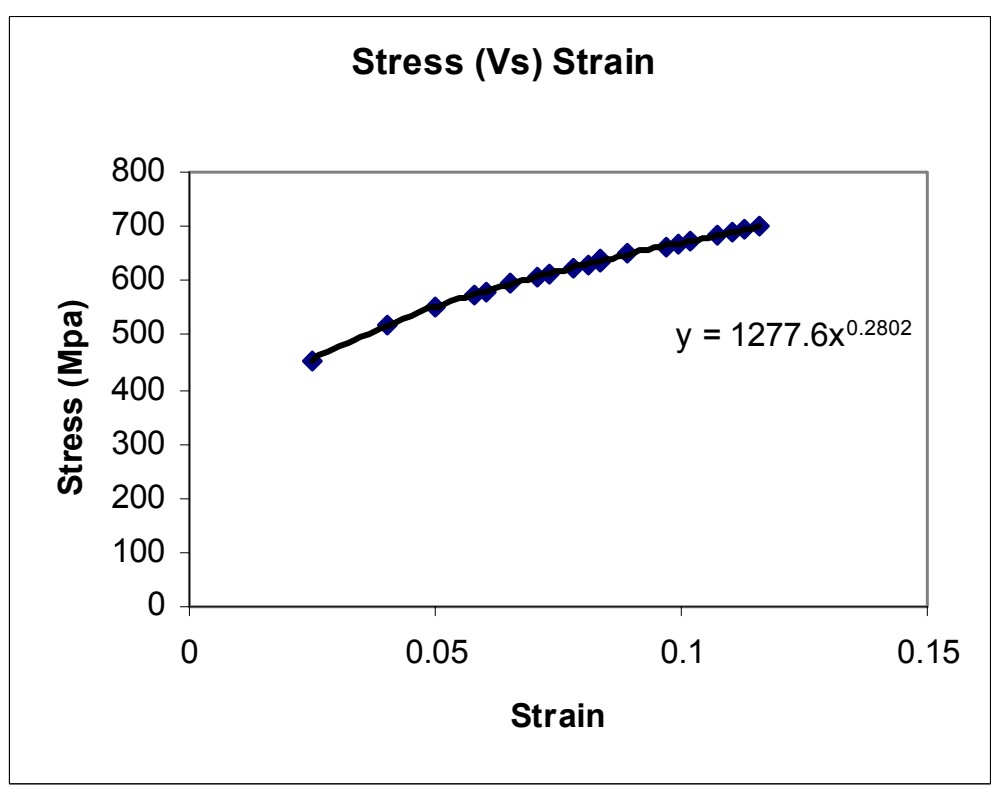

Figure 5.6 Stress Versus strain for aluminum, E=69 GPa

$$
\mathrm{S}_{y}=275 \mathrm{MPa}, \mathrm{n}=0.27
$$




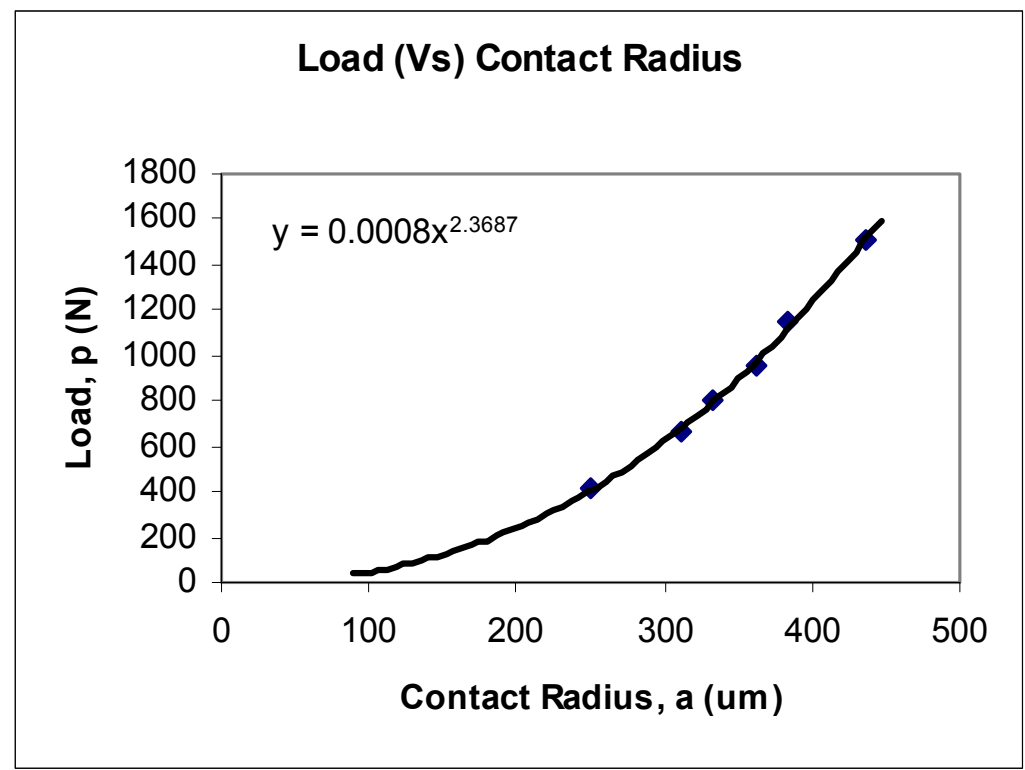

Figure 5.7 Load Versus contact radius for aluminum $\mathrm{E}=69 \mathrm{GPa}, \mathrm{S}_{y}=275 \mathrm{MPa}, \mathrm{n}=0.36$

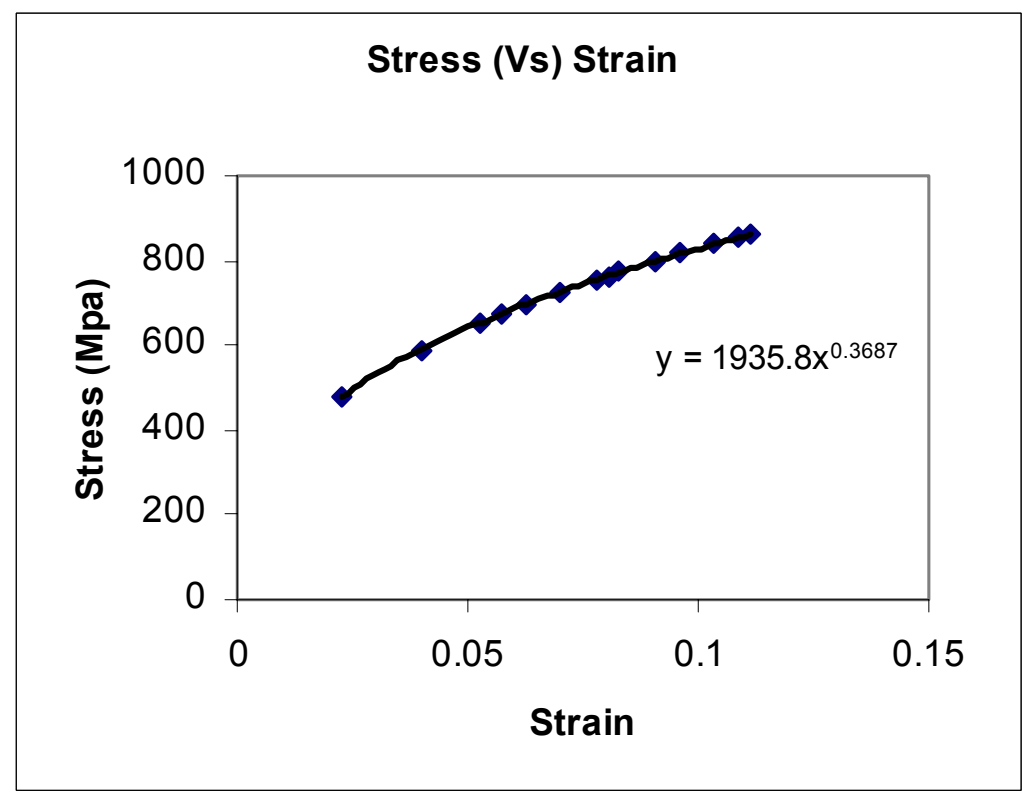

Figure 5.8 Stress Versus strain for aluminum, E=69 GPa,

$$
\mathrm{S}_{y}=275 \mathrm{MPa}, \mathrm{n}=0.36
$$


From load versus contact radius graph, the strain hardening exponent of the material is obtained by subtracting 2 from the exponent of the curve obtained. And then using the Tabor's empirical stress and strain equation, we obtain the stress versus strain graph.

Numerical results with the theoretical values are tabulated below.

\begin{tabular}{|c|c|c|c|c|}
\hline Input $\mathrm{n}$ & $\begin{array}{c}\mathrm{n} \text { obtained from } \\
\text { Load Versus } \\
\text { Contact Radius } \\
\text { graph }\end{array}$ & $\begin{array}{c}\text { Input yield } \\
\text { (Mpa) }\end{array}$ & $\begin{array}{c}\text { Yield stress } \\
\text { from Graph } \\
\text { (Mpa) }\end{array}$ & Error (\%) \\
\hline 0.09 & 0.094 & 275 & 280.7 & $2.09 \%$ \\
\hline 0.18 & 0.182 & 275 & 284.2 & $3.37 \%$ \\
\hline 0.27 & 0.28 & 275 & 270.39 & $1.67 \%$ \\
\hline 0.36 & 0.368 & 275 & 240.13 & $12.67 \%$ \\
\hline
\end{tabular}

Table 5.2 Comparison of the results obtained for aluminum

$$
\mathrm{E}=69 \mathrm{GPa}, \mathrm{S}_{y}=275 \mathrm{MPa}
$$

From the above Table 5.2 we observe that values of the strain hardening coefficient, $\mathrm{n}$, obtained from the finite element simulations using the proposed methodology are in good agreement with the input values. Yield stresses are also in good agreement with error percentage ranging from 2 to $12 \%$. Yield stress values calculated for the material with $\mathrm{n}$ values of $0.9,0.18$, and 0.27 are in good agreement, however, the error percentage is high for material with $\mathrm{n}=0.36$. This error can be attributed to the Tabor's constant. This issue will be discussed in detail in the later part of this chapter. 
Aluminum, $\mathbf{E}=69 \mathrm{GPa}, \mathbf{S}_{y}=500 \mathrm{MPa}$

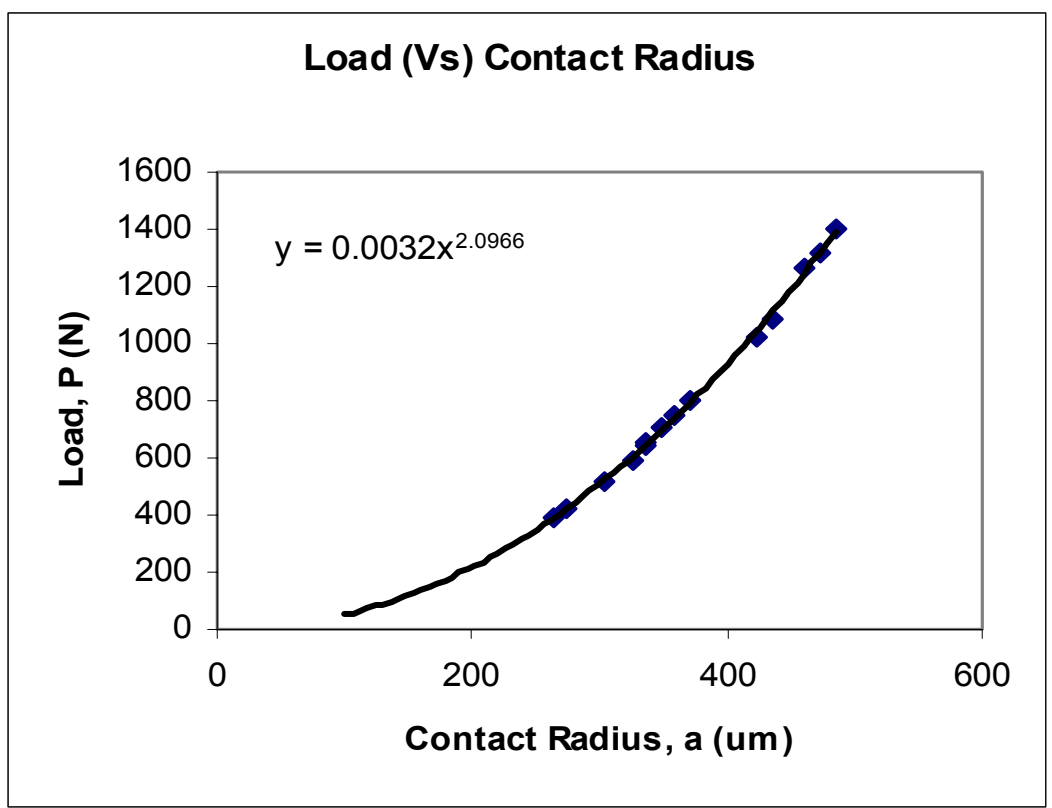

Figure 5.9 Load Versus contact radius for aluminum $\mathrm{E}=69 \mathrm{GPa}, \mathrm{S}_{y}=500 \mathrm{MPa}, \mathrm{n}=0.09$

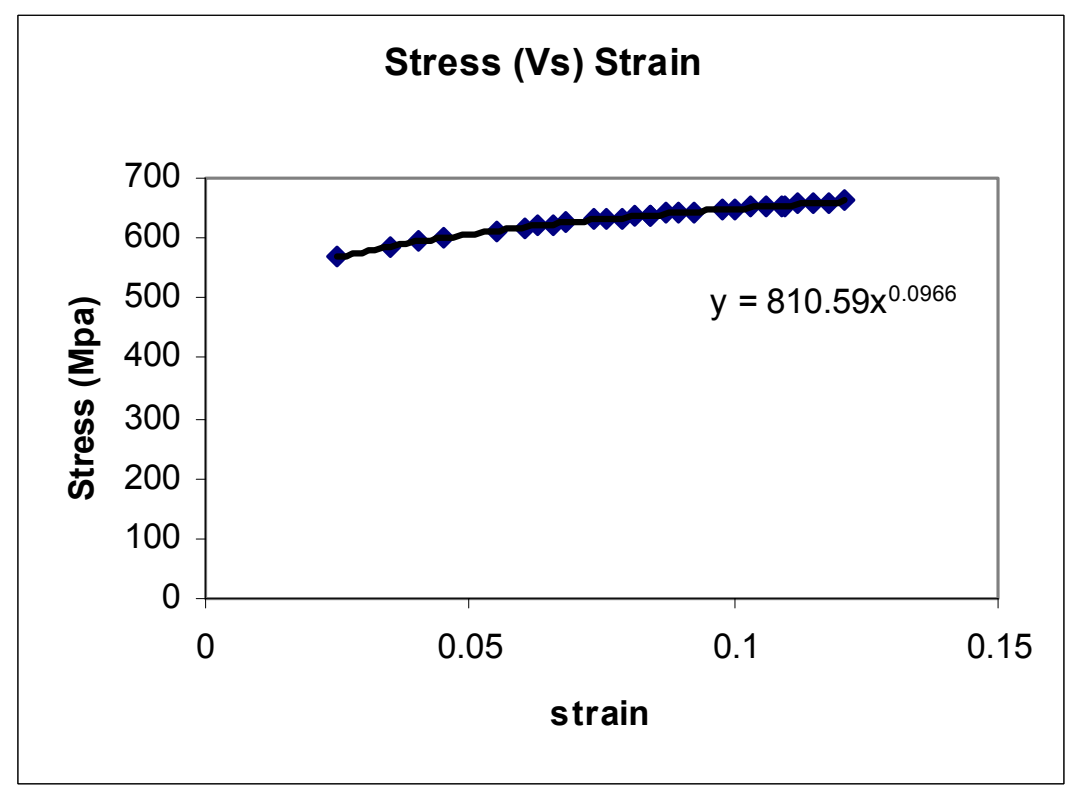

Figure 5.10 Stress Versus strain for aluminum, E=69 GPa

$$
\mathrm{S}_{y}=500 \mathrm{MPa}, \mathrm{n}=0.09
$$




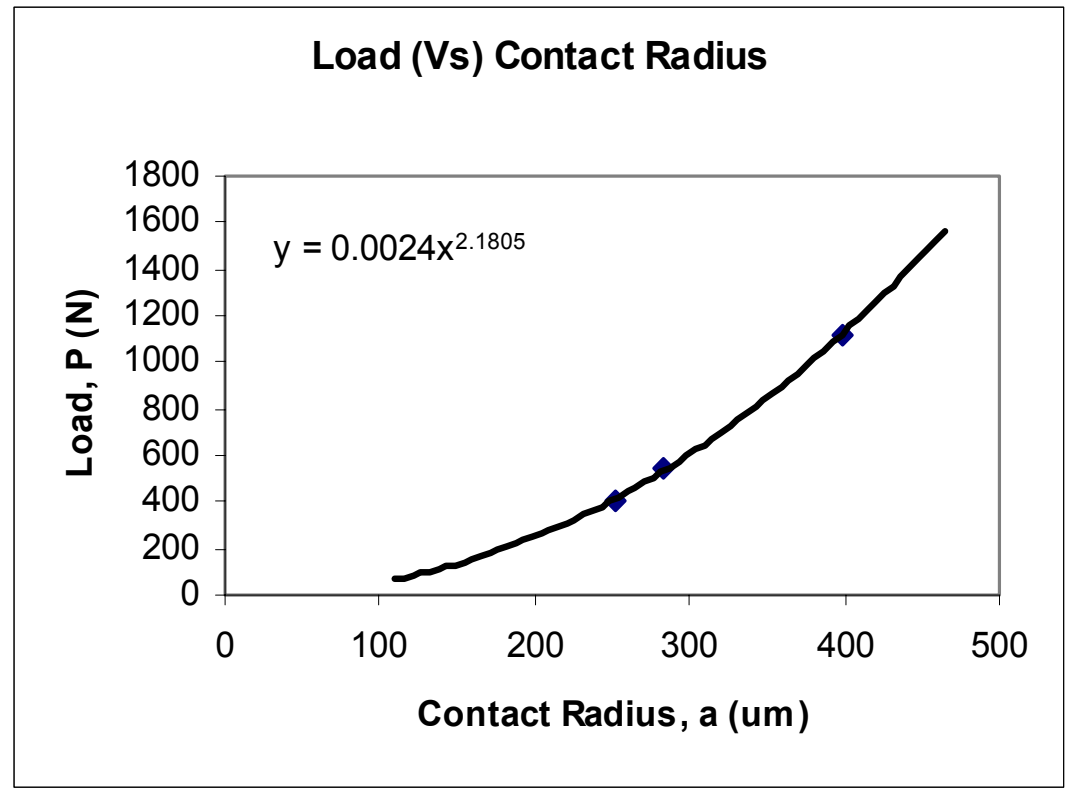

Figure 5.11 Load Versus contact radius for aluminum $\mathrm{E}=69 \mathrm{GPa}, \mathrm{S}_{y}=500 \mathrm{MPa}, \mathrm{n}=0.18$

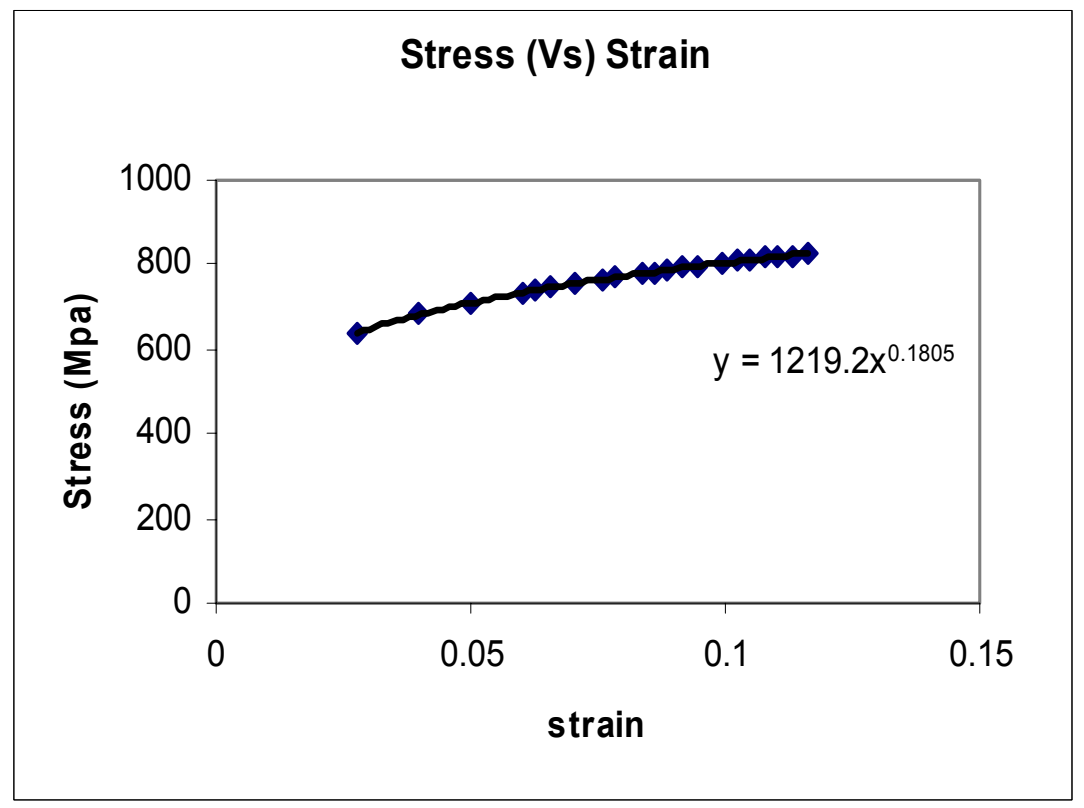

Figure 5.12 Stress Versus strain for aluminum, E=69 GPa

$$
\mathrm{S}_{y}=500 \mathrm{MPa}, \mathrm{n}=0.18
$$




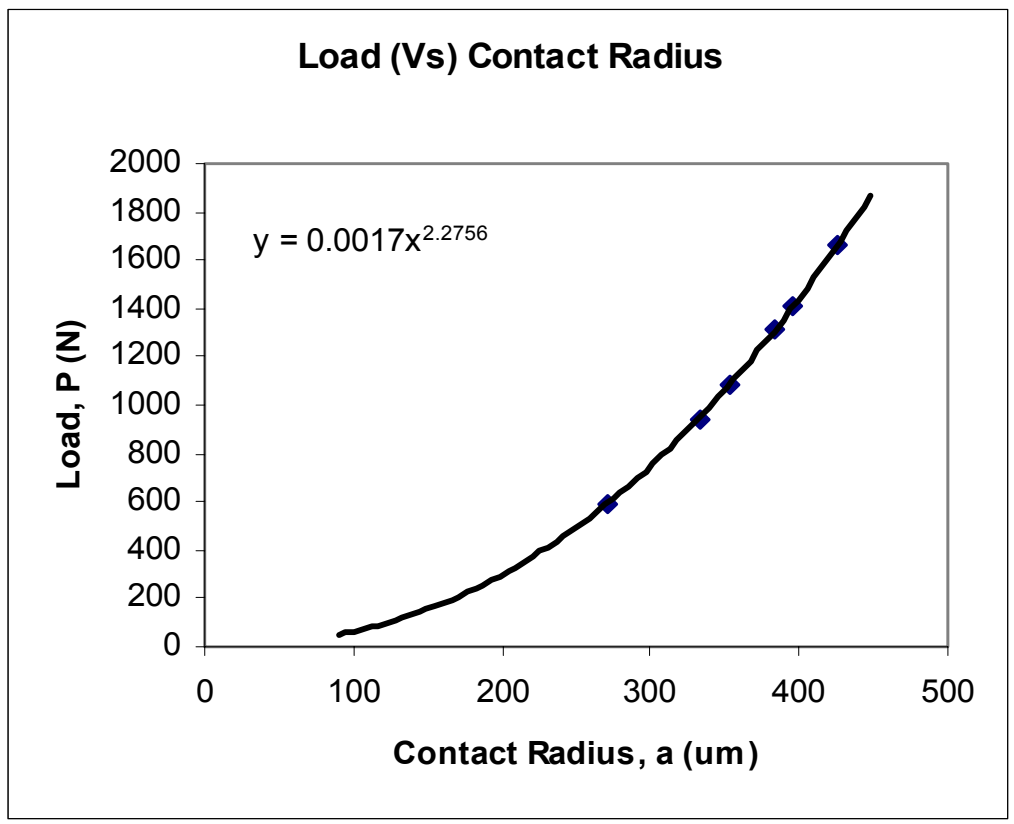

Figure 5.13 Load Versus contact radius for aluminum $\mathrm{E}=69 \mathrm{GPa}, \mathrm{S}_{y}=500 \mathrm{MPa}, \mathrm{n}=0.27$

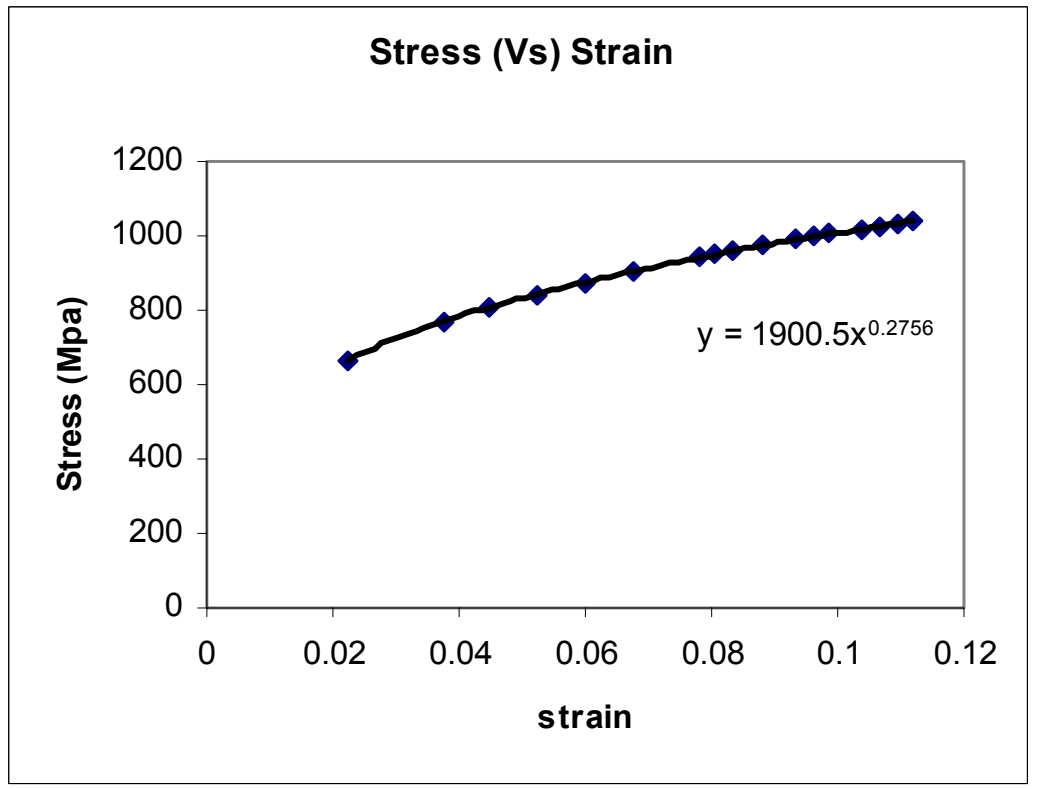

Figure 5.14 Stress Versus strain for aluminum, E=69 GPa

$$
\mathrm{S}_{y}=500 \mathrm{MPa}, \mathrm{n}=0.27
$$




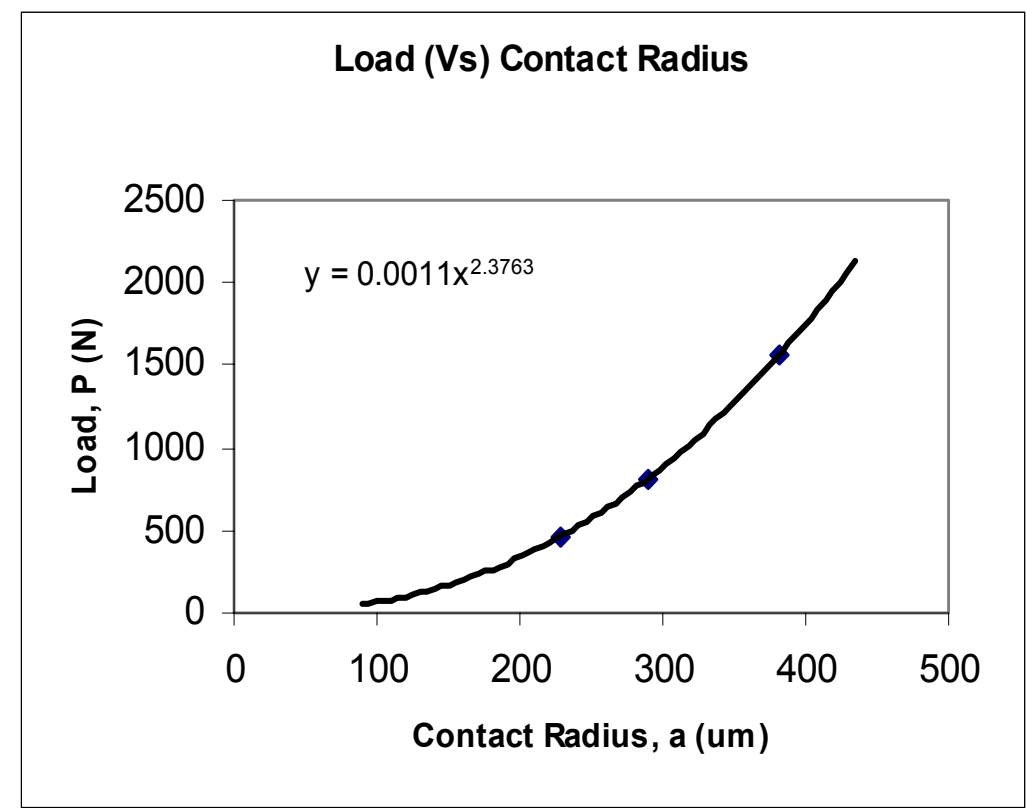

Figure 5.15 Load Versus contact radius for aluminum $\mathrm{E}=69 \mathrm{GPa}, \mathrm{S}_{y}=500 \mathrm{MPa}, \mathrm{n}=0.36$

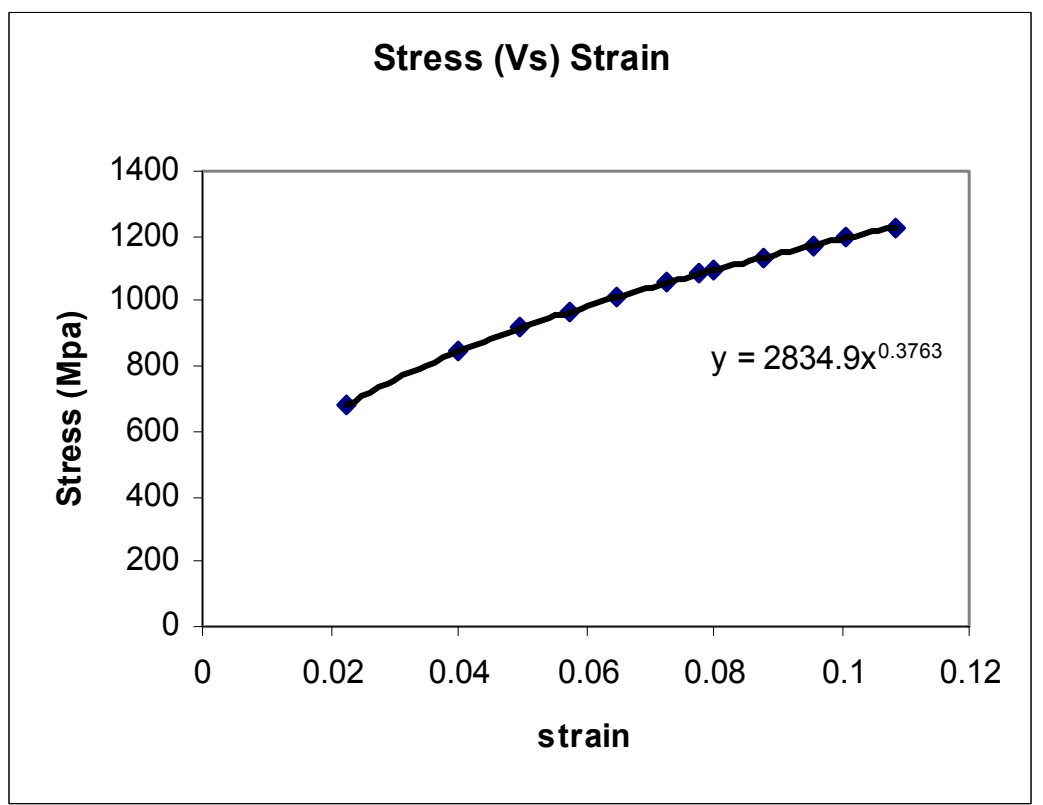

Figure 5.16 Stress Versus strain for aluminum, E=69 GPa

$$
\mathrm{S}_{y}=500 \mathrm{MPa}, \mathrm{n}=0.36
$$


Numerical results with the theoretical values are tabulated below.

\begin{tabular}{|c|c|c|c|c|}
\hline Input $\mathrm{n}$ & $\begin{array}{c}\mathrm{n} \text { obtained from } \\
\text { Load Versus } \\
\text { Contact Radius } \\
\text { graph }\end{array}$ & $\begin{array}{c}\text { Input yield } \\
(\mathrm{MPa})\end{array}$ & $\begin{array}{c}\text { Yield stress } \\
\text { from Graph } \\
(\mathrm{MPa})\end{array}$ & Error (\%) \\
\hline 0.09 & 0.096 & 500 & 503.9 & $0.79 \%$ \\
\hline 0.18 & 0.18 & 500 & 501.2 & $0.24 \%$ \\
\hline 0.27 & 0.275 & 500 & 484.5 & $3.08 \%$ \\
\hline 0.36 & 0.376 & 500 & 413.1 & $17.36 \%$ \\
\hline
\end{tabular}

Table 5.3 Comparison of the results obtained for aluminum

$$
\mathrm{E}=69 \mathrm{GPa}, \mathrm{S}_{y}=500 \mathrm{MPa}
$$

From the above Table 5.3, values of the strain hardening coefficient, n, obtained from the finite element simulations using the proposed methodology are in good agreement with the input values. Yield stress is also in good agreement for strain hardening materials of $0.09,0.18$, and 0.27 . However, the error is $17 \%$ for material with $\mathrm{n}$ $=0.36$. This error in yield stress calculation can be attributed to the Tabor's constant. This issue will be discussed in detail in the later part of this chapter. 


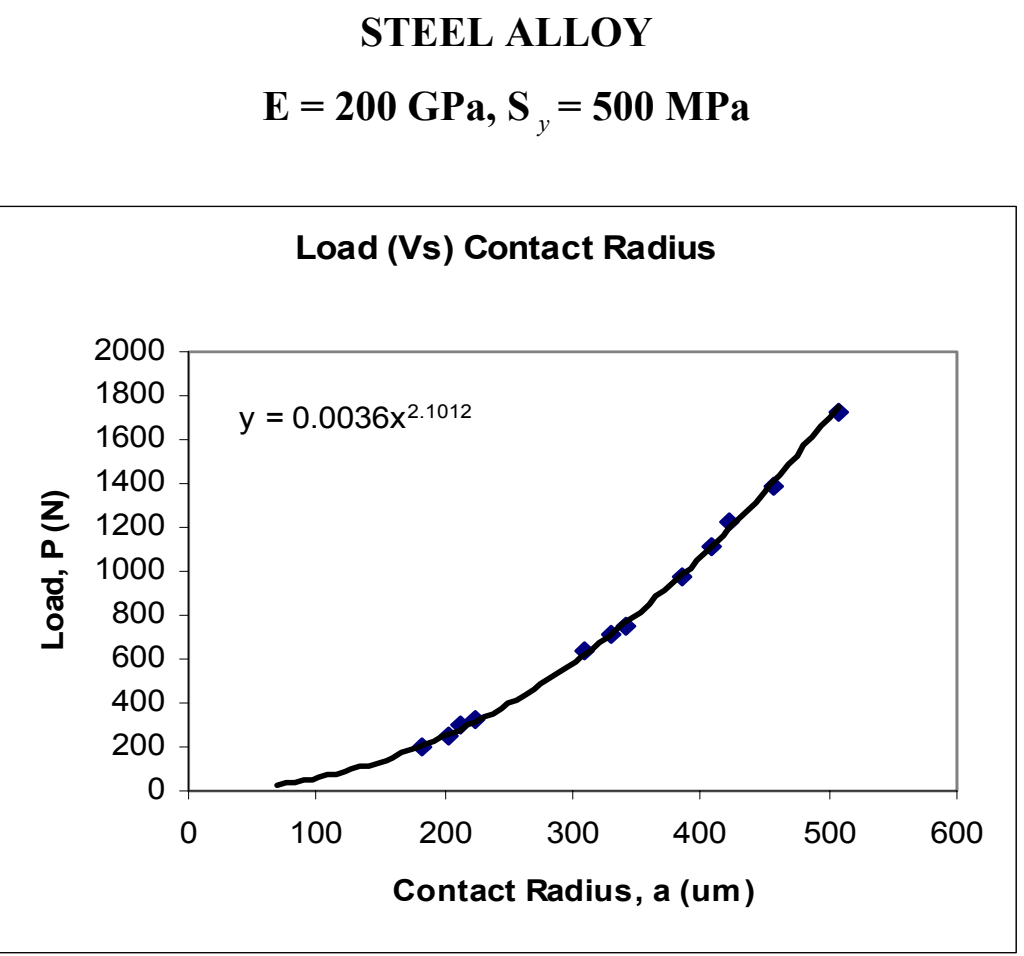

Figure 5.17 Load Versus contact radius for steel, E=200 GPa

$$
\mathrm{S}_{y}=500 \mathrm{MPa}, \mathrm{n}=0.1
$$

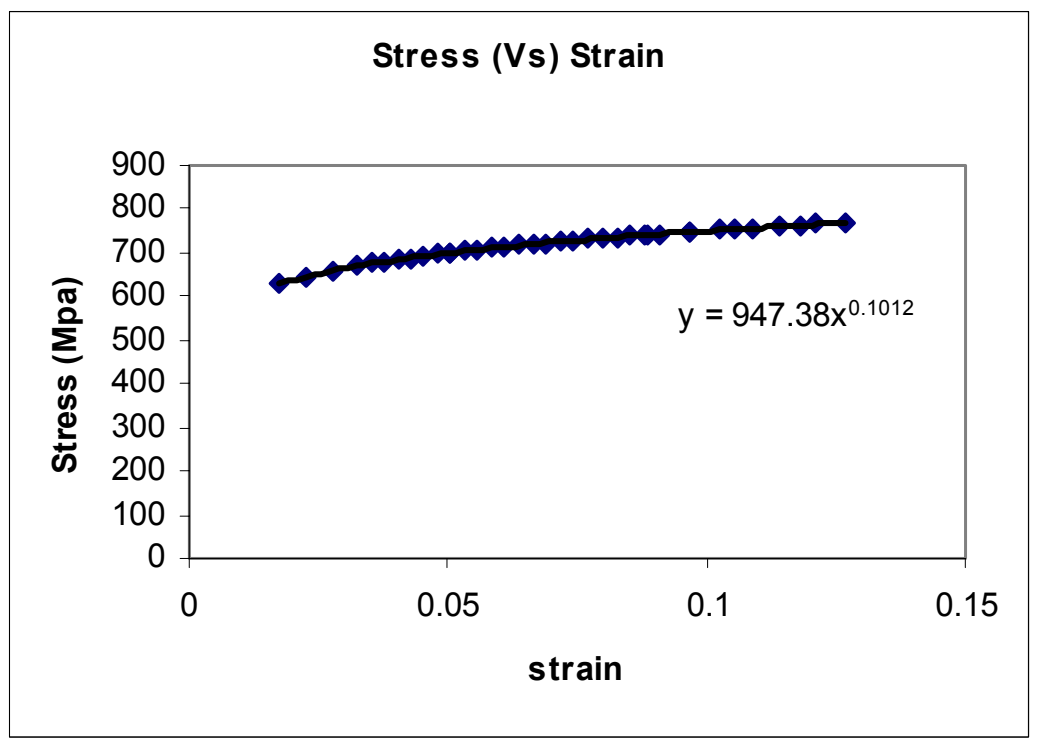

Figure 5.18 Stress Versus strain for steel, E=200 GPa

$$
\mathrm{S}_{y}=500 \mathrm{MPa}, \mathrm{n}=0.1
$$




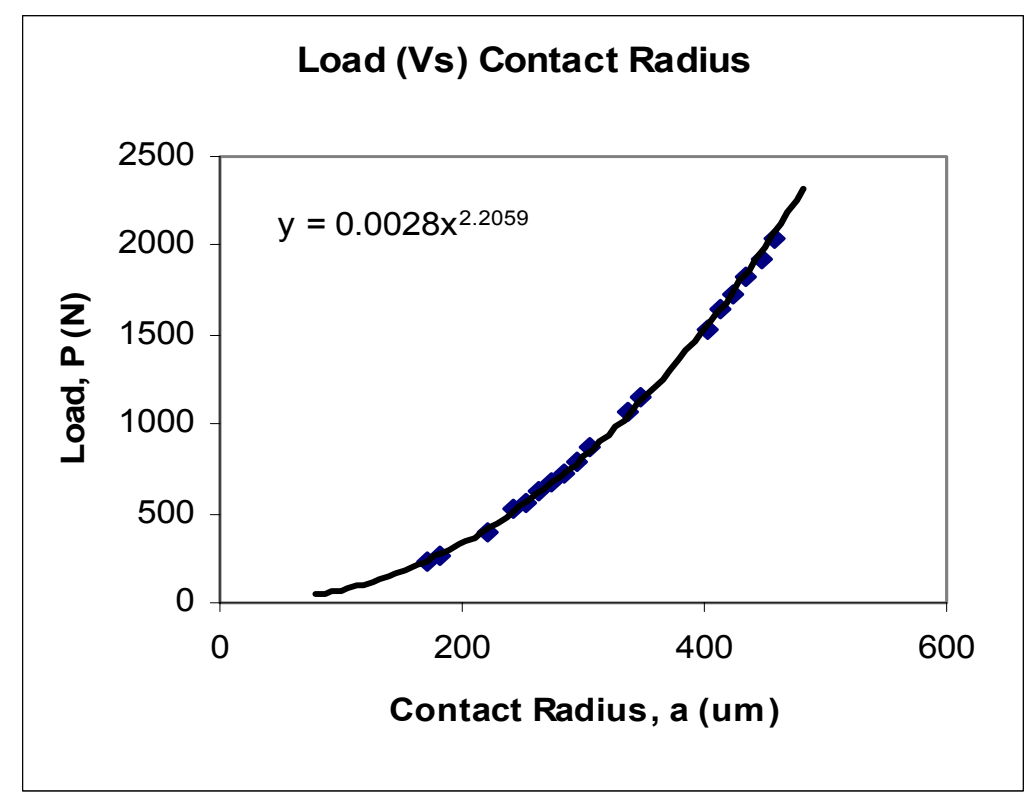

Figure 5.19 Load Versus contact radius for steel, E=200 GPa

$$
\mathrm{S}_{y}=500 \mathrm{MPa}, \mathrm{n}=0.2
$$

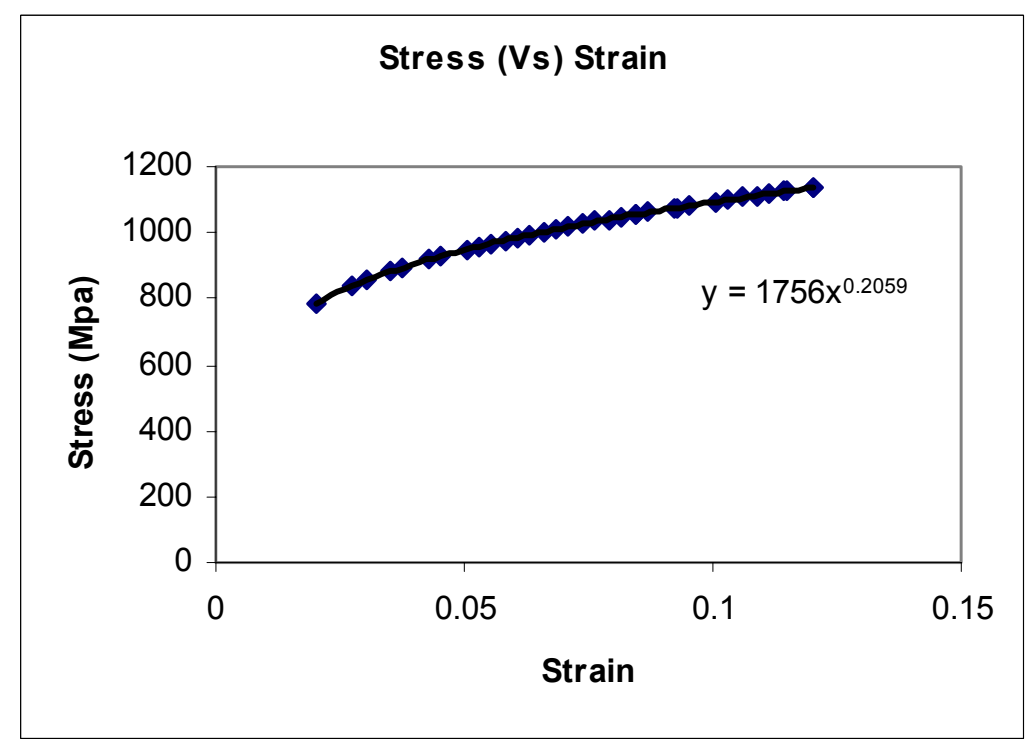

Figure 5.20 Stress Versus strain for steel, E=200 GPa

$$
\mathrm{S}_{y}=500 \mathrm{MPa}, \mathrm{n}=0.2
$$




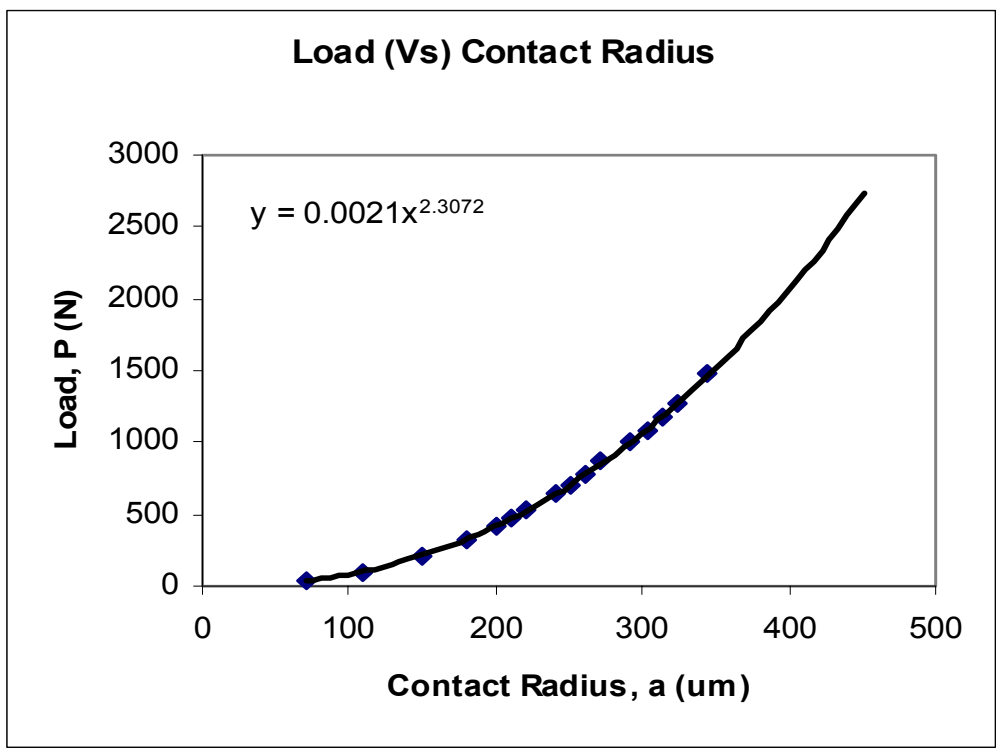

Figure 5.21 Load Versus contact radius for steel, E=200 GPa

$$
\mathrm{S}_{y}=500 \mathrm{MPa}, \mathrm{n}=0.3
$$

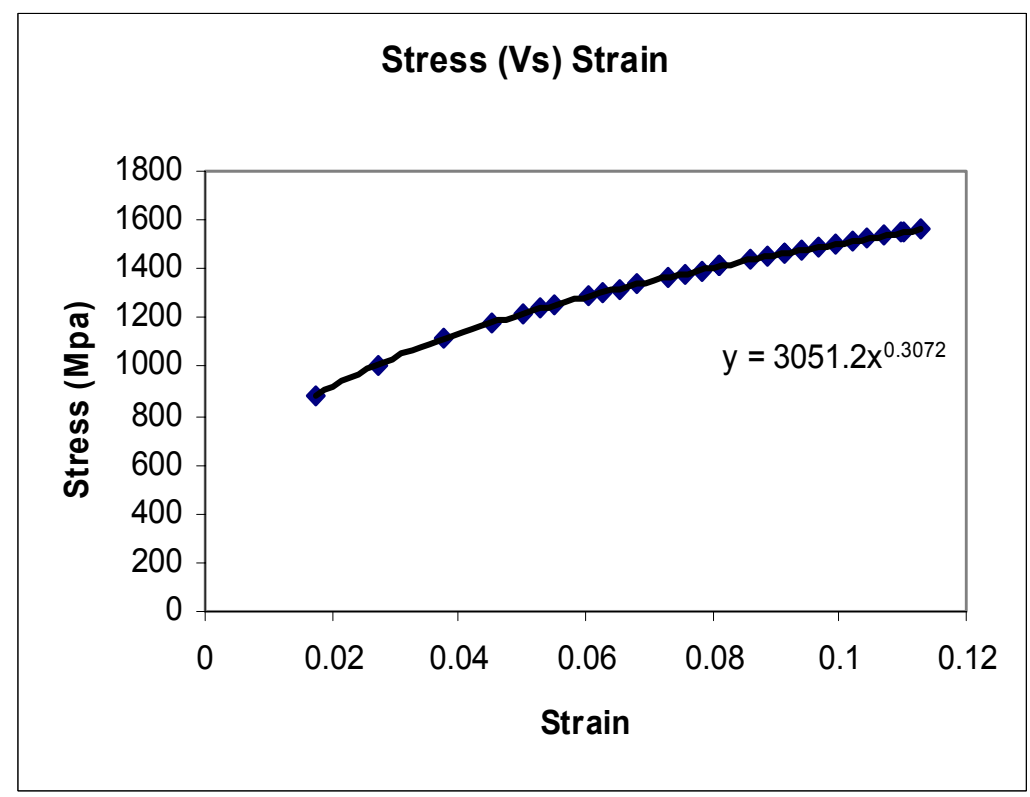

Figure 5.22 Stress Versus strain for steel, E=200 GPa

$$
\mathrm{S}_{y}=500 \mathrm{MPa}, \mathrm{n}=0.3
$$




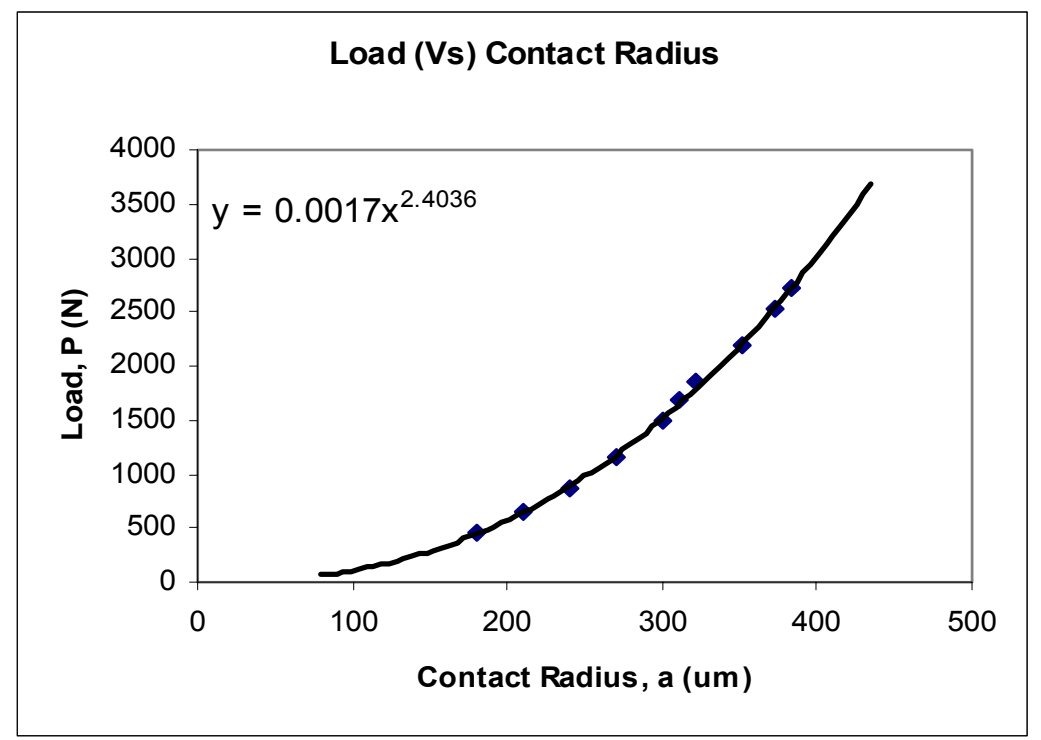

Figure 5.23 Load Versus contact radius for steel, E=200 GPa

$$
\mathrm{S}_{y}=500 \mathrm{MPa}, \mathrm{n}=0.4
$$

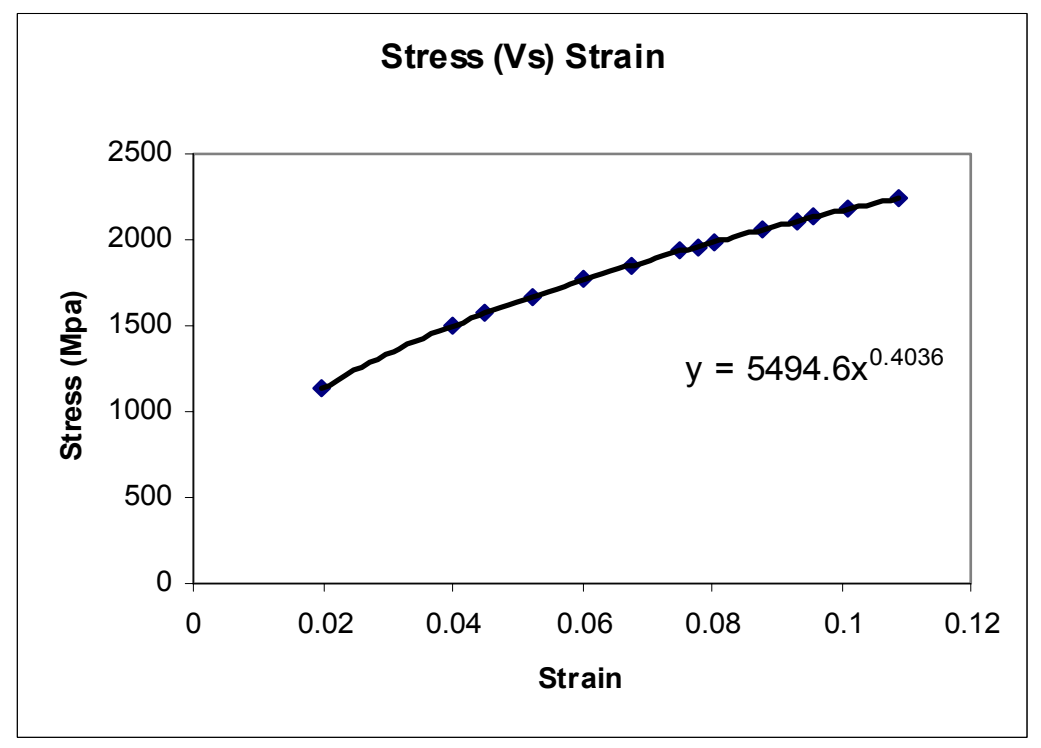

Figure 5.24 Stress Versus strain for steel, E=200 GPa

$$
\mathrm{S}_{y}=500 \mathrm{MPa}, \mathrm{n}=0.4
$$


Numerical results with the theoretical values are tabulated below.

\begin{tabular}{|c|c|c|c|c|}
\hline Input $\mathrm{n}$ & $\begin{array}{c}\mathrm{n} \text { obtained from } \\
\text { Load Versus } \\
\text { Contact Radius } \\
\text { graph }\end{array}$ & $\begin{array}{c}\text { Input yield } \\
(\mathrm{MPa})\end{array}$ & $\begin{array}{c}\text { Yield stress } \\
\text { from Graph } \\
(\mathrm{MPa})\end{array}$ & Error (\%) \\
\hline 0.1 & 0.1012 & 500 & 518.5 & $3.71 \%$ \\
\hline 0.2 & 0.2059 & 500 & 514.3 & $2.87 \%$ \\
\hline 0.3 & 0.3072 & 500 & 477.5 & $4.49 \%$ \\
\hline 0.4 & 0.4036 & 500 & 430.04 & $14.01 \%$ \\
\hline
\end{tabular}

Table 5.4 Comparison of the results obtained for steel

$$
\mathrm{E}=200 \mathrm{GPa}, \mathrm{S}_{y}=500 \mathrm{MPa}
$$

From the above Table 5.4, the strain hardening coefficient values obtained from the finite element simulations are in good agreement with the input values. Yield stress is also in good agreement, with error being 2 to $5 \%$ for material with $n$ values less than 0.3 . High error percentage is observed for material with $n=0.4$. 


$$
\mathbf{E}=200 \mathrm{GPa}, \mathbf{S}_{y}=750 \mathrm{MPa}
$$

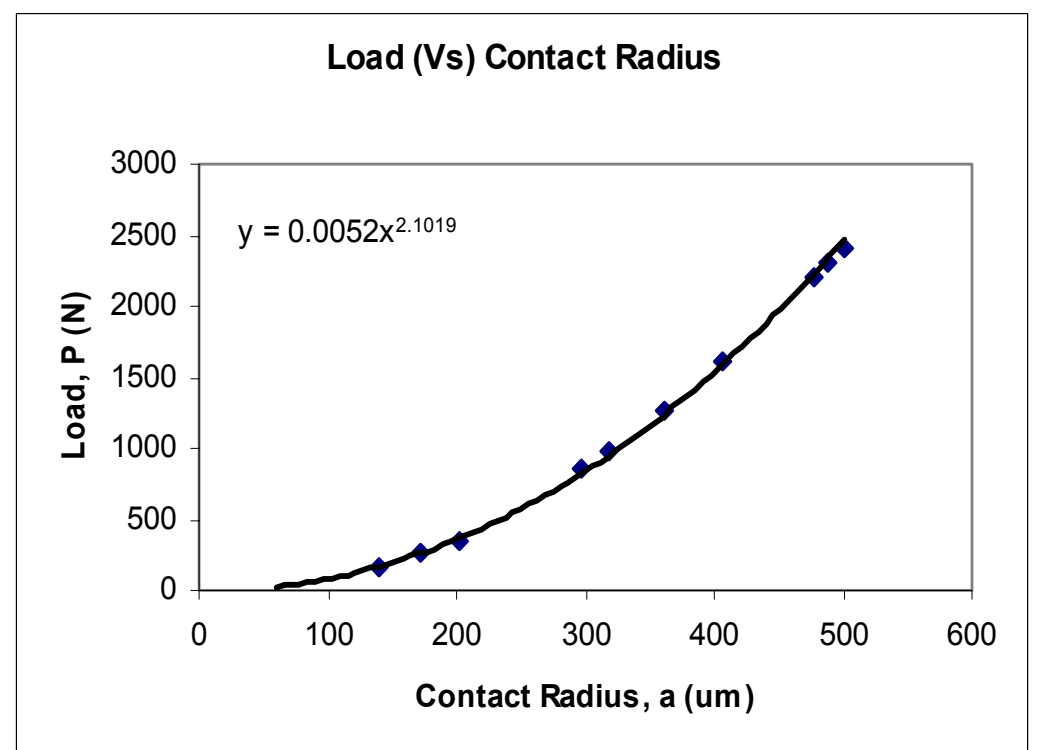

Figure 5.25 Load Versus contact radius for steel, E=200 GPa

$$
\mathrm{S}_{y}=750 \mathrm{MPa}, \mathrm{n}=0.1
$$

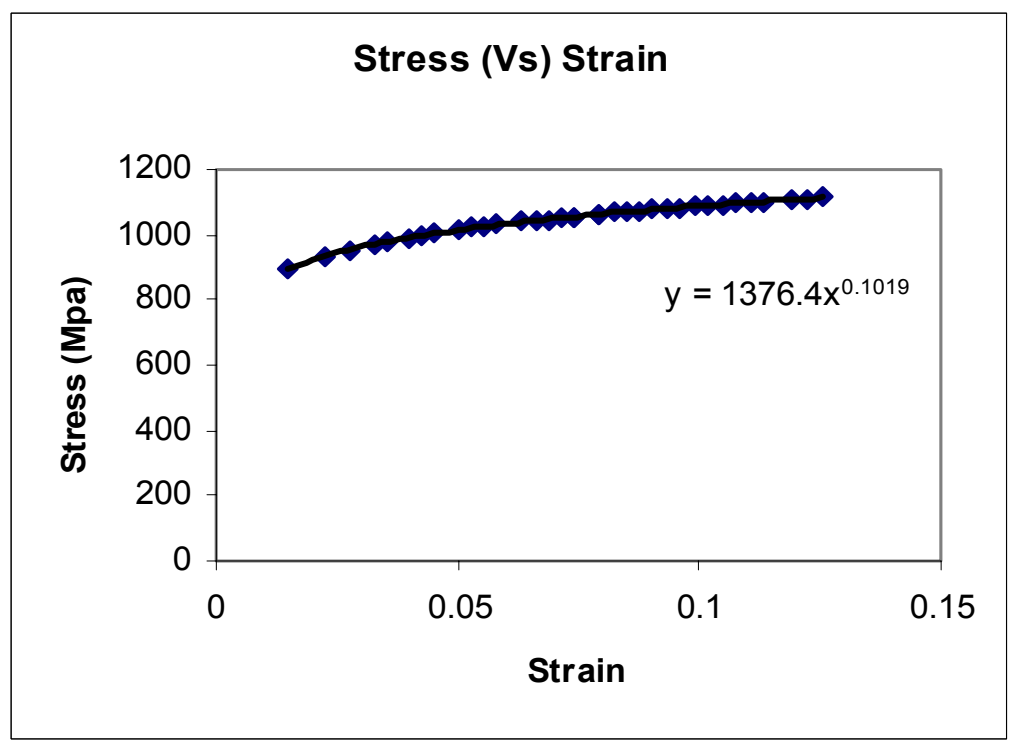

Figure 5.26 Stress Versus strain for steel, E=200 GPa

$$
\mathrm{S}_{y}=750 \mathrm{MPa}, \mathrm{n}=0.1
$$




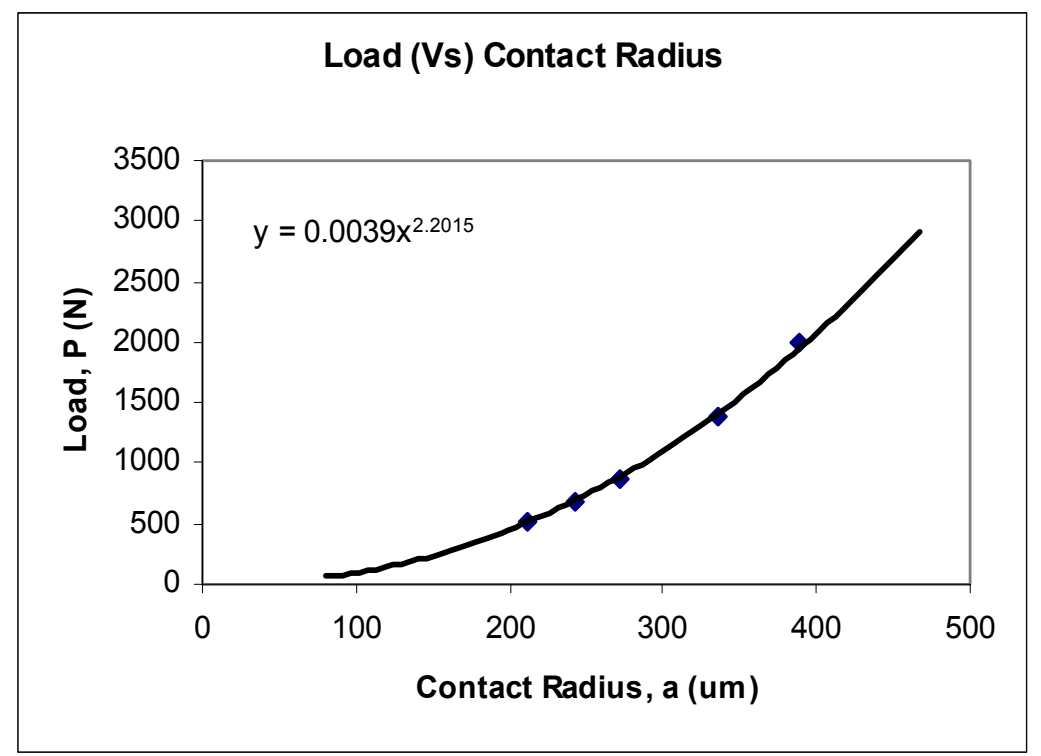

Figure 5.27 Load Versus contact radius for steel, E=200 GPa

$$
\mathrm{S}_{y}=750 \mathrm{MPa}, \mathrm{n}=0.2
$$

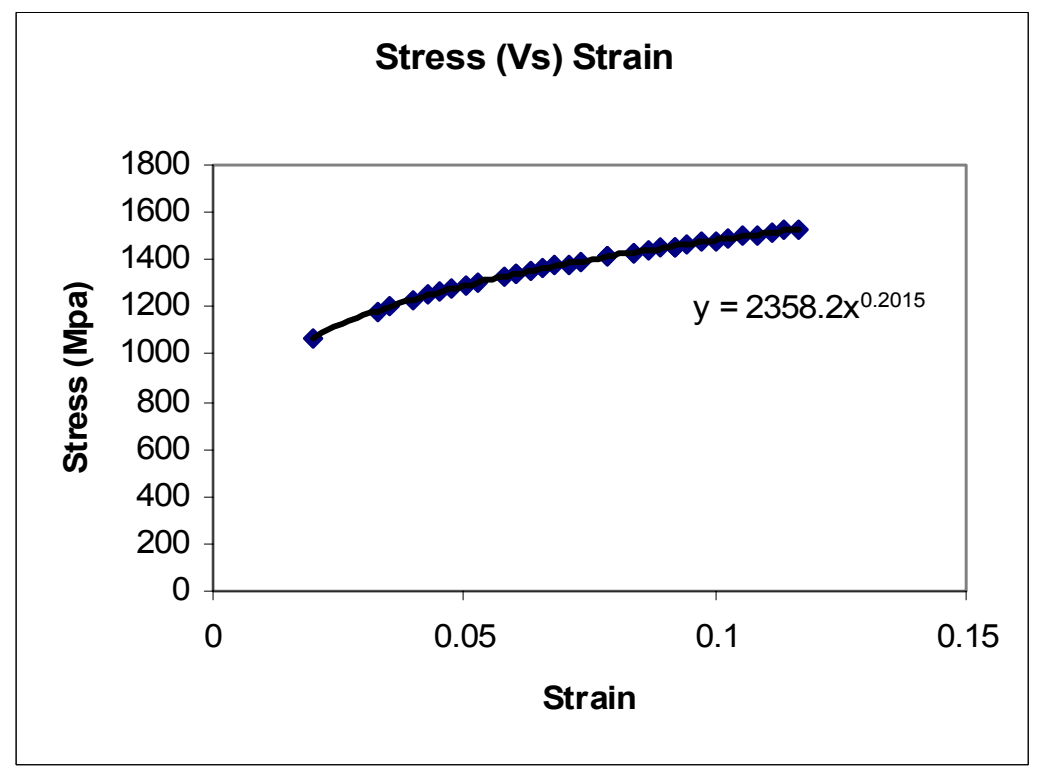

Figure 5.28 Stress Versus strain for steel, E=200 GPa

$$
\mathrm{S}_{y}=750 \mathrm{MPa}, \mathrm{n}=0.2
$$




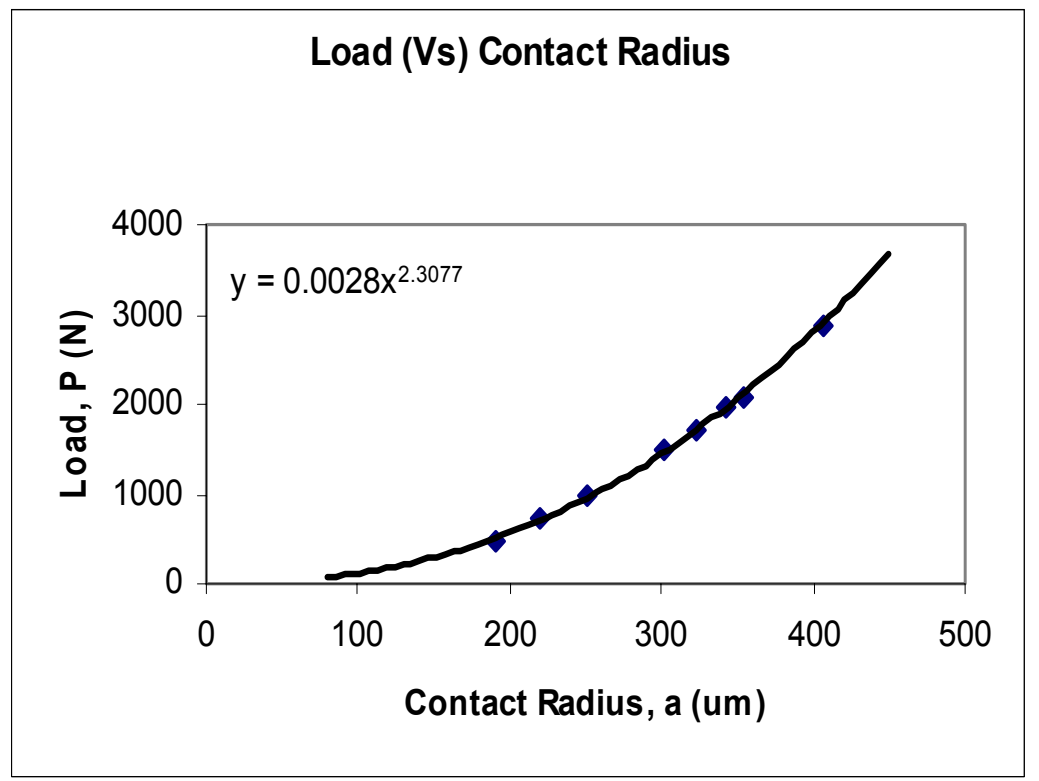

Figure 5.29 Load Versus contact radius for steel, E=200 GPa

$$
\mathrm{S}_{y}=750 \mathrm{MPa}, \mathrm{n}=0.3
$$

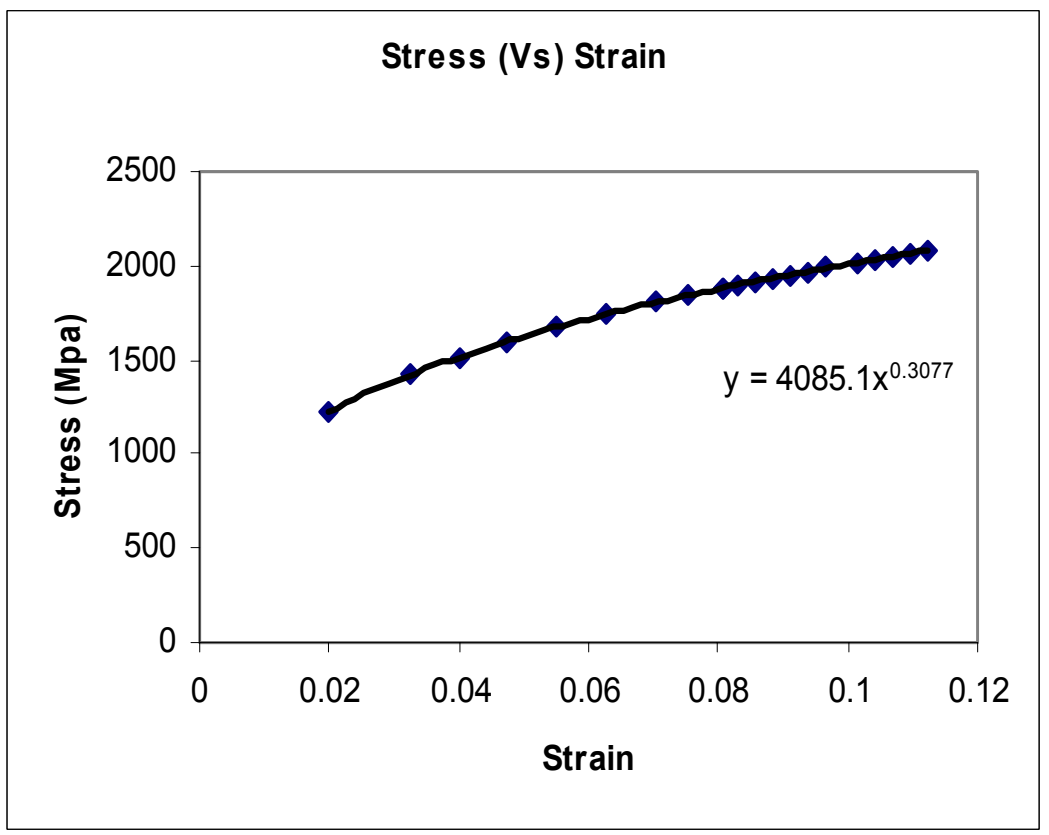

Figure 5.30 Stress Versus strain for steel, E=200 GPa

$$
\mathrm{S}_{y}=750 \mathrm{MPa}, \mathrm{n}=0.3
$$




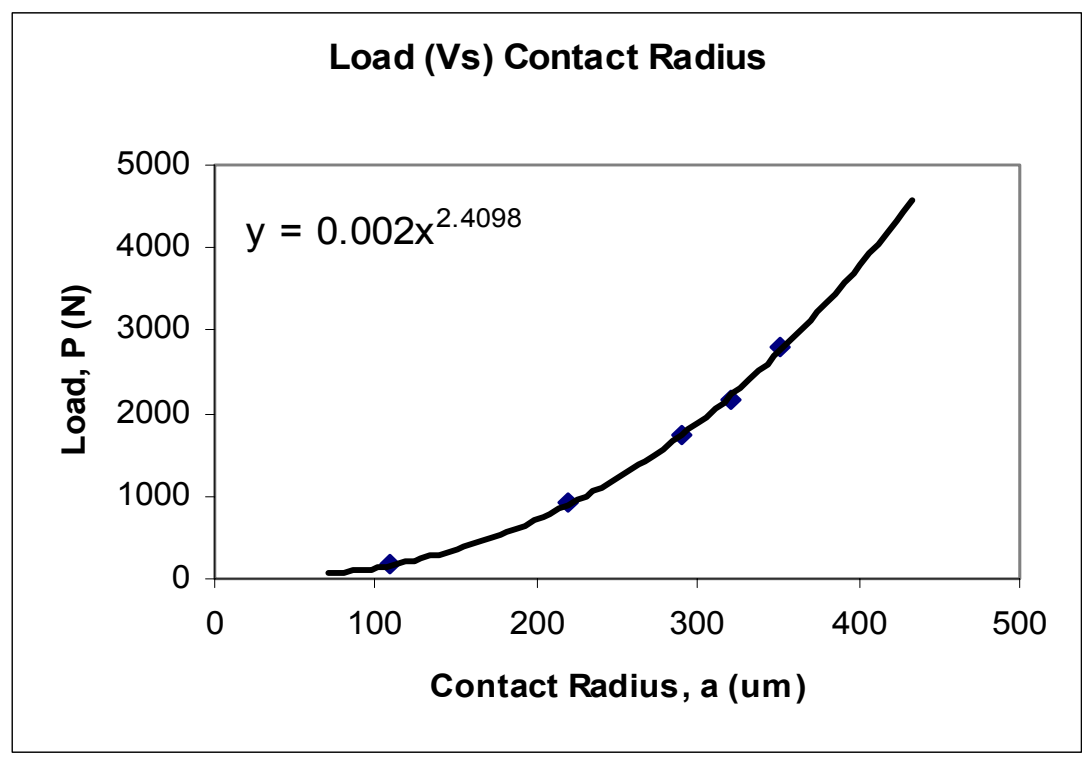

Figure 5.31 Load Versus contact radius for steel, E=200 GPa

$$
\mathrm{S}_{y}=750 \mathrm{MPa}, \mathrm{n}=0.4
$$

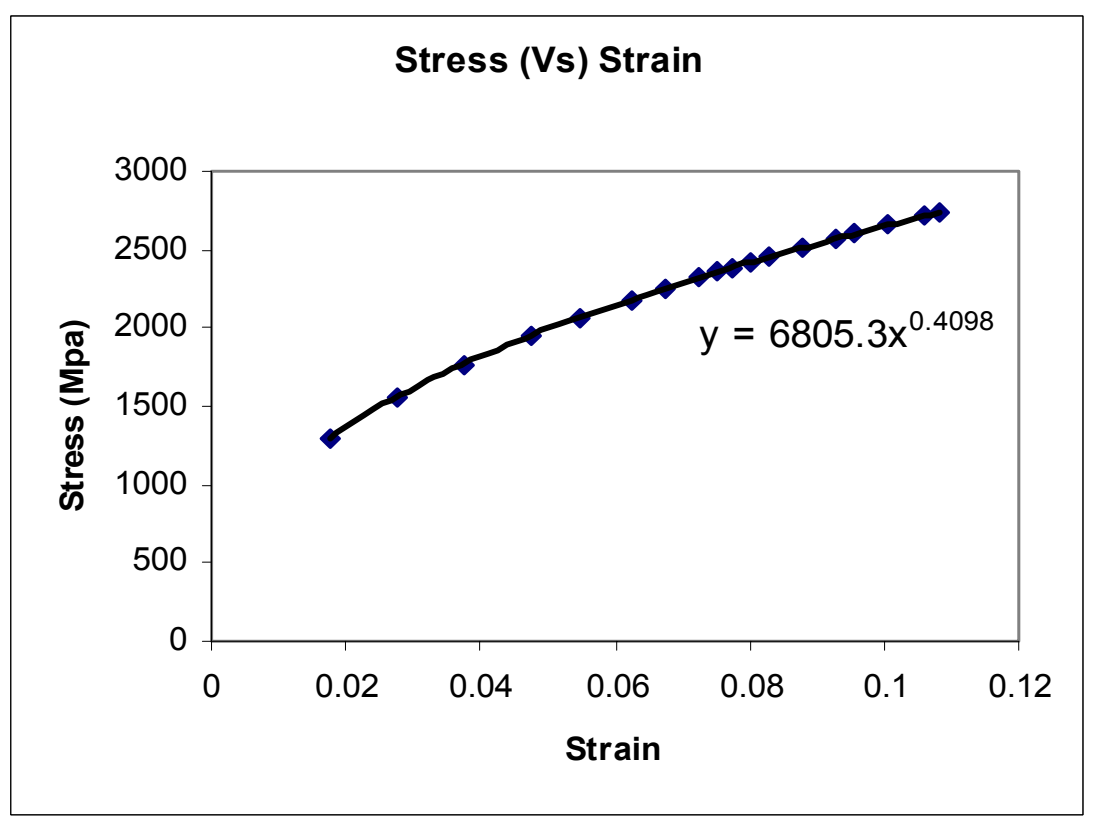

Figure 5.32 Stress Versus strain for steel, E=200 GPa

$$
\mathrm{S}_{y}=750 \mathrm{MPa}, \mathrm{n}=0.4
$$


Numerical results with the theoretical values are tabulated below:

\begin{tabular}{|c|c|c|c|c|}
\hline Input $\mathrm{n}$ & $\begin{array}{c}\mathrm{n} \text { obtained from } \\
\text { Load Versus } \\
\text { Contact Radius } \\
\text { graph }\end{array}$ & $\begin{array}{c}\text { Input yield } \\
(\mathrm{MPa})\end{array}$ & $\begin{array}{c}\text { Yield stress } \\
\text { from Graph } \\
(\mathrm{MPa})\end{array}$ & Error (\%) \\
\hline 0.1 & 0.1019 & 750 & 782.36 & $4.31 \%$ \\
\hline 0.2 & 0.2015 & 750 & 769.02 & $2.53 \%$ \\
\hline 0.3 & 0.3077 & 750 & 724.67 & $3.37 \%$ \\
\hline 0.4 & 0.4098 & 750 & 650.77 & $15.24 \%$ \\
\hline
\end{tabular}

Table 5.5 CoMparison of the results obtained for Steel

$$
\mathrm{E}=200 \mathrm{GPa}, \mathrm{S}_{y}=750 \mathrm{MPa}
$$

Values of the strain hardening coefficient, $n$, obtained from the finite element simulations are in good agreement with the input values. Yield stresses are also in good agreement with errors ranging form 2 to $4 \%$ for strain hardening exponent less than 0.3 . However, the error is around $14 \%$ for material with strain hardening coefficient 0.4 . 
Steel, E=200 GPa, $\mathbf{S}_{y}=1000 \mathrm{MPa}$

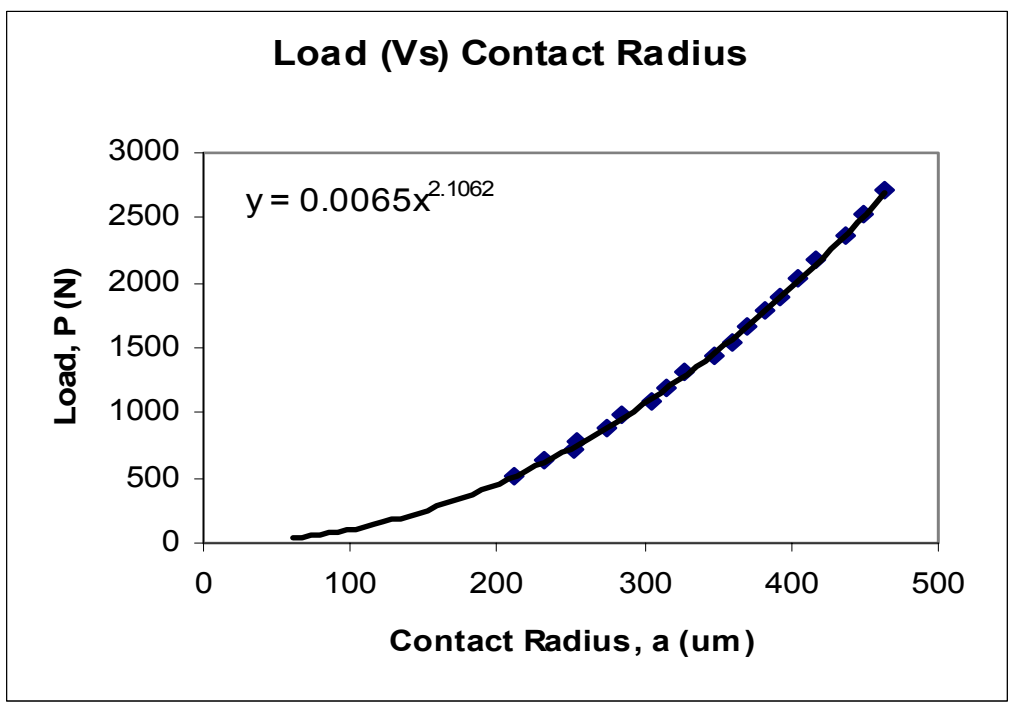

Figure 5.33 Load Versus contact radius for steel E=200 GPa

$$
\mathrm{S}_{y}=1000 \mathrm{MPa}, \mathrm{n}=0.1
$$

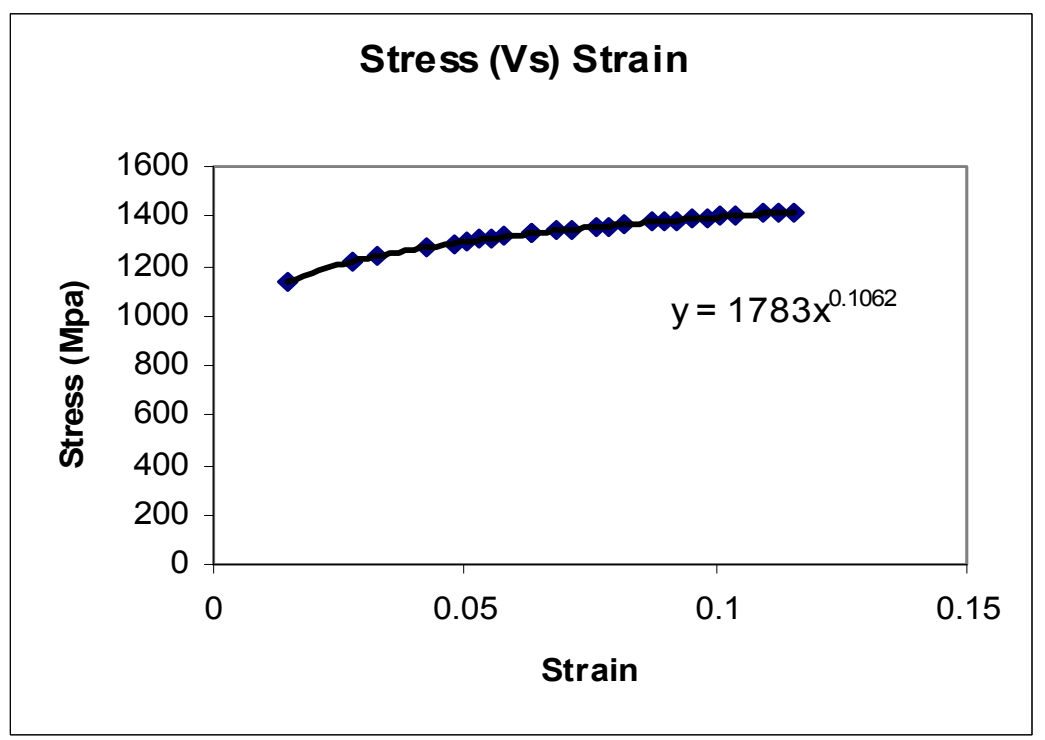

Figure 5.34 Stress Versus strain for steel, E=200 GPa

$$
\mathrm{S}_{y}=1000 \mathrm{MPa}, \mathrm{n}=0.1
$$




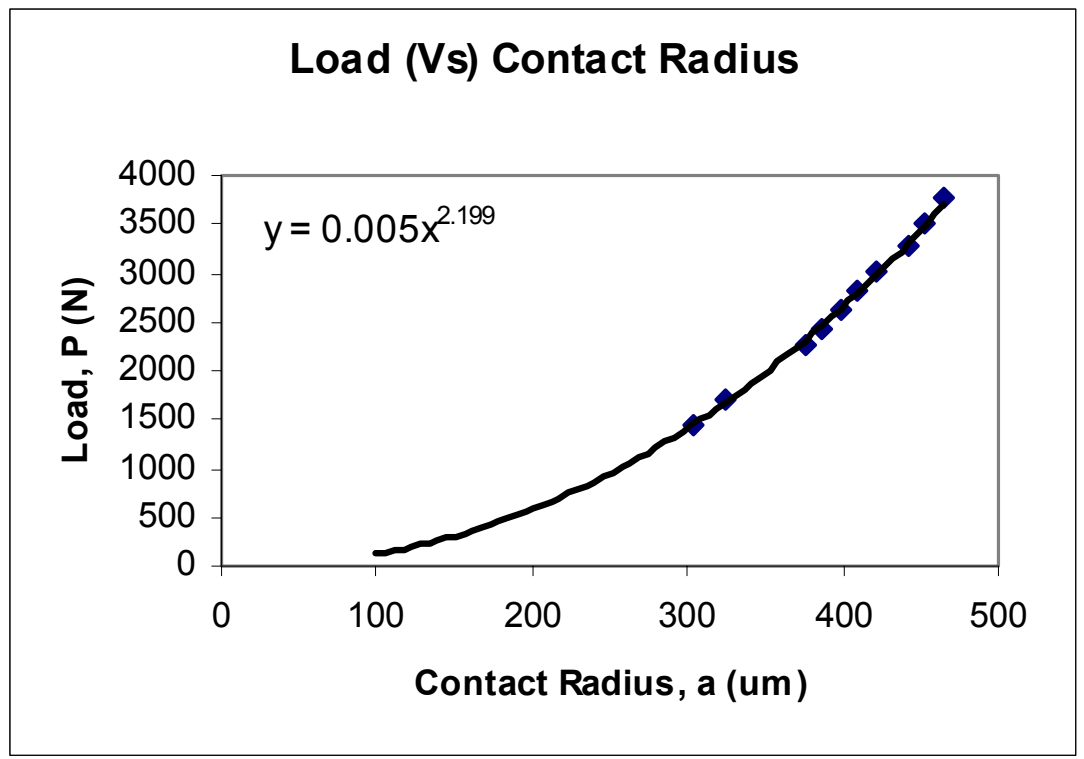

Figure 5.35 Load Versus contact radius for steel, E=200 GPa

$$
\mathrm{S}_{y}=1000 \mathrm{MPa}, \mathrm{n}=0.2
$$

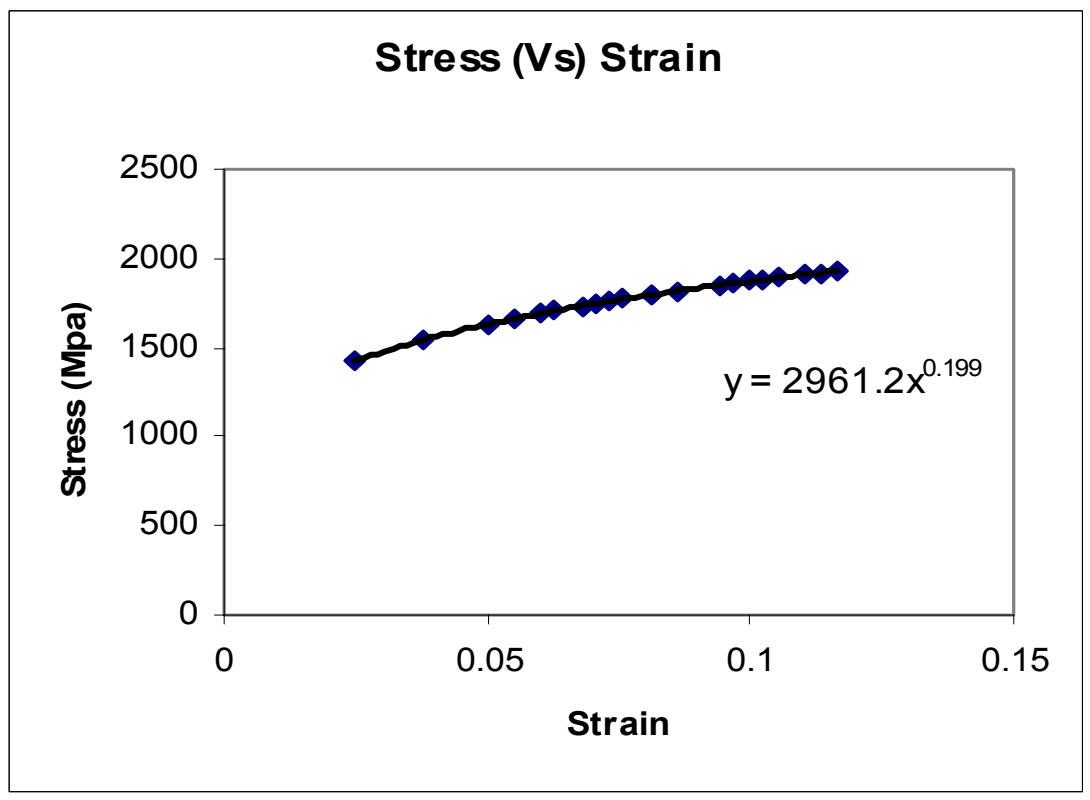

Figure 5.36 Stress Versus strain for steel, E=200 GPa

$$
\mathrm{S}_{y}=1000 \mathrm{MPa}, \mathrm{n}=0.2
$$




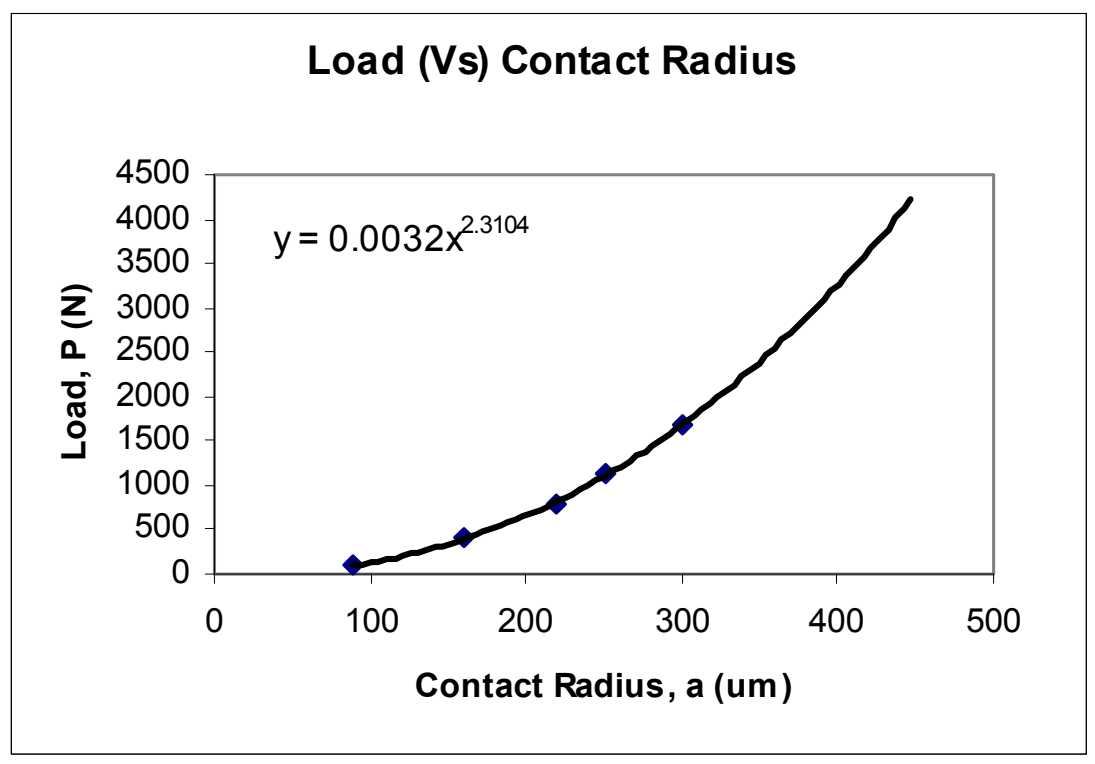

Figure 5.37 Load Versus contact radius for steel, E=200 GPa

$$
\mathrm{S}_{y}=1000 \mathrm{MPa}, \mathrm{n}=0.3
$$

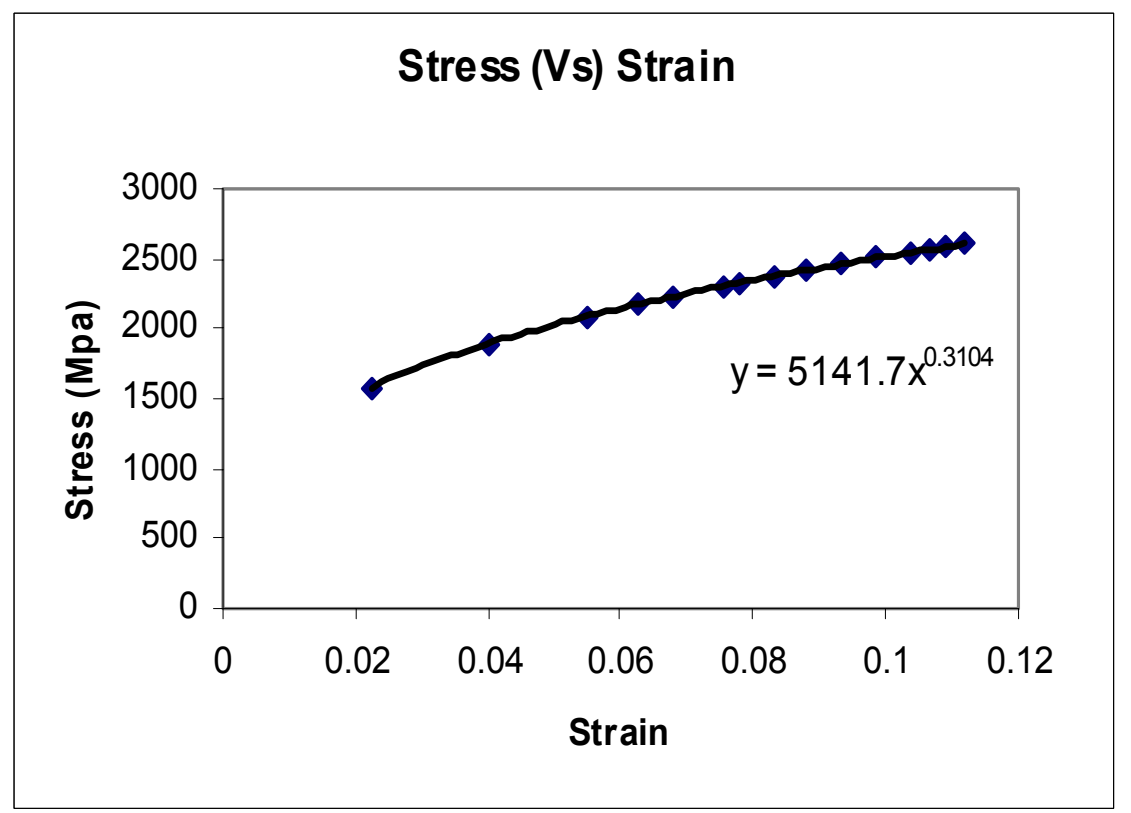

Figure 5.38 Stress Versus strain for steel, E=200 GPa

$$
\mathrm{S}_{y}=1000 \mathrm{MPa}, \mathrm{n}=0.3
$$




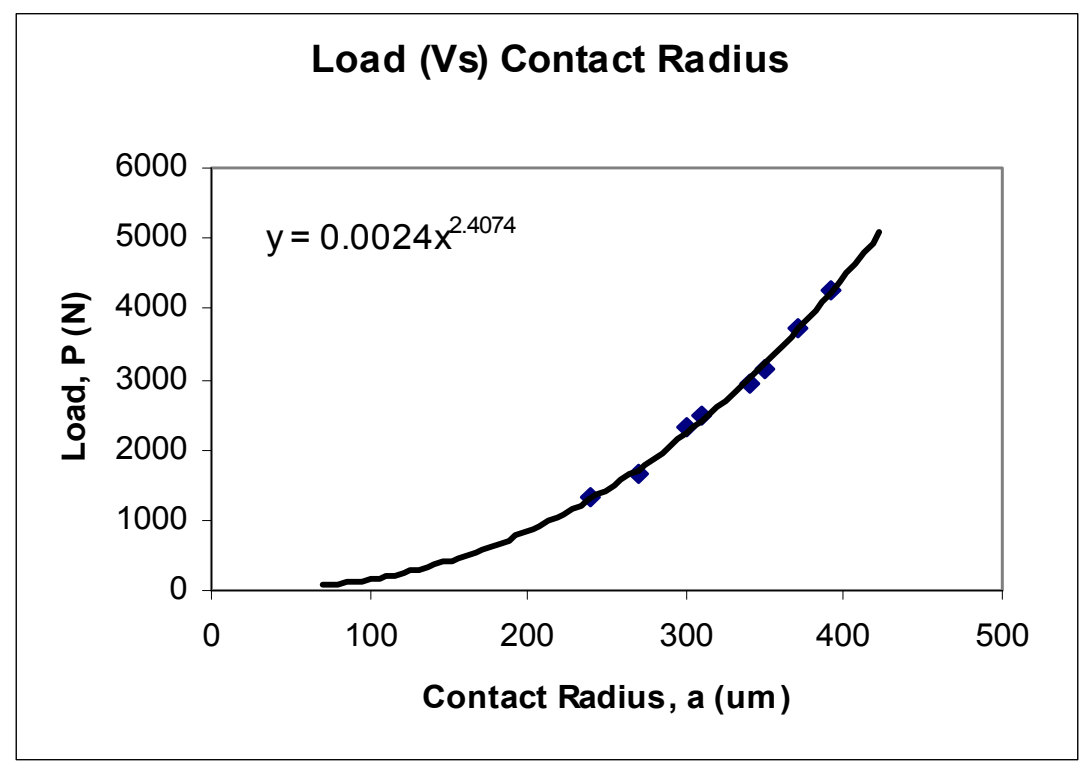

Figure 5.39 Load Versus contact radius for steel, E=200 GPa

$$
\mathrm{S}_{y}=1000 \mathrm{MPa}, \mathrm{n}=0.4
$$

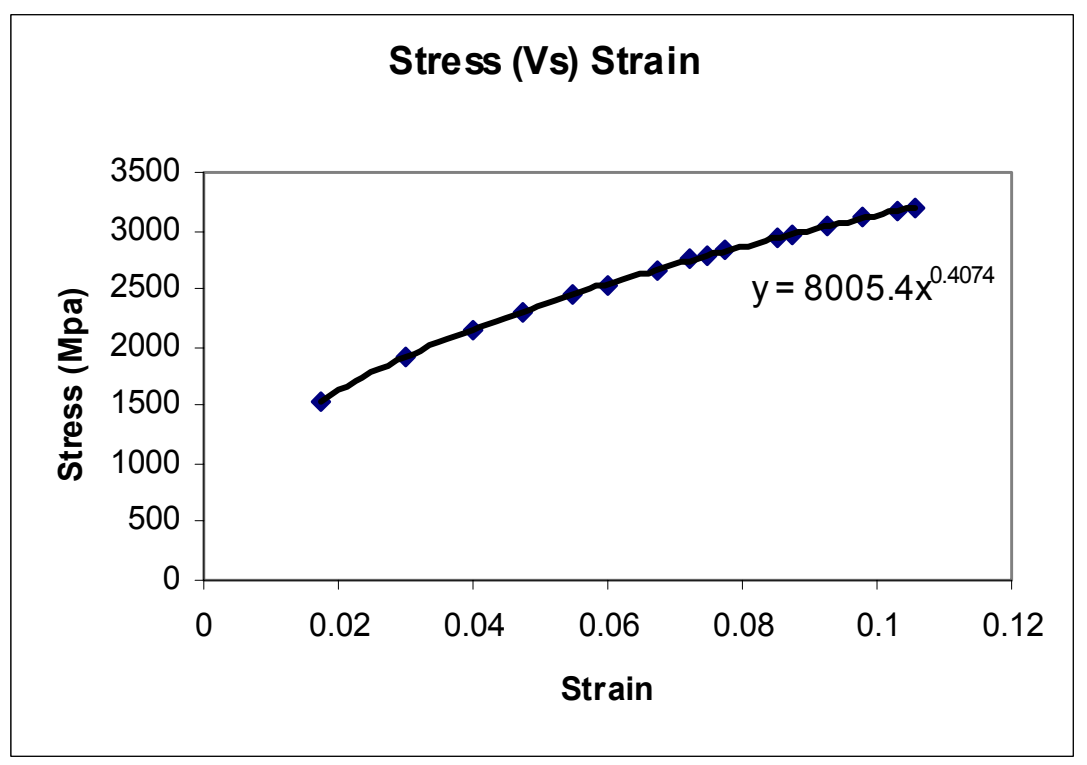

Figure 5.40 Stress Versus strain for steel, E=200 GPa

$$
\mathrm{S}_{y}=1000 \mathrm{MPa}, \mathrm{n}=0.4
$$


Numerical results with the theoretical values are tabulated below.

\begin{tabular}{|c|c|c|c|c|}
\hline Input $\mathrm{n}$ & $\begin{array}{c}\mathrm{n} \text { obtained from } \\
\text { Load Versus } \\
\text { Contact Radius } \\
\text { graph }\end{array}$ & $\begin{array}{c}\text { Input yield } \\
(\mathrm{MPa})\end{array}$ & $\begin{array}{c}\text { Yield stress } \\
\text { from Graph } \\
(\mathrm{MPa})\end{array}$ & Error (\%) \\
\hline 0.1 & 0.1008 & 1000 & 1017.62 & $1.76 \%$ \\
\hline 0.2 & 0.204 & 1000 & 1039.75 & $3.97 \%$ \\
\hline 0.3 & 0.3028 & 1000 & 989.59 & $1.04 \%$ \\
\hline 0.4 & 0.4074 & 1000 & 876.05 & $12.39 \%$ \\
\hline
\end{tabular}

Table 5.6 Comparison of the results obtained for steel

$$
\mathrm{E}=200 \mathrm{GPa}, \mathrm{S}_{y}=1000 \mathrm{MPa}
$$

It is observed that the values of the strain hardening coefficient, obtained from the finite element simulations are in good agreement with the input values. Yield stresses are also in good agreement, with errors ranging from 1 to $4 \%$ for $n$ less than 0.3 . Error is around $13 \%$ for material with $\mathrm{n}$ 0.4. Error in the yield stress calculation can be attributed to the Tabor's constant. This issue will be discussed in detail in the later part of this chapter. 


\subsection{Variation in error percentage with increase of strain hardening coefficient}

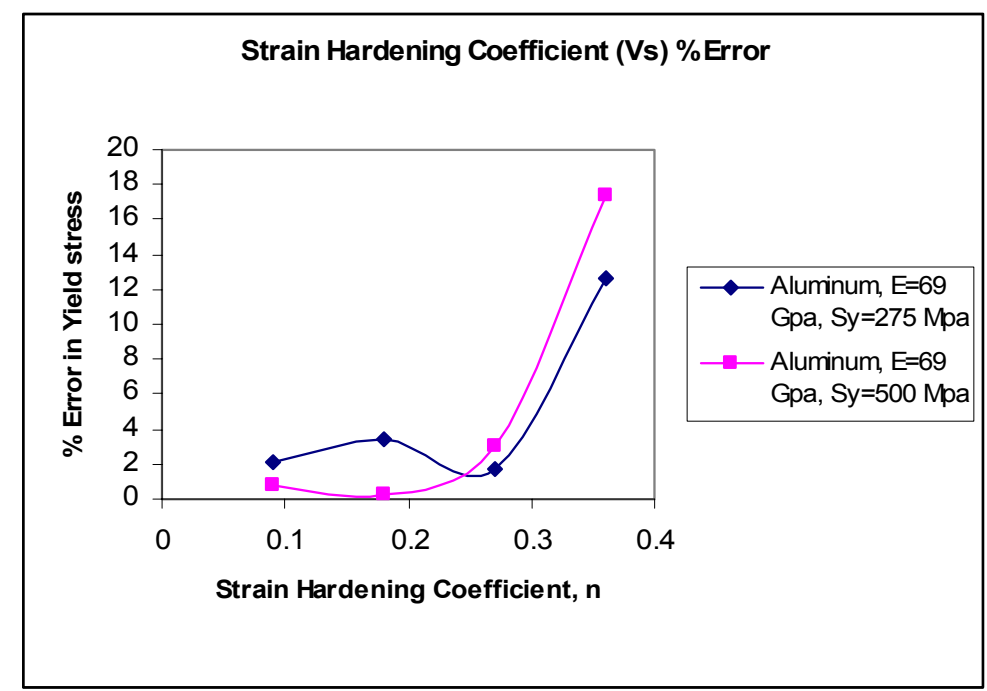

Figure 5.41 Percentage error variations with strain hardening coefficient in aluminum alloys

From the above Figure 5.41, it is clear that percentage error in the calculation of yield stress is high for material with n over 0.3. It is observed that the percentage error increases with the increase of material strain hardening coefficient.

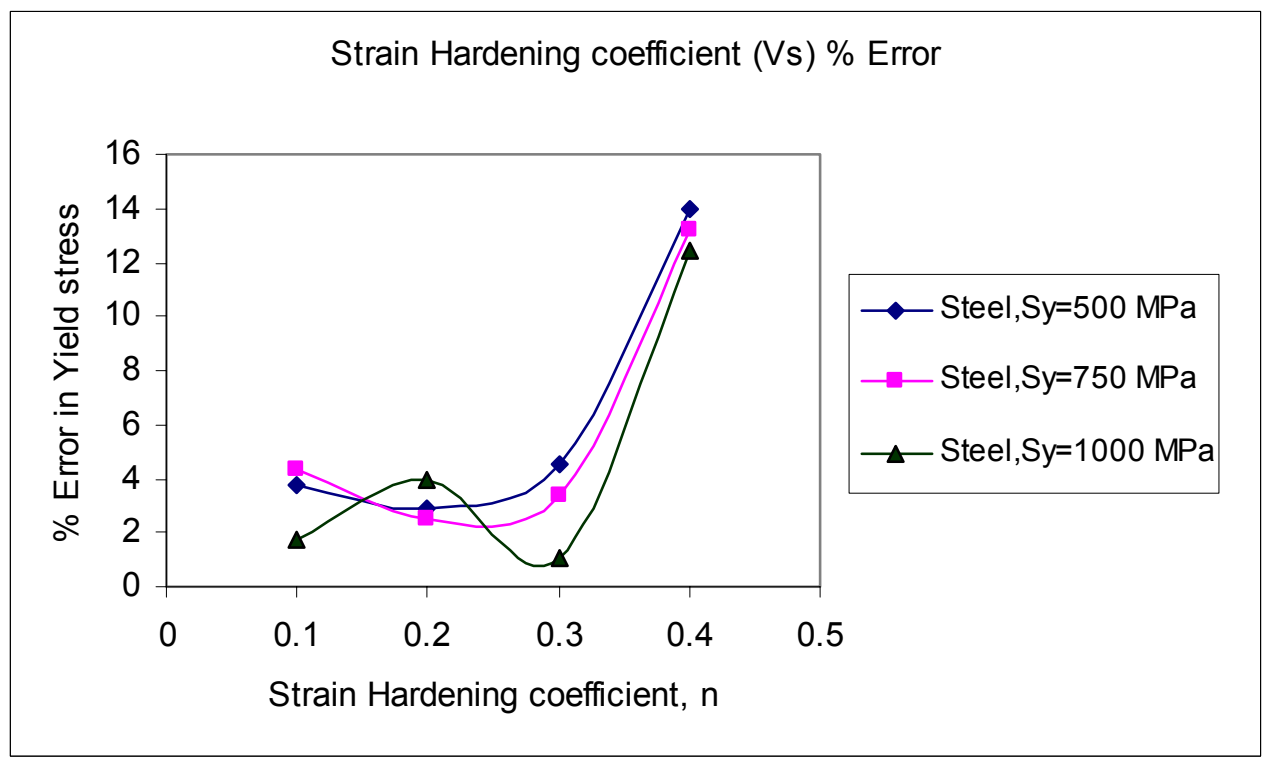

Figure 5.42 Percentage error variations with strain hardening coefficient of steel alloys 
From the above discussions, we can see that in spite of good agreement in determining the strain hardening coefficient, there is error in the calculation of the yield stress of the material for $\mathrm{n}$ values larger than 0.3 .

\subsection{Results from Modified Tabor's Constant}

It is necessary to study the effect of Tabor's Constant on the behavior of stress strain curve. It is noticed that by varying the Tabor's constant, nature of the stress strain curve remains same but the curve shifts either up or down depending on the constants value.

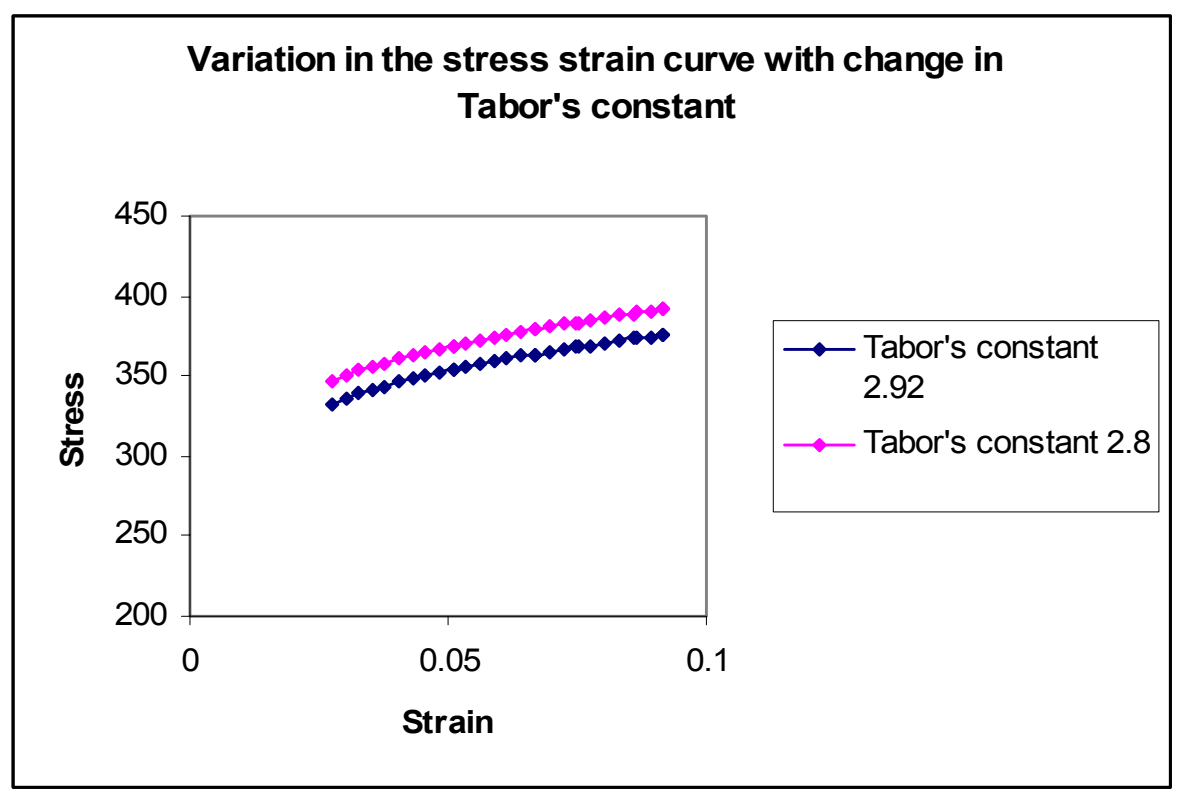

Figure 5.43 Effect of Tabor's constant on stress strain curve

From the above Figure 5.43, we notice that the curve shifts down when the constant has been changed from 2.8 to 2.92 . This behavior has to be observed carefully as this effects the calculation of the yield stress. As the yield stress is calculated by the intersection of post yielding stress-strain curve with the linear part of the stress strain 
curve, the location of the former is important for the correct calculation of the yield stress.

It can be concluded that error in the calculation of yield stress is an effect of the Tabor's constant. One can minimize the error by varying the Tabor's constant for a given materials with different strain hardening. This understanding has been employed to see how the Tabor's constant varies with the increase of strain hardening exponent. In this process, we will try to either increase or decrease the value of the Tabor's constant so that the yield stress value obtained from the stress strain curve is close to the input values. Then we will study how the value of Tabor's constant changes with the change in strain hardening coefficient. The above discussed method has been employed to all the 20 material models being analyzed in this research.

Curve blue in color corresponds to the Tabor's constant 2.8 and the curve pink in color corresponds to the modified value of Tabor's constant which is different for different materials and depends on the value of strain hardening exponent. The following results were obtained. 


\section{Aluminum, E $=69 \mathrm{GPa}, \mathrm{S}_{y}=275 \mathrm{MPa}$}

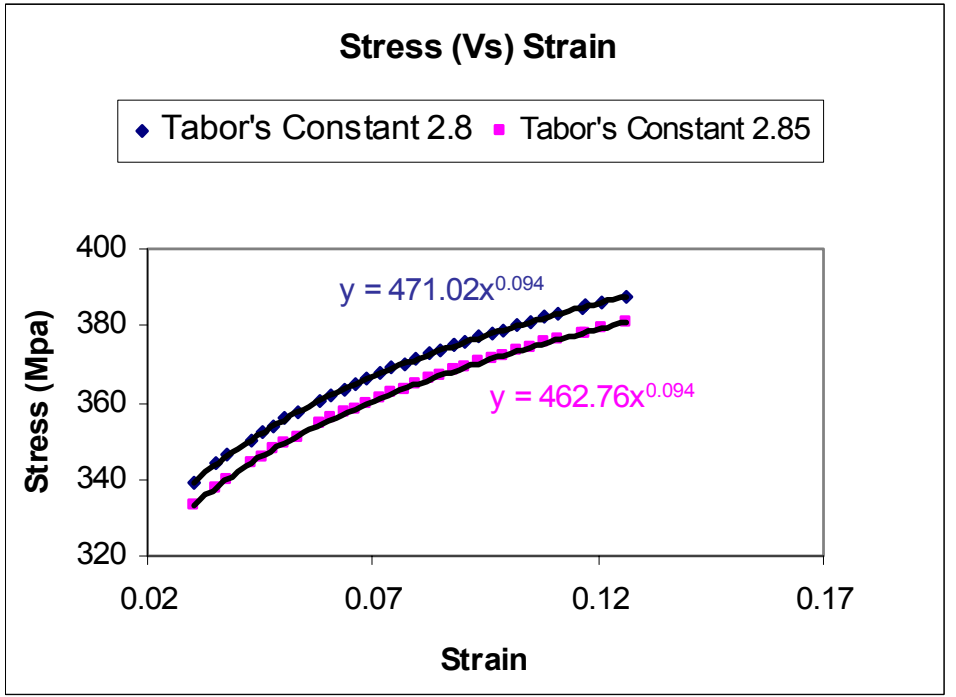

Figure 5.44 Comparison of stress Versus strain curves for aluminum, $\mathrm{E}=69 \mathrm{GPa}$,

$$
\mathrm{S}_{y}=275 \mathrm{MPa}, \mathrm{n}=0.09
$$

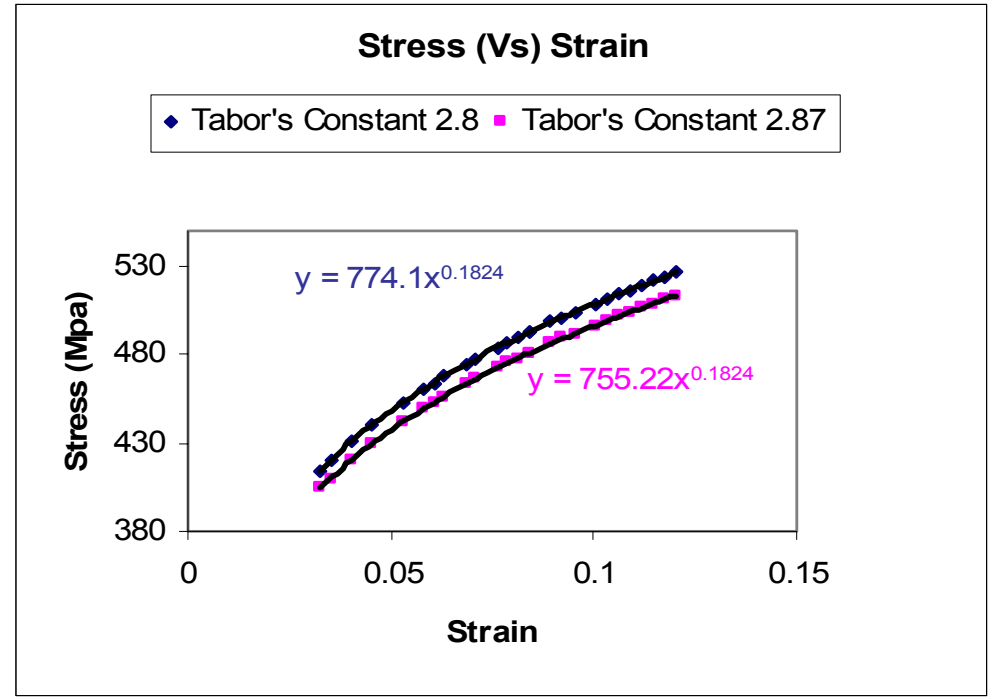

Figure 5.45 Comparison of stress Versus strain curves for aluminum, $\mathrm{E}=69 \mathrm{GPa}$,

$$
\mathrm{S}_{y}=275 \mathrm{MPa}, \mathrm{n}=0.18
$$

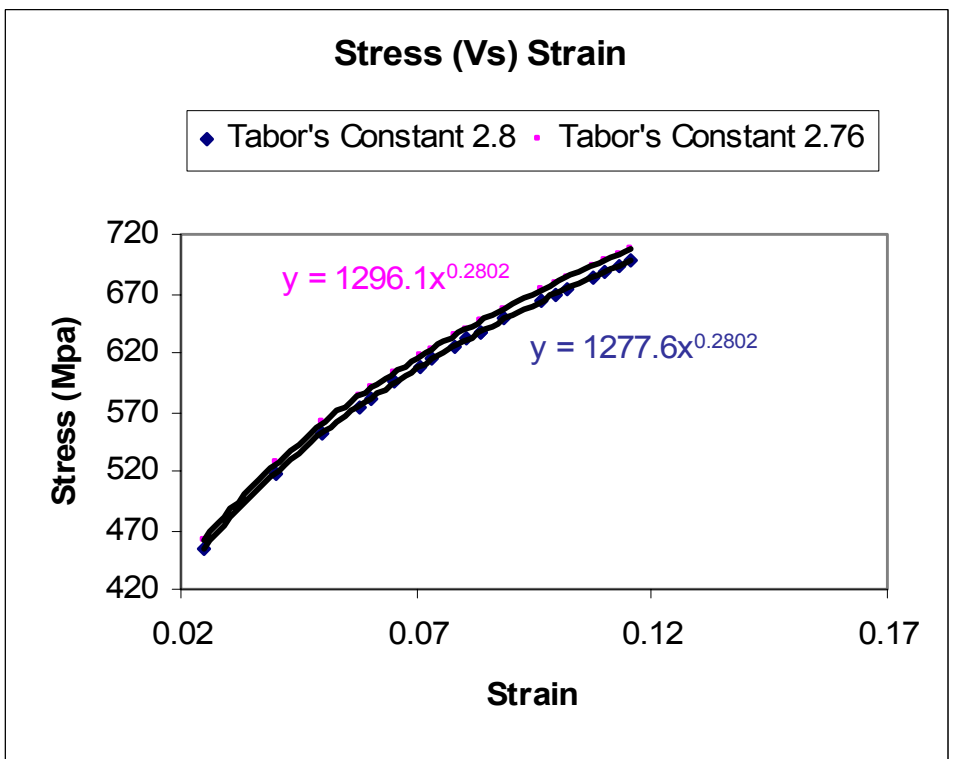

Figure 5.46 Comparison of stress Versus strain curves for aluminum, $\mathrm{E}=69 \mathrm{GPa}$,

$$
\mathrm{S}_{y}=275 \mathrm{MPa}, \mathrm{n}=0.27
$$

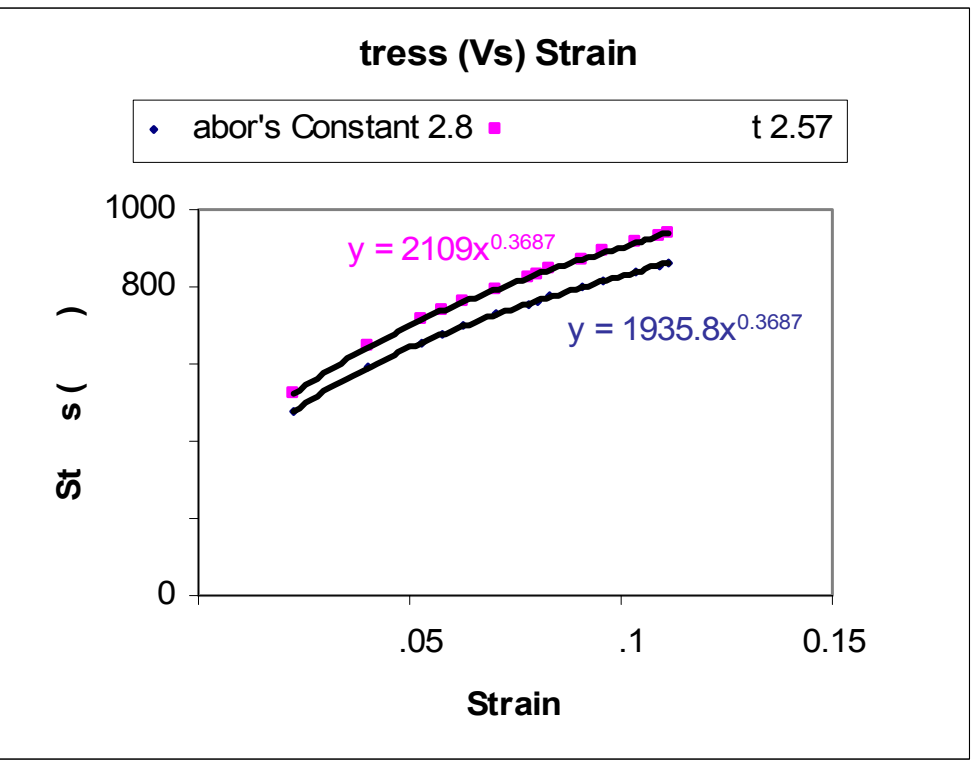

Figure 5.47 Comparison of stress Versus strain curves for aluminum, $\mathrm{E}=69 \mathrm{GPa}$, $\mathrm{S}_{y}=275 \mathrm{MPa}, \mathrm{n}=0.36$ 
5.4.1 Comparison of the yield stress values obtained from Tabor's Constant 2.8 and modified Tabor's Constant for Aluminum E=69 GPa, $S_{y}=275$ MPa.

\begin{tabular}{|c|c|c|c|c|c|c|c|}
\hline $\begin{array}{c}\text { Input } \\
\mathrm{n}\end{array}$ & $\begin{array}{c}\text { Input } \\
\mathrm{S}_{y}(\mathrm{MPa})\end{array}$ & $\begin{array}{c}\text { Tabor's } \\
\text { constant }\end{array}$ & $\begin{array}{c}\mathrm{S}_{y}(\mathrm{MPa}) \\
\text { obtained }\end{array}$ & $\begin{array}{c}\text { Error } \\
(\%)\end{array}$ & $\begin{array}{c}\text { Modified } \\
\text { Tabor's } \\
\text { constant }\end{array}$ & $\begin{array}{c}\mathrm{S}_{y} \text { from } \\
\text { modified } \\
\text { constant }\end{array}$ & $\begin{array}{c}\text { Error } \\
(\%)\end{array}$ \\
\hline \multicolumn{7}{|l|}{} \\
\hline 0.09 & 275 & 2.8 & 280.7 & $2.09 \%$ & 2.85 & 275.3 & $0.11 \%$ \\
\hline 0.18 & 275 & 2.8 & 284.2 & $3.37 \%$ & 2.87 & 275.82 & $0.30 \%$ \\
\hline 0.27 & 275 & 2.8 & 270.3 & $1.67 \%$ & 2.76 & 275.84 & $0.30 \%$ \\
\hline 0.36 & 275 & 2.8 & 240.13 & $12.67 \%$ & 2.57 & 275.04 & $0.05 \%$ \\
\hline
\end{tabular}

Table 5.7 Comparison of the results obtained before and after the change in Tabor's constant for aluminum, $\mathrm{E}=69 \mathrm{GPa}, \mathrm{S}_{y}=275 \mathrm{MPa}$

From the above table we can see that the percentage error in the calculation of yield stress with modified Tabor's constant is low, i.e. less than 1\%. Figure 5.48 below shows the variation of the modified Tabor's constant with the strain hardening exponent. We can see that the constant value decreases as the $\mathrm{n}$ increases.

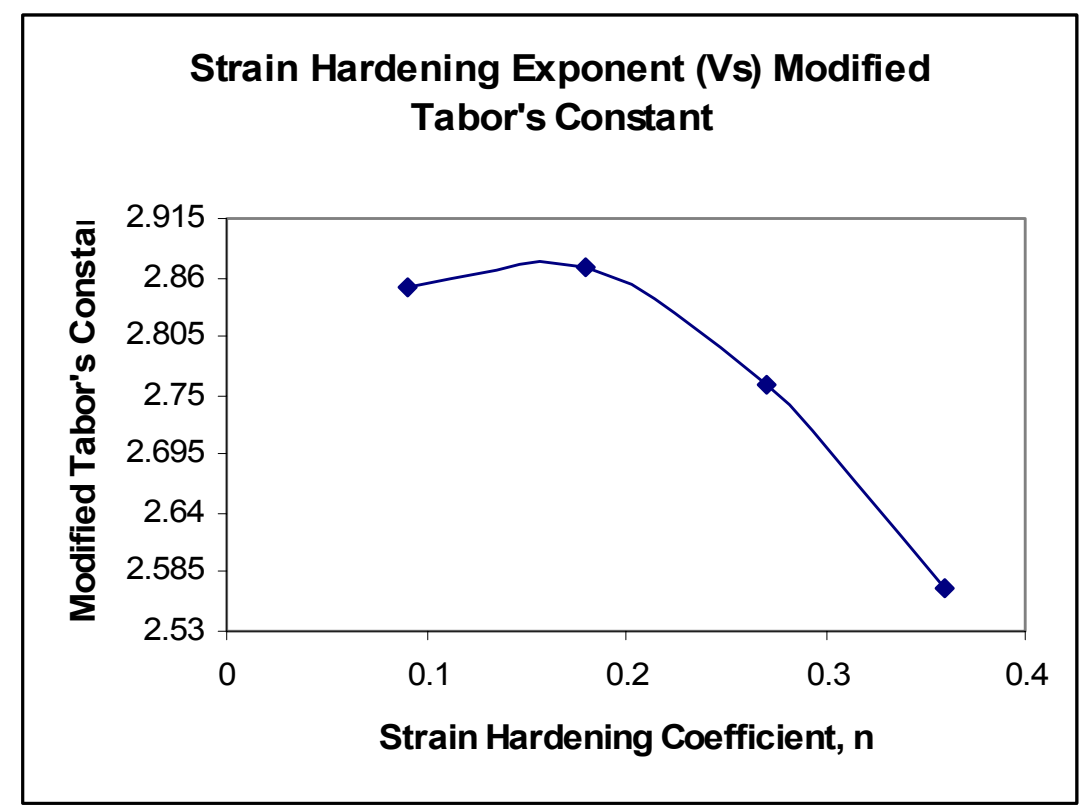

Figure 5.48 Strain hardening exponent Versus modified constant for aluminum, $\mathrm{E}=69 \mathrm{GPa}, \mathrm{S}_{y}=275 \mathrm{MPa}$ 


\section{Aluminum, $\mathbf{E}=69$ GPa, $\mathbf{S}_{y}=500 \mathrm{MPa}$}

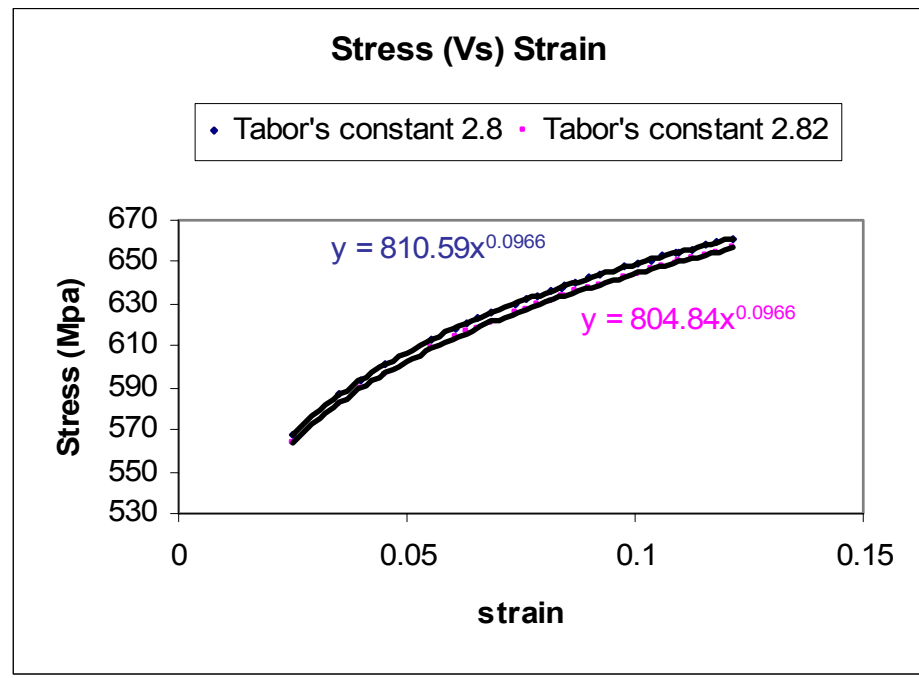

Figure 5.49 Comparison of stress Versus strain curves for aluminum, $\mathrm{E}=69 \mathrm{GPa}$,

$$
\mathrm{S}_{y}=500 \mathrm{MPa}, \mathrm{n}=0.09
$$

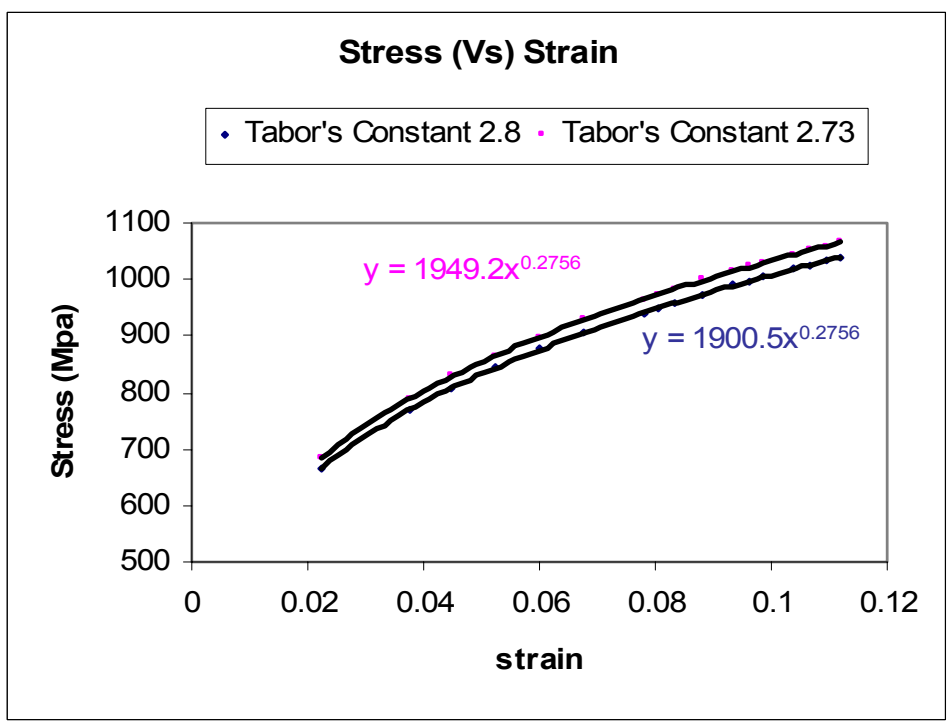

Figure 5.51 Comparison of stress Versus strain curves for aluminum, $\mathrm{E}=69 \mathrm{GPa}$,

$$
\mathrm{S}_{y}=500 \mathrm{MPa}, \mathrm{n}=0.27
$$

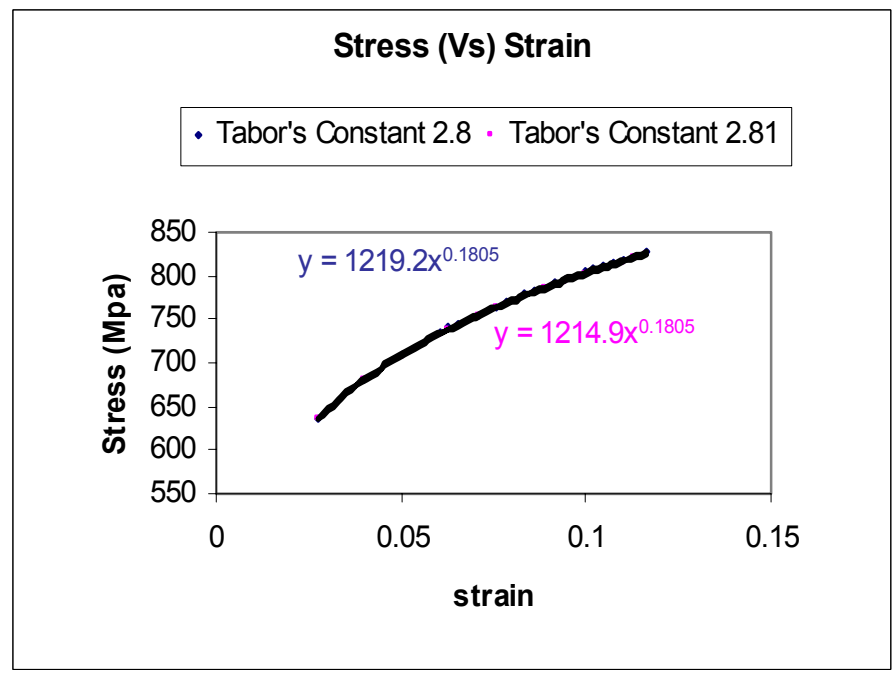

Figure 5.50 Comparison of stress Versus strain curves for aluminum, $\mathrm{E}=69 \mathrm{GPa}$,

$$
\mathrm{S}_{y}=500 \mathrm{MPa}, \mathrm{n}=0.18
$$

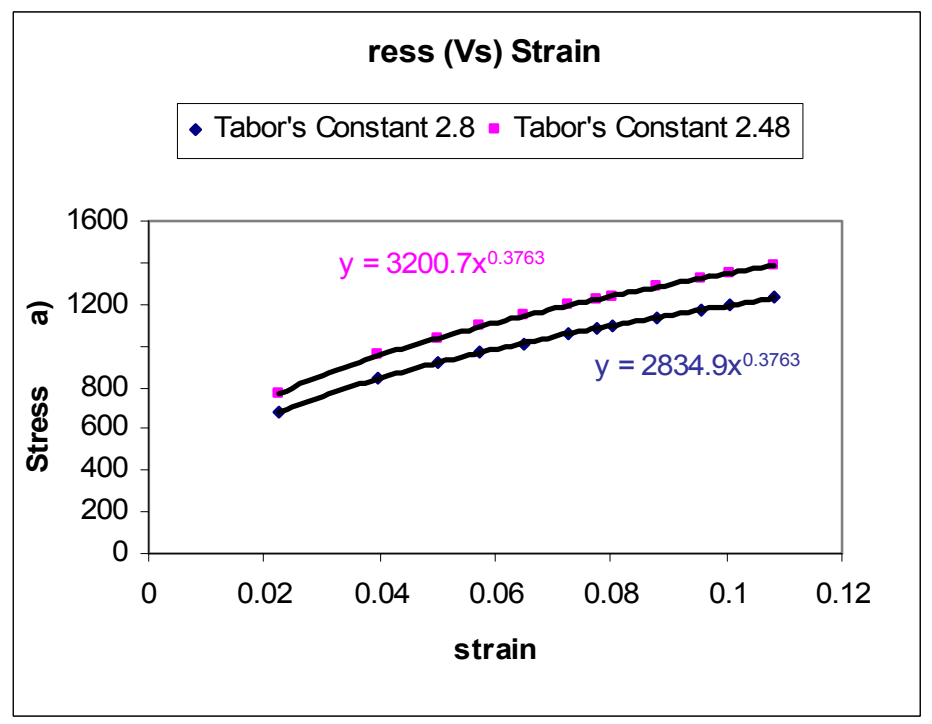

Figure 5.52 Comparison of stress Versus strain curves for aluminum, $\mathrm{E}=69 \mathrm{GPa}$,

$$
\mathrm{S}_{y}=500 \mathrm{MPa}, \mathrm{n}=0.36
$$




\subsubsection{Comparison of the yield stress values obtained from Tabor's Constant 2.8 and modified Tabor's Constant for Aluminum E=69 GPa, $\mathbf{S}_{y}=500 \mathrm{MPa}$}

\begin{tabular}{|c|c|c|c|c|c|c|c|}
\hline $\begin{array}{c}\text { Input } \\
\mathrm{n}\end{array}$ & $\begin{array}{c}\text { Input } \\
\mathrm{S}_{y}(\mathrm{MPa})\end{array}$ & $\begin{array}{c}\text { Tabor's } \\
\text { constant }\end{array}$ & $\begin{array}{c}\mathrm{S}_{y}(\mathrm{MPa}) \\
\text { obtained }\end{array}$ & $\begin{array}{c}\text { Error } \\
(\%)\end{array}$ & $\begin{array}{c}\text { Modified } \\
\text { Tabor's } \\
\text { constant }\end{array}$ & $\begin{array}{c}\mathrm{S}_{y} \text { from } \\
\text { modified } \\
\text { constant }\end{array}$ & $\begin{array}{c}\text { Error } \\
(\%)\end{array}$ \\
\hline 0.09 & 500 & 2.8 & 503.9 & $0.79 \%$ & 2.82 & 500.03 & $0.06 \%$ \\
\hline 0.18 & 500 & 2.8 & 501.2 & $0.24 \%$ & 2.81 & 499.04 & $0.19 \%$ \\
\hline 0.27 & 500 & 2.8 & 484.5 & $3.08 \%$ & 2.73 & 501.8 & $0.36 \%$ \\
\hline 0.36 & 500 & 2.8 & 413.1 & $17.36 \%$ & 2.48 & 501.92 & $0.38 \%$ \\
\hline
\end{tabular}

Table 5.8 Comparison of the results obtained before and after the change in Tabor's constant for aluminum, $\mathrm{E}=69 \mathrm{GPa}, \mathrm{S}_{y}=500 \mathrm{MPa}$

Table 5.8 above shows the percentage error in the calculation of yield stress with modified Tabor's constant is less than $0.5 \%$ when compared with $17 \%$ with Tabor's constant set to 2.8. Figure 5.53 below shows the variation of the modified Tabor's constant with the strain hardening exponent. We can see that the constant value decreases as the value of $\mathrm{n}$ increases. It decreases very rapidly for material with $\mathrm{n}$ over 0.3 .

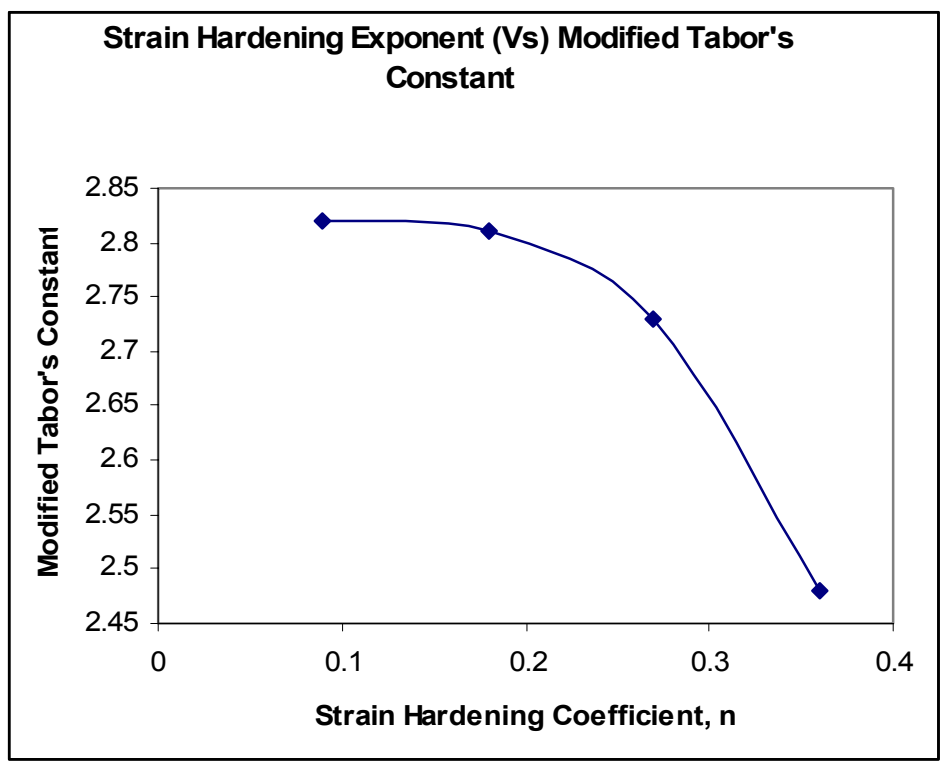

Figure 5.53 Strain hardening exponent Versus modified constant for aluminum, $\mathrm{E}=69 \mathrm{GPa}, \mathrm{S}_{y}=500 \mathrm{MPa}$ 
Steel, E=200 GPa, $\mathbf{S}_{y}=\mathbf{5 0 0} \mathrm{MPa}$

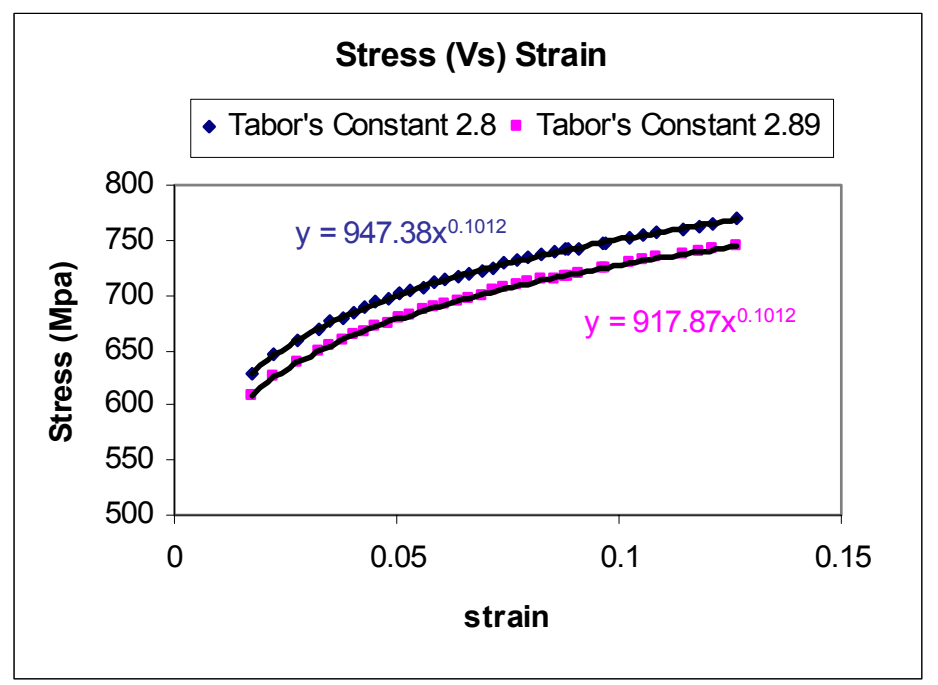

Figure 5.54 Comparison of stress Versus strain curves for steel, $\mathrm{E}=200 \mathrm{GPa}$,

$\mathrm{S}_{y}=500 \mathrm{MPa}, \mathrm{n}=0.1$

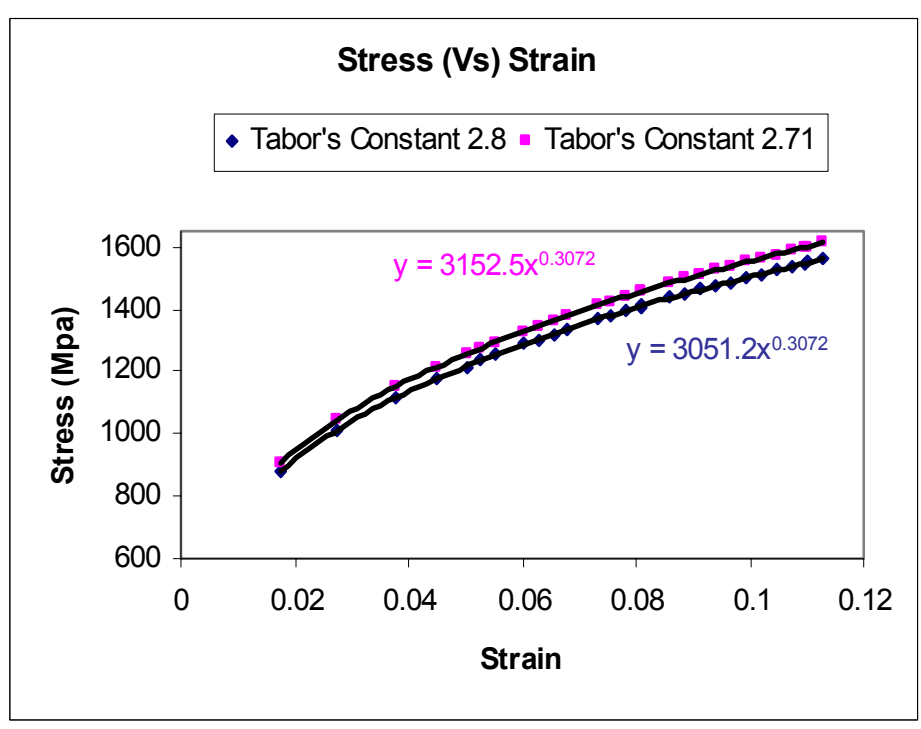

Figure 5.56 Comparison of stress Versus strain curves for steel, $\mathrm{E}=200 \mathrm{GPa}$,

$$
\mathrm{S}_{y}=500 \mathrm{MPa}, \mathrm{n}=0.3
$$

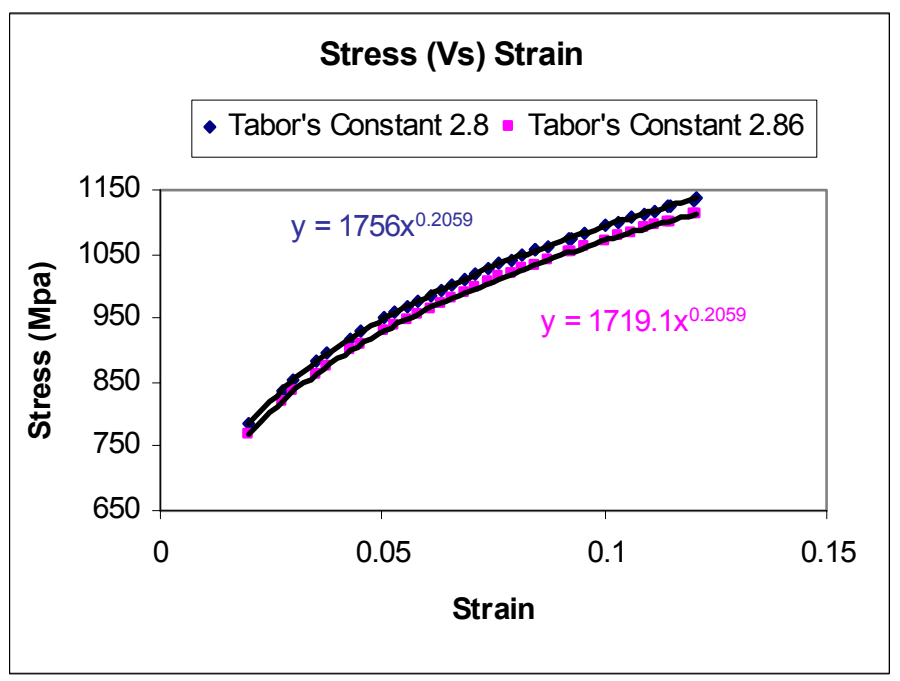

Figure 5.55 Comparison of stress Versus strain curves for steel, $\mathrm{E}=200 \mathrm{GPa}$,

$$
\mathrm{S}_{y}=500 \mathrm{MPa}, \mathrm{n}=0.2
$$

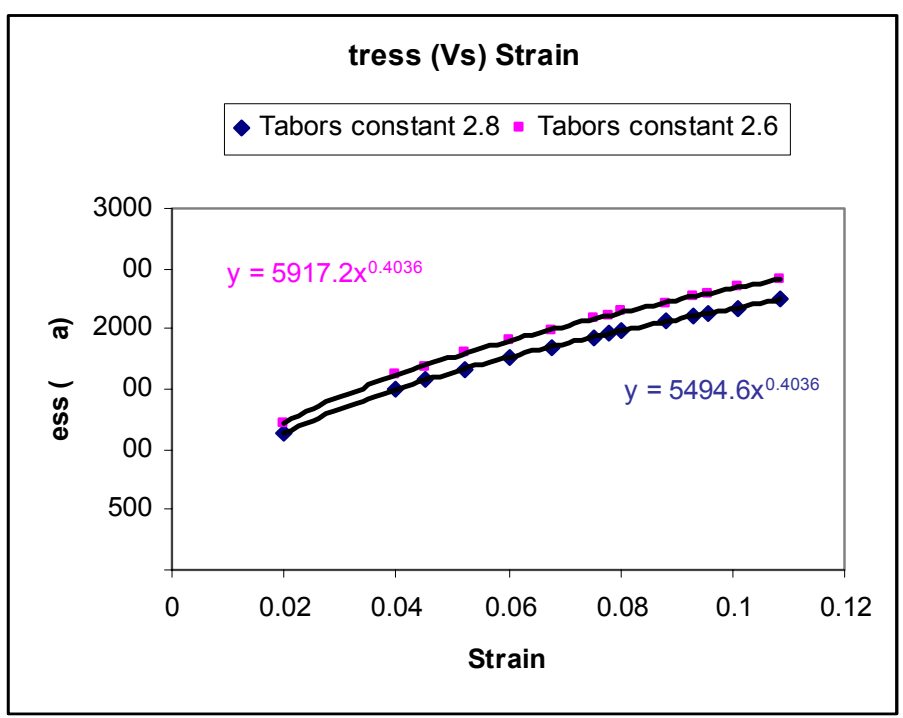

Figure 5.57 Comparison of stress Versus strain curves for steel, $\mathrm{E}=200 \mathrm{GPa}$,

$$
\mathrm{S}_{y}=500 \mathrm{MPa}, \mathrm{n}=0.4
$$




\subsubsection{Comparison of the yield stress values obtained from Tabor's Constant 2.8 and modified Tabor's constant for steel $\mathbf{E}=200 \mathrm{GPa}, \mathrm{S}_{y}=500 \mathrm{MPa}$}

\begin{tabular}{|c|c|c|c|c|c|c|c|}
\hline $\begin{array}{c}\text { Input } \\
\mathrm{n}\end{array}$ & $\begin{array}{c}\text { Input } \\
\mathrm{S}_{y}(\mathrm{MPa})\end{array}$ & $\begin{array}{c}\text { Tabor's } \\
\text { constant }\end{array}$ & $\begin{array}{c}\mathrm{S}_{y}(\mathrm{MPa}) \\
\text { obtained }\end{array}$ & $\begin{array}{c}\text { Error } \\
(\%)\end{array}$ & $\begin{array}{c}\text { Modified } \\
\text { Tabor's } \\
\text { constant }\end{array}$ & $\begin{array}{c}\mathrm{S}_{y} \text { from } \\
\text { modified } \\
\text { constant }\end{array}$ & $\begin{array}{c}\text { Error } \\
(\%)\end{array}$ \\
\hline \multicolumn{7}{|l|}{} \\
\hline 0.1 & 500 & 2.8 & 518.55 & $3.71 \%$ & 2.89 & 500.61 & $0.12 \%$ \\
\hline 0.2 & 500 & 2.8 & 514.39 & $2.87 \%$ & 2.86 & 500.82 & $0.16 \%$ \\
\hline 0.3 & 500 & 2.8 & 477.50 & $4.49 \%$ & 2.71 & 500.55 & $0.11 \%$ \\
\hline 0.4 & 500 & 2.8 & 430.04 & $14.01 \%$ & 2.6 & 501.62 & $0.32 \%$ \\
\hline
\end{tabular}

Table 5.9 Comparison of the results obtained before and after the change in Tabor's constant for steel, E=200 GPa, $\mathrm{S}_{y}=500 \mathrm{MPa}$

Yield stress values obtained from the methodology proposed after varying the Tabor's constant are in good agreement with the input values. The constant value drops rapidly for materials with $\mathrm{n}$ greater than 0.3 as shown below.

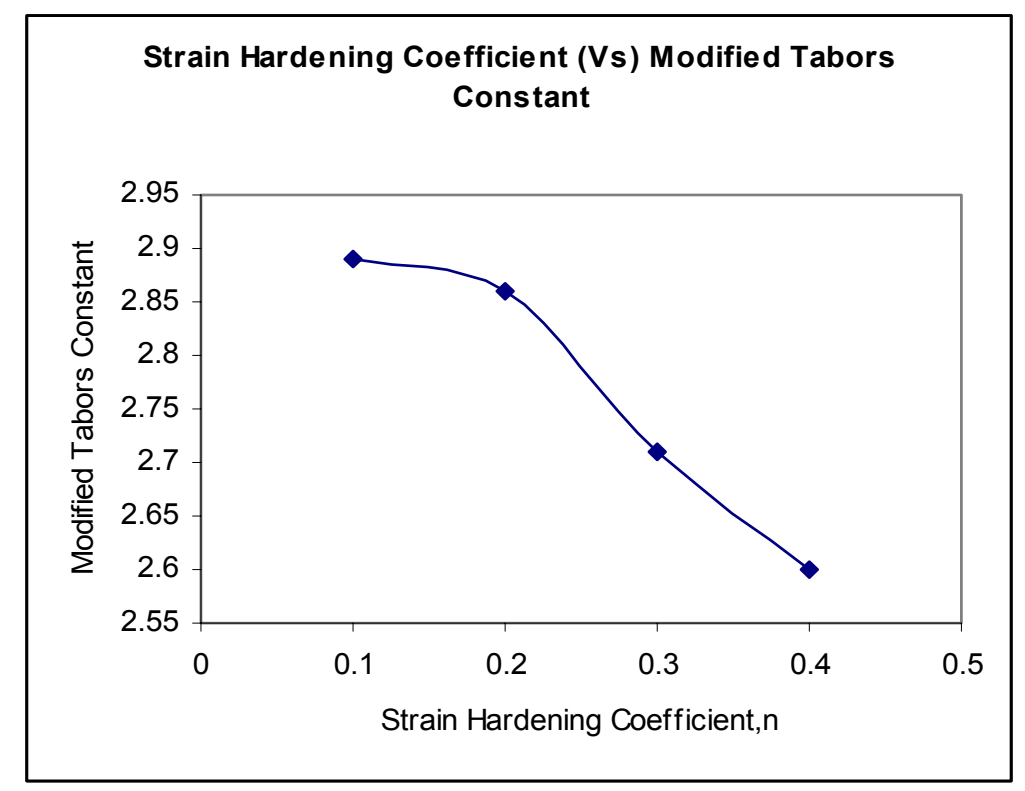

Figure 5.58 Strain hardening exponent Versus modified constant for steel, $\mathrm{E}=200 \mathrm{GPa}, \mathrm{S}_{y}=500 \mathrm{MPa}$ 
Steel, E=200 GPa, $\mathbf{S}_{y}=\mathbf{7 5 0} \mathrm{MPa}$

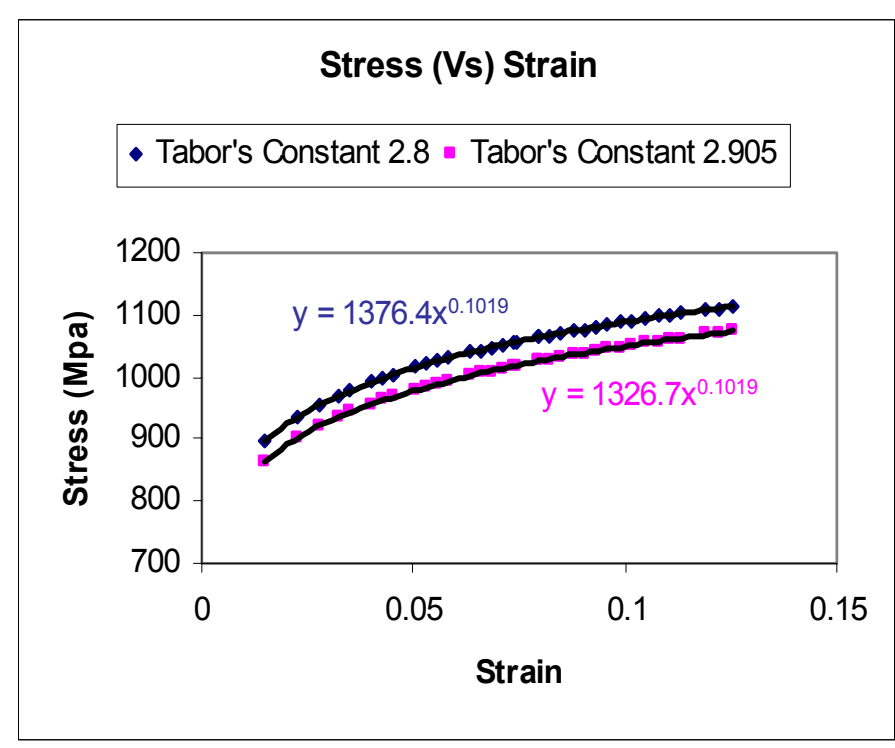

Figure 5.59 Comparison of stress Versus strain curves for steel, $\mathrm{E}=200 \mathrm{GPa}$,

$$
\mathrm{S}_{y}=750 \mathrm{MPa}, \mathrm{n}=0.1
$$

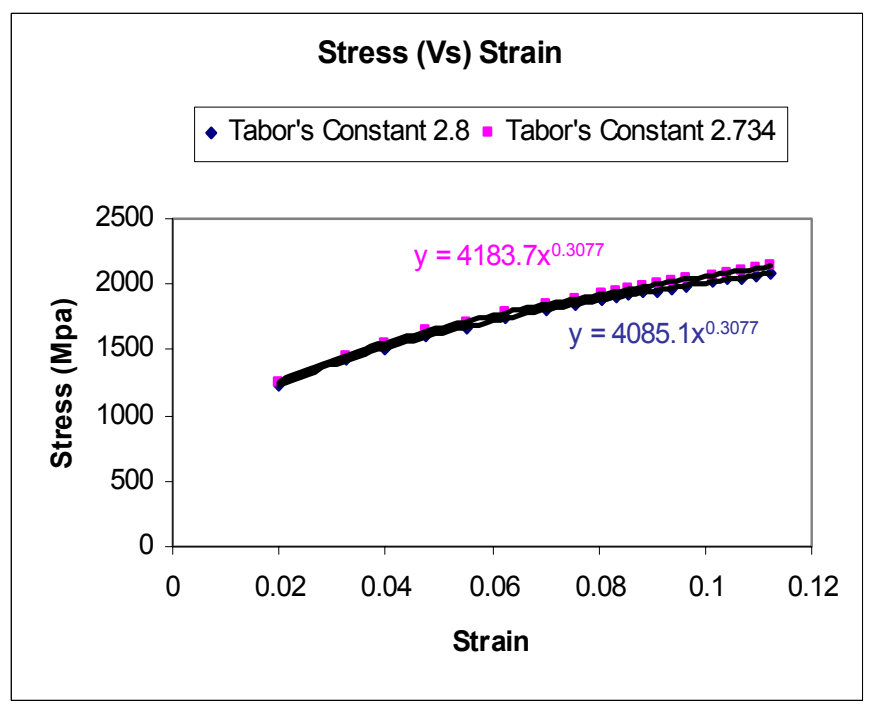

Figure 5.61 Comparison of stress Versus strain curves for steel, $\mathrm{E}=200 \mathrm{GPa}$,

$$
\mathrm{S}_{y}=750 \mathrm{MPa}, \mathrm{n}=0.3
$$

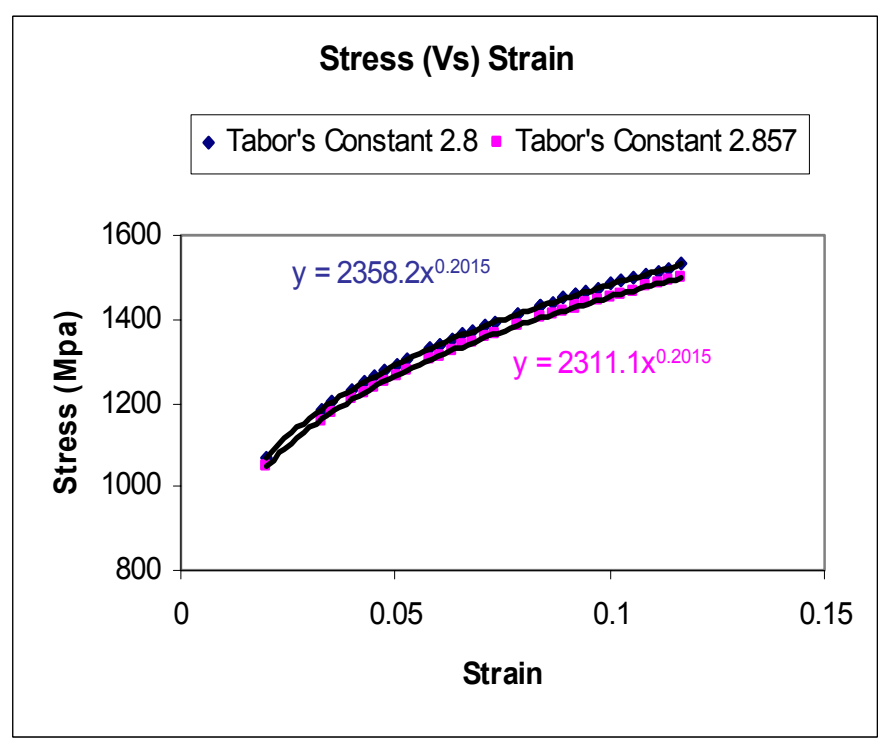

Figure 5.60 Comparison of stress Versus strain curves for steel, $\mathrm{E}=200 \mathrm{GPa}$,

$$
\mathrm{S}_{y}=750 \mathrm{MPa}, \mathrm{n}=0.2
$$

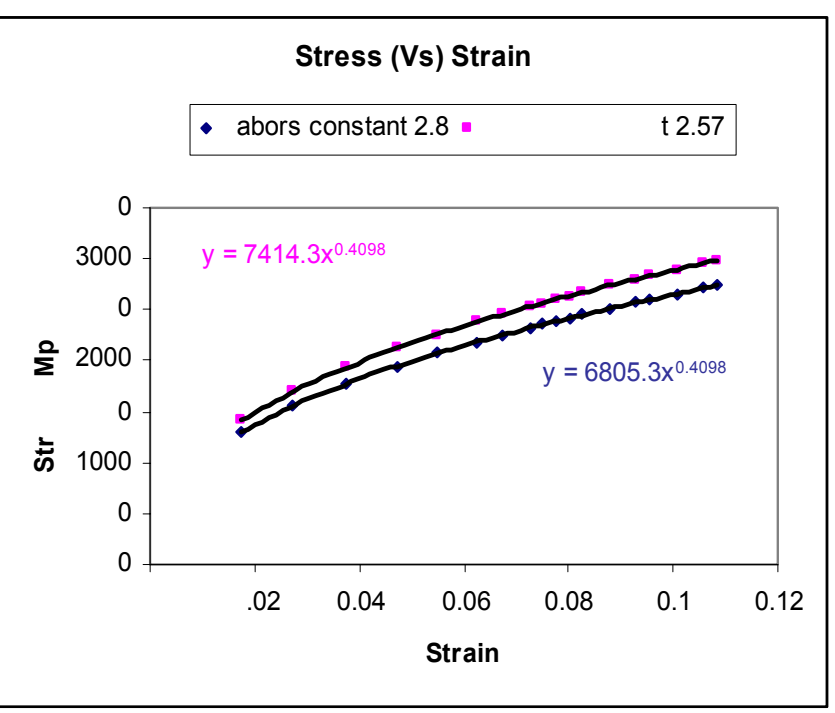

Figure 5.62 Comparison of stress Versus strain curves for steel, $\mathrm{E}=200 \mathrm{GPa}$,

$$
\mathrm{S}_{y}=750 \mathrm{MPa}, \mathrm{n}=0.4
$$




\subsubsection{Comparison of the yield stress values obtained from Tabor's constant 2.8 and modified Tabor's constant for steel $\mathbf{E}=200 \mathrm{GPa}, \mathrm{S}_{y}=\mathbf{7 5 0} \mathrm{MPa}$}

\begin{tabular}{|c|c|c|c|c|c|c|c|}
\hline Input n & $\begin{array}{c}\text { Input } \\
\mathrm{S}_{y}(\mathrm{MPa})\end{array}$ & $\begin{array}{c}\text { Tabor's } \\
\text { constant }\end{array}$ & $\begin{array}{c}\mathrm{S}_{y}(\mathrm{MPa}) \\
\text { obtained }\end{array}$ & Error (\%) & $\begin{array}{c}\text { Modified } \\
\text { Tabor's } \\
\text { constant }\end{array}$ & $\begin{array}{c}\mathrm{S}_{y} \text { from } \\
\text { modified } \\
\text { constant }\end{array}$ & Error (\%) \\
\hline \multicolumn{7}{|l|}{} \\
\hline 0.1 & 750 & 2.8 & 782.36 & $4.31 \%$ & 2.905 & 750.97 & $0.12 \%$ \\
\hline 0.2 & 750 & 2.8 & 769.02 & $2.53 \%$ & 2.857 & 749.83 & $0.02 \%$ \\
\hline 0.3 & 750 & 2.8 & 724.67 & $3.37 \%$ & 2.734 & 750.07 & $0.05 \%$ \\
\hline 0.4 & 750 & 2.8 & 650.77 & $15.24 \%$ & 2.57 & 750.07 & $0.03 \%$ \\
\hline
\end{tabular}

Table 5.10 Comparison of the results obtained before and after the change in Tabor's constant for steel, $\mathrm{E}=200 \mathrm{GPa}, \mathrm{S}_{y}=750 \mathrm{MPa}$

The behavior in the variation of the Tabor constant with $\mathrm{n}$ is the same as in the previous case. There is a steep decrease in the value of the modified constant for the material with $\mathrm{n}$ greater than 0.3 .

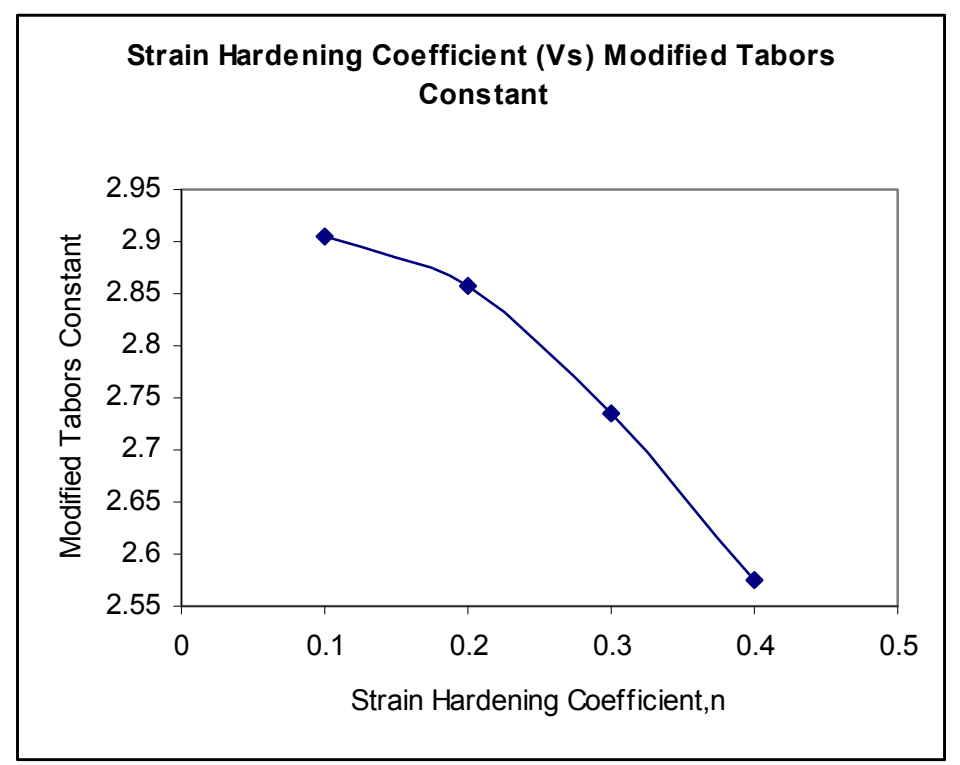

Figure 5.63 Strain hardening exponent Versus modified constant for steel, E=200 GPa, $\mathrm{S}_{y}=750 \mathrm{MPa}$ 
Steel, $\mathbf{E}=200 \mathrm{GPa}, \mathbf{S}_{y}=1000 \mathrm{MPa}$

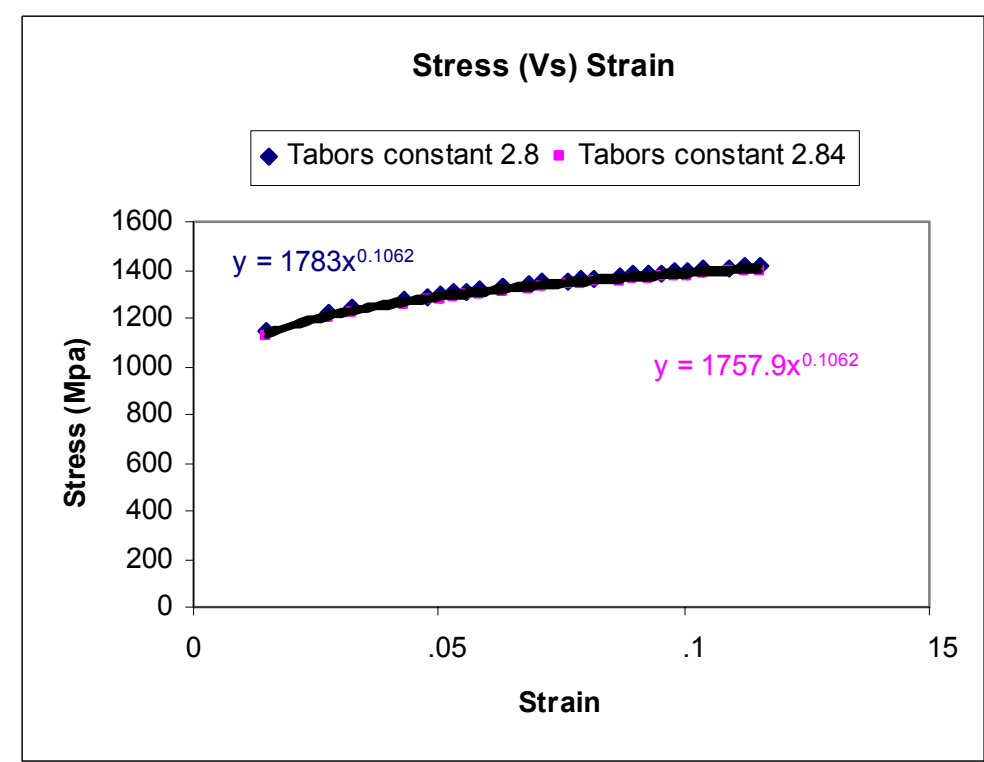

Figure 5.64 Comparison of stress Versus strain curves for steel, $\mathrm{E}=200 \mathrm{GPa}$,

$$
\mathrm{S}_{y}=1000 \mathrm{MPa}, \mathrm{n}=0.1
$$

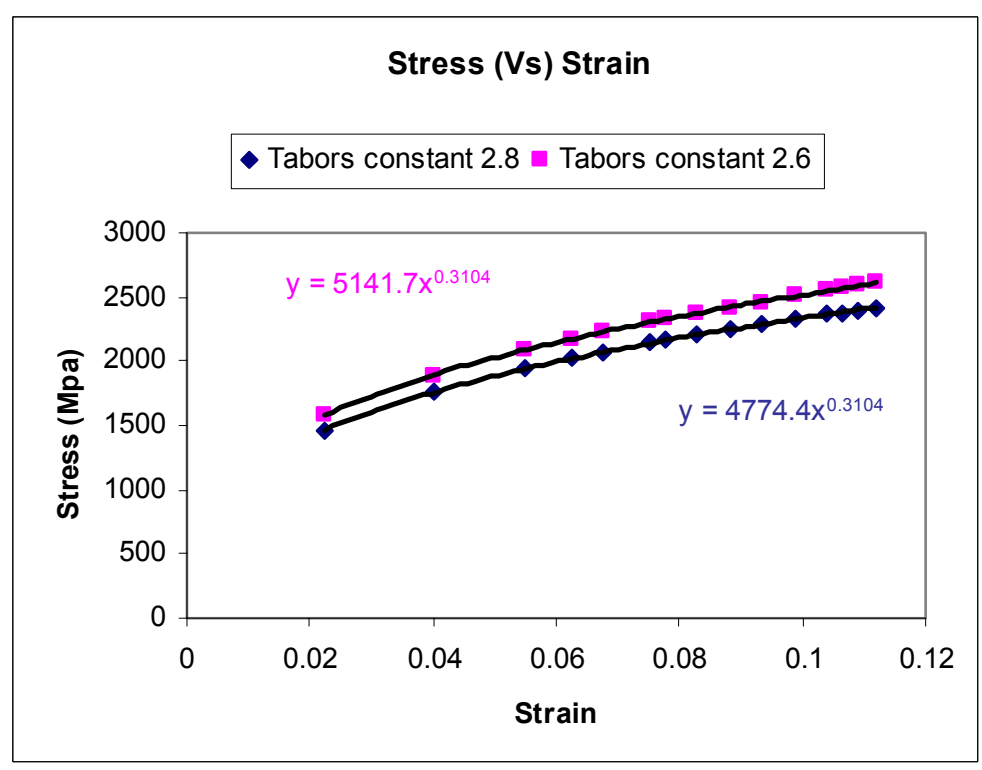

Figure 5.66 Comparison of stress Versus strain curves for steel, $\mathrm{E}=200 \mathrm{GPa}$,

$$
\mathrm{S}_{y}=1000 \mathrm{MPa}, \mathrm{n}=0.3
$$

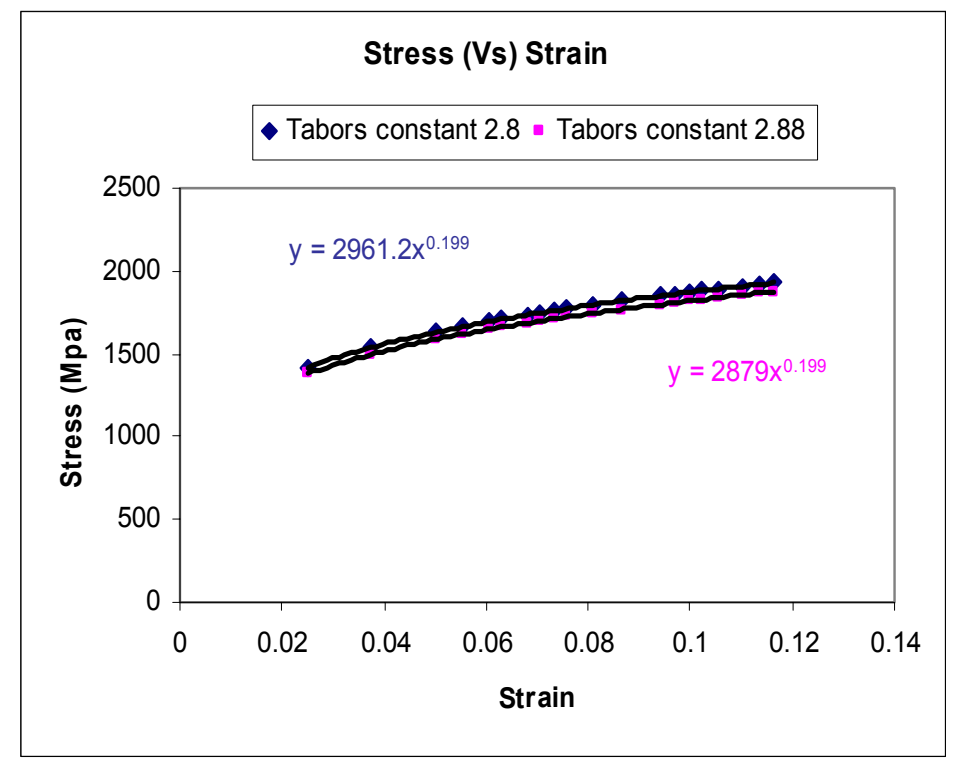

Figure 5.65 Comparison of stress Versus strain curves for steel, $\mathrm{E}=200 \mathrm{GPa}$,

$$
\mathrm{S}_{y}=1000 \mathrm{MPa}, \mathrm{n}=0.2
$$

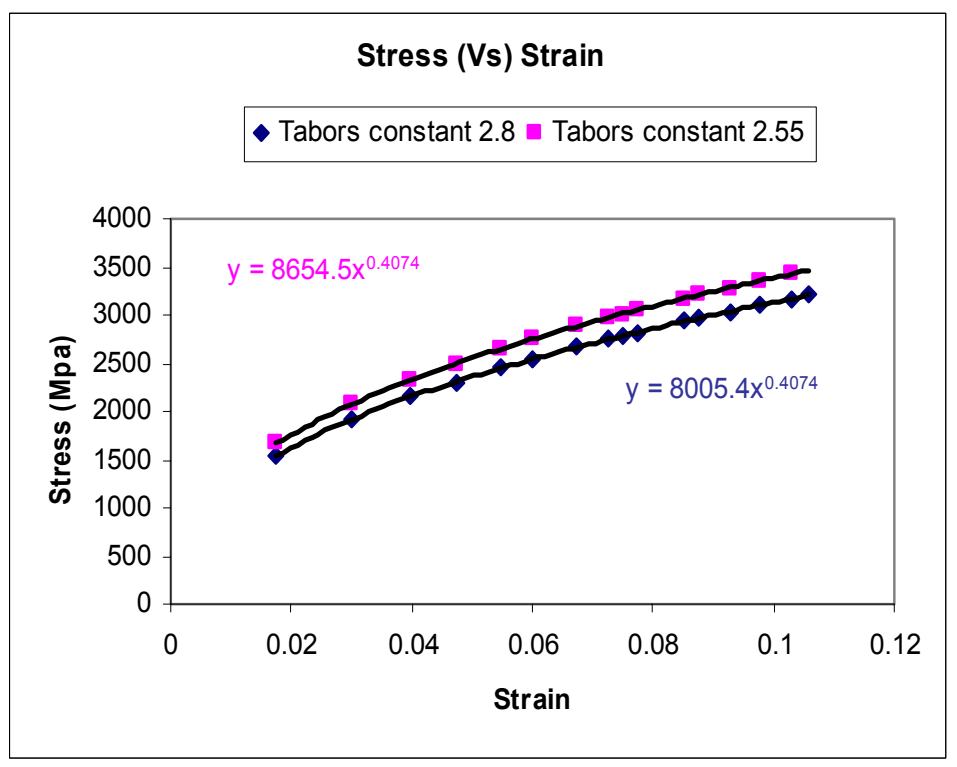

Figure 5.67 Comparison of stress Versus strain curves for steel, $\mathrm{E}=200 \mathrm{GPa}$,

$$
\mathrm{S}_{y}=1000 \mathrm{MPa}, \mathrm{n}=0.4
$$




\subsubsection{Comparison of the yield stress values obtained from Tabor's Constant 2.8 and}

modified Tabor's constant for steel $\mathbf{E}=200 \mathrm{GPa}, \mathrm{S}_{y}=1000 \mathrm{MPa}$

\begin{tabular}{|c|c|c|c|c|c|c|c|}
\hline $\begin{array}{c}\text { Input } \\
\mathrm{n}\end{array}$ & $\begin{array}{c}\text { Input } \\
\mathrm{S}_{y}(\mathrm{MPa})\end{array}$ & $\begin{array}{c}\text { Tabor's } \\
\text { constant }\end{array}$ & $\begin{array}{c}\mathrm{S}_{y}(\mathrm{MPa}) \\
\text { obtained }\end{array}$ & $\begin{array}{c}\text { Error } \\
(\%)\end{array}$ & $\begin{array}{c}\text { Modified } \\
\text { Tabor's } \\
\text { constant }\end{array}$ & $\begin{array}{c}\mathrm{S}_{y} \text { from } \\
\text { modified } \\
\text { constant }\end{array}$ & $\begin{array}{c}\text { Error } \\
(\%)\end{array}$ \\
\hline 0.1 & 1000 & 2.8 & 1017.6 & $1.76 \%$ & 2.84 & 1001.6 & $0.36 \%$ \\
\hline 0.2 & 1000 & 2.8 & 1039.7 & $3.97 \%$ & 2.88 & 1003.8 & $0.13 \%$ \\
\hline 0.3 & 1000 & 2.8 & 989.5 & $1.04 \%$ & 2.62 & 995.1 & $0.07 \%$ \\
\hline 0.4 & 1000 & 2.8 & 876.05 & $12.39 \%$ & 2.55 & 999.2 & $0.01 \%$ \\
\hline
\end{tabular}

Table 5.11 Comparison of the results obtained before and after the change in Tabor's constant for steel, $\mathrm{E}=200 \mathrm{GPa}, \mathrm{S}_{y}=1000 \mathrm{MPa}$

Good results are obtained with the modified Tabor's constant. The error is small when compared to the results obtained by taking the Tabor's constant as 2.8. Variation of the constant with $\mathrm{n}$ is shown in the Figure 5.68 below.

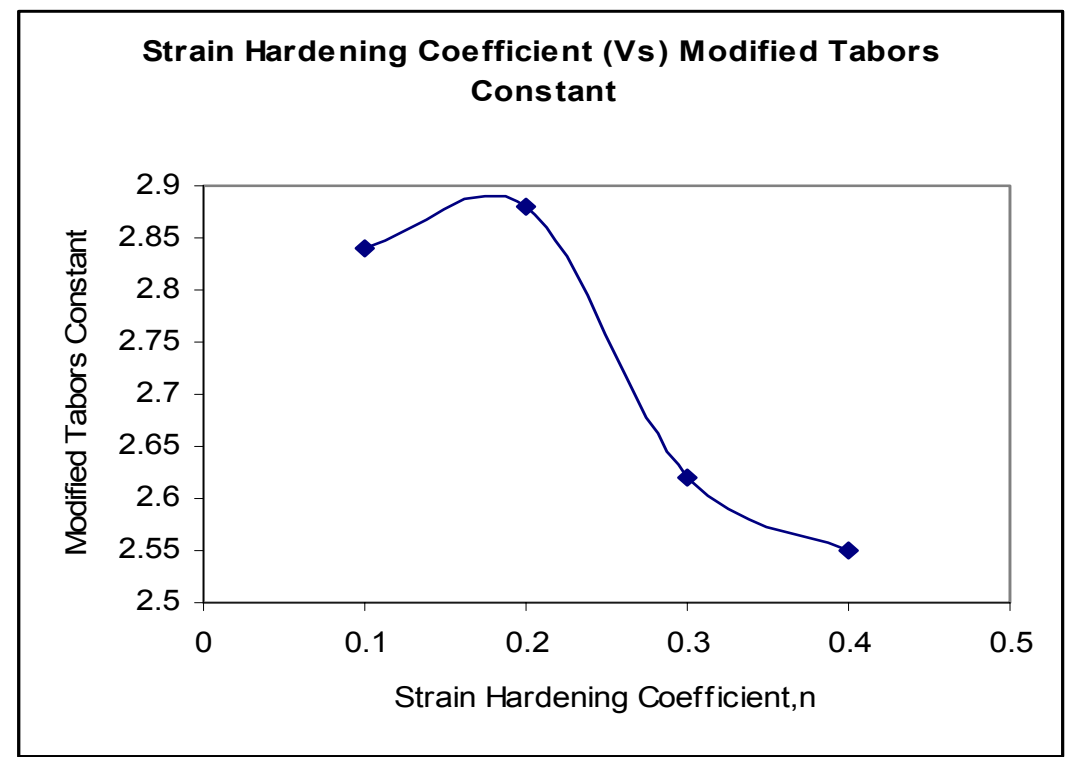

Figure 5.68 Strain hardening exponent Versus modified constant for steel, E=200 GPa, $\mathrm{S}_{y}=1000 \mathrm{MPa}$ 
Figure 5.69 below shows the variation of Tabors constant with strain hardening coefficient in all the materials.

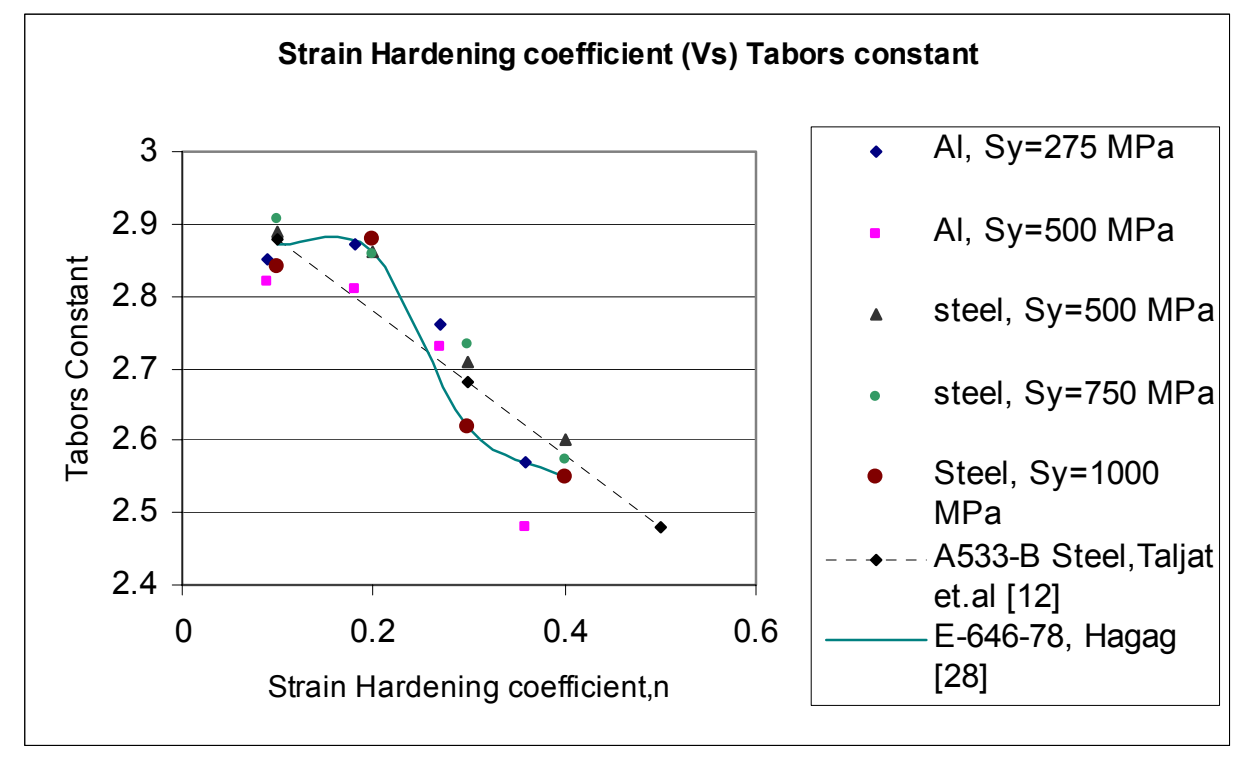

Figure 5.69 Strain hardening exponent Versus modified Tabor constant

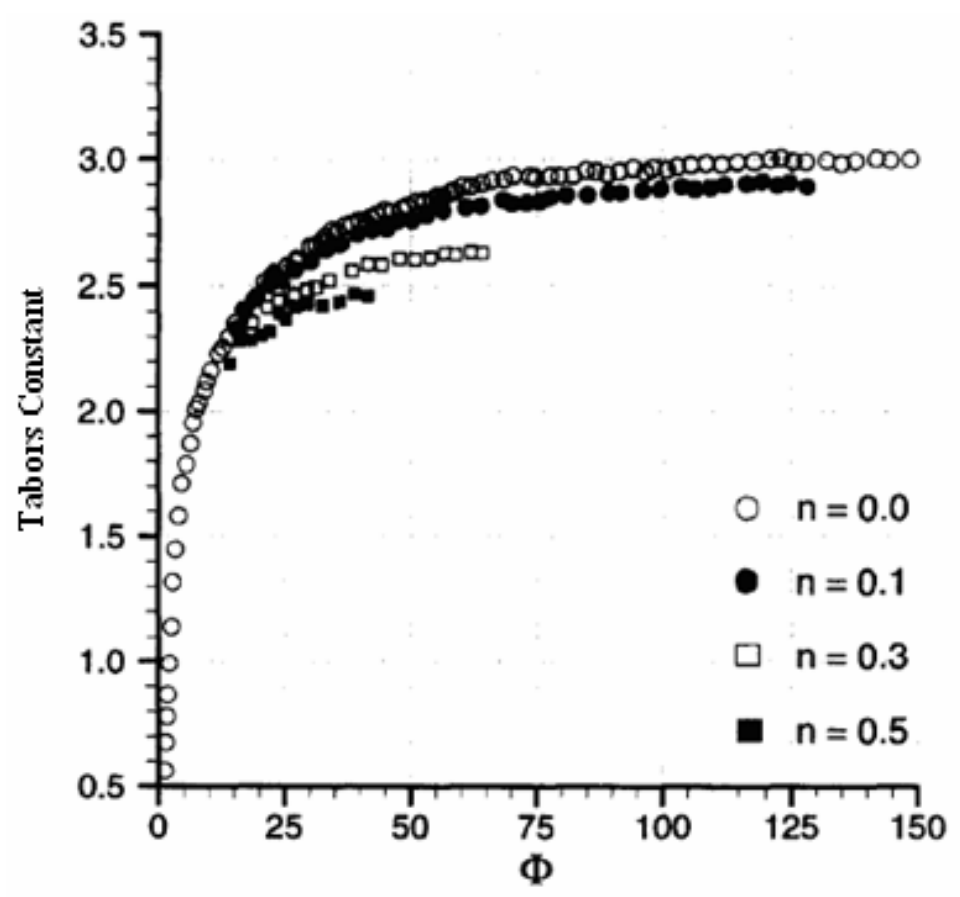

Figure 5.70 Results from the work of B.Taljat [12] 
Variation of the Tabors constant observed in the present research has been compared with the results obtained by B.Taljat, et al.[12] for the material A533-B Steel, with material properties: Young's modulus $210 \mathrm{GPa}$ and Yield stress $400 \mathrm{MPa}$. Results have also been compared with the work of Hagag [28].

\subsection{Simulation results for Ramberg-Osgood model}

Finite element simulations were also carried out on steel alloys whose stressstrain curve is defined by Ramberg-Osgood model with $\mathrm{E}=208 \mathrm{GPa}, \mathrm{v}=0.333, \mathrm{~S}_{y}=256$ MPa, yield offset $\alpha=17.176$, exponent $\mathrm{N}=3.585$ where $\mathrm{N}=\frac{1}{n}$ and $\mathrm{n}=0.2889$.
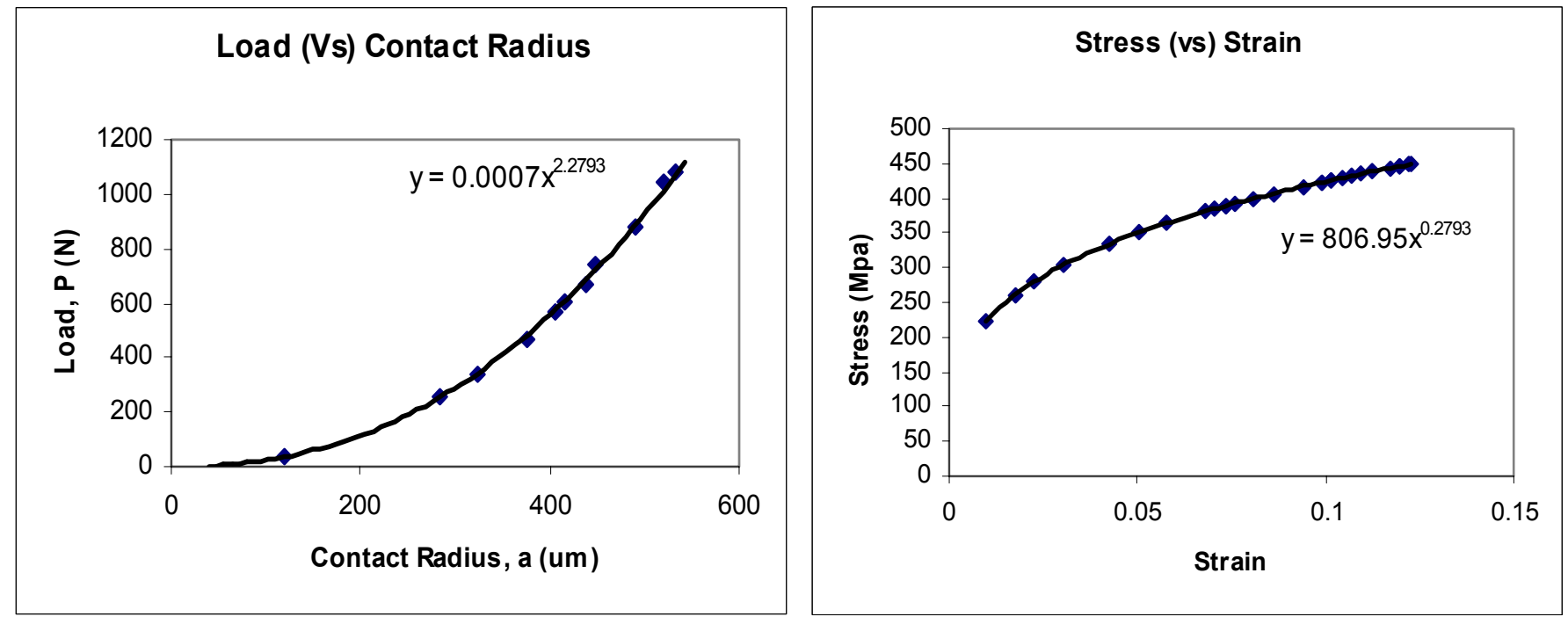

Figure 5.72 Stress Versus strain obtained for Ramberg-Osgood model

The value of the strain hardening exponent obtained from the above is in good agreement with the input $\mathrm{n}$ value defined by Ramberg-osgood model. 


\subsection{Simulation results for Power Law hardening model}

One of the most commonly used models to define the stress-strain curve is power law hardening. Curve defined by this model has no definite elastic region. This model typically describes soft ductile materials such as lead. Equation below describes the power law hardening model.

$$
\sigma=\mathrm{A} \varepsilon^{n}
$$

For the FE simulation, the stress-strain curve defined by equation $\sigma=1000 \varepsilon^{0.3968}$ is used as an input. The following results were obtained.

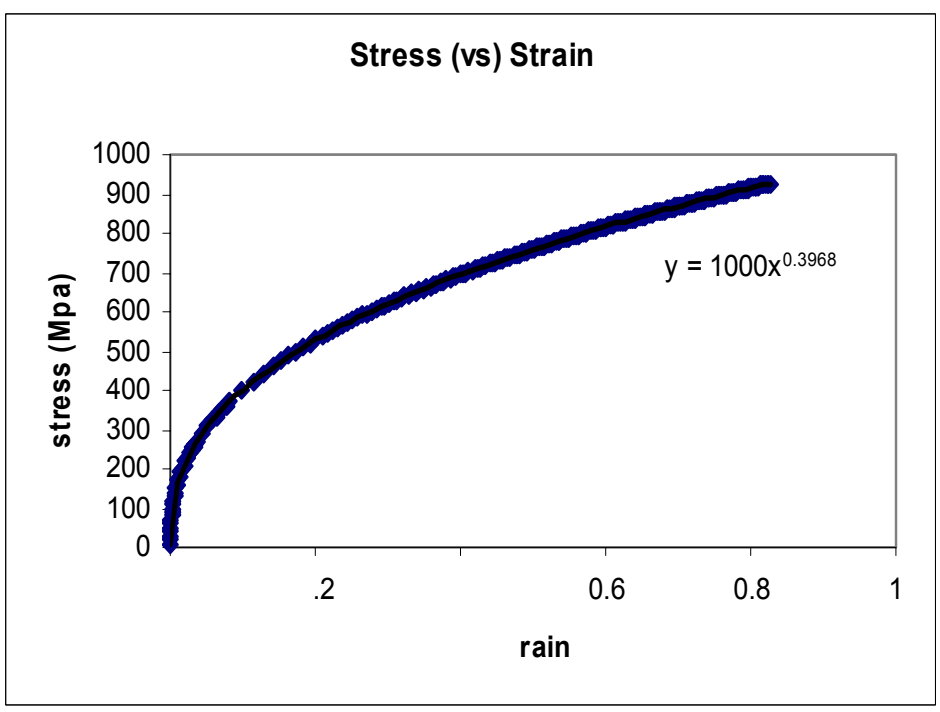

Figure 5.73 Input Stress Versus strain curve describing power law model

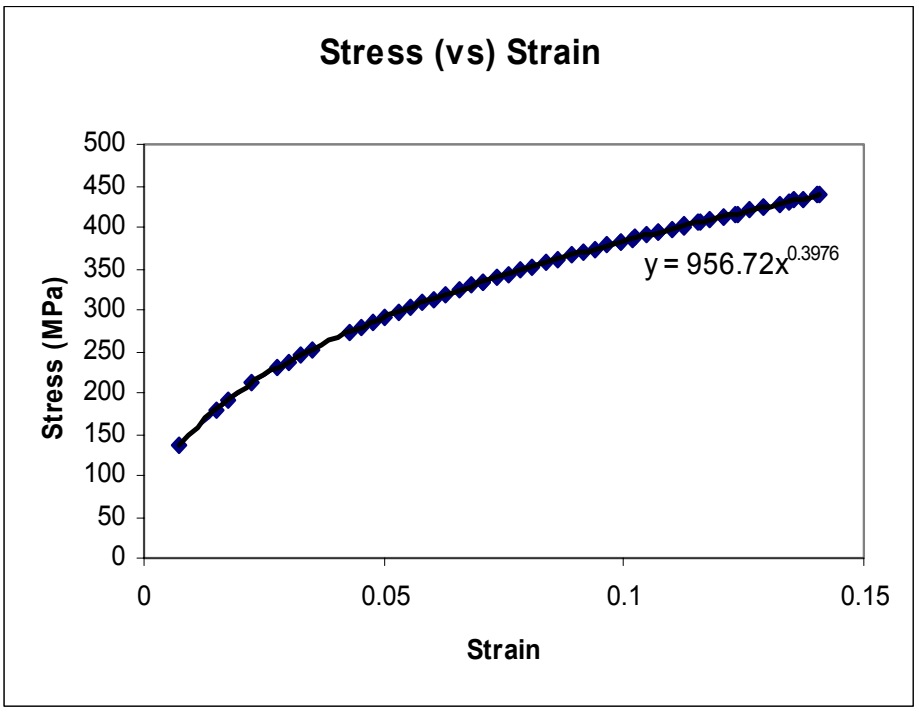

Figure 5.74 Stress Versus strain curve obtained from simulation for power law model

Value of strain hardening exponent obtained for the power law hardening model is in good agreement with the input data. 
Based on the results obtained in this research, validity of the proposed methodology for metallic alloys is established. It can be successfully employed to determine stress-strain curve and thus material mechanical properties. Strain hardening exponent obtained using the Meyer's empirical equations are in good agreement with the input data. Large percentage error in the calculation of yield stress is an effect of Tabors constant. Analysis of the results shows that the Tabors constant is not a fixed value and varies with material strain hardening. Error in the calculation of yield stress can be minimized by picking the appropriate Tabors constant value. 


\section{Chapter 6}

\section{Conclusions and Discussions}

Finite element spherical indentation simulations of 20 materials (aluminum and steel alloys) were carried out. A methodology is proposed to determine the material mechanical properties such as yield stress and strain hardening parameter, from the indentation data using Meyer's and Tabor's empirical equations.

It has been found that results obtained from the proposed methodology and input material properties are in good agreement. Strain hardening exponent calculated from the Meyer's equation is in close agreement to the input value. It is observed that there is high error percentage in the calculation of yield stress using Tabor's empirical equation for materials with strain hardening exponent over 0.3 . Based on the series of results obtained, this error in the calculation of yield stress has been attributed to the Tabor's constant. It is concluded that Tabor's constant (2.8) is not a universal value for all the materials. It changes from material to material and is a function of strain hardening coefficient. Results have been analyzed by modifying the Tabor's constant. Error percentage is low when Tabor's empirical equation is used with modified Tabor's constant. Variation of the modified Tabor's constant with strain hardening exponent has been studied. It is observed that the constant takes value ranging from 2.5 to 2.9 depending on the material strain hardening coefficient. Variation of the constant for materials with $n$ less than 0.25 is small but high for $\mathrm{n}$ over 0.25 .

Another finding is that data of indentation load and contact diameter corresponding to 3 to $12 \%$ of strain will give good curve fitting and results of strain hardening exponent and yield stress. The above observation is helpful to guide 
indentation test as one can concentrate on the data of load and contact diameter corresponding to the proposed strain range. And once the strain hardening coefficient is obtained from the load versus contact diameter curve, the appropriate Tabor's constant can be picked from the strain hardening exponent versus modified Tabor's constant curve (Figure 5.69). Use of this constant in Tabor's equation reduces the percentage error in the calculation the yield stress of the material.

\subsection{Limitations}

From the finite element results, it is clear that the Tabors constant is not fixed, thus arising the question, how does one pick the right Tabor constant when the indentation of an unknown material is carried out experimentally? How can one determine the right stress-strain model that the material follows? These are few questions that have to be looked upon in future work.

More importantly, the above discussed indentation procedure is limited only to ductile materials. Thus, the research has been done for the application of this procedure on ductile metals. Very little is known about the validity in employment of this approach to brittle materials. Development of cracks in early stages at relatively small loads limits the use of indentation procedure on brittle materials.

Future work should focus on producing the relation between strain hardening coefficient and the correct Tabors constant so that the yield stress can be calculated experimentally with less percentage error. Future research work should also try to develop a methodology to determine the correct stress-strain model from the indentation data. Effort should be placed to extend the indentation technique to determine the mechanical properties of brittle materials. 


\section{References}

[1] M. F. Doerner and W. D. Nix, "A method for interpreting the data from depth-sensing indentation instruments", J. Mater. Res.1 (4), pp 601-609, (1986).

[2] W. C. Oliver and G. M. Pharr, "An improved technique for determining hardness and elastic modulus using load and displacement sensing indentation measurements", J. Mater. Res. 7 (6), pp 1564-1583, (1992).

[3] I. N. Sneddon, "The relationship between load and penetration in the axisymmetric Boussinesq problem for a punch of arbitrary Profile”, Int. J. Engng. Sci. 3, pp 47-57, (1965).

[4] A.E. Giannakopoulos, P.L. Larsson and R. Vestergaard, "Analysis of Vickers indentation”, Int. J. Solids Structures, Vol. 31, No. 19, pp 2679-2708, (1994).

[5] J. S. Field and M. V. Swain, "Determining the mechanical properties of small volumes of material from submicrometer spherical indentations", J. Mater. Res., Vol.10, No.1, pp 101-112, (1995).

[6] Y. Cheng and C. Cheng, "Can stress-strain relationships be obtained from indentation curves using conical and pyramidal indenters?”, J. Mater. Res., Vol.14, No.9, pp 34933496, (1999).

[7] Tabor D, "Hardness of metals". Oxford: Clarendon Press, (1951).

[8] ABAQUS theory manual version 6.3, Pawtucket: Hibbitt, Karlsson and Sorensen, Inc., (2002). 
[9] Johnson KL, “Contact mechanics". London: Cambridge University Press, (1985).

[10] J. R. Barber and M. Ciavarella, "Contact mechanics", International Journal of Solids and Structures, vol 37 pp 29-43, (2000).

[11] "Review of Instrumented Indentation", J. Res. Natl. Inst. Stand. Technol. Vol 108, pp 249-265, (2003).

[12] B. TALJAT, T. ZACHARIA, "New Analytical procedure to determine Stress-Strain Curve from Spherical indentation data", Oak Ridge National Laboratory, Metals and Ceramics Division, Oak Ridge, TN 37831-6140, U.S.A.

[13] J. Alcalá, A.C. Barone and M. Anglada, "The influence of plastic hardening on surface deformation modes around Vickers and spherical indents", originally published in Acta Materialia, volume 48, pp 3451-3464, (2000).

[14] Y. Cheng and C. Cheng, "Can stress-strain relationships be obtained from indentation curves using conical and pyramidal indenters?", J. Mater. Res., Vol.14, No.9, pp 3493-3496, (1999).

[15] http://www.hydrocarbide.com/pg6.htm

[16] A. K. Bhattacharya and W.D. Nix, "Analysis of elastic and plastic deformation associated with indentation testing of thin films on substrates", Int. J. Solids Structures, Vol. 24, No.12, pp 1287-1298, (1988). 
[17] M. Futakawa, T. Wakui, I. Ioka and M. Eto, "Mechanical-property evaluation of thin corroded surface layer of ceramic materials by micro indentation technique", J. Euro. Ceram. Soci, 20, pp 1135, (2000).

[18] J. S. Field and M. V. Swain, "Determining the mechanical properties of small volumes of material from submicrometer spherical indentations", J. Mater. Res., Vol.10, No.1, pp101-112, (1995).

[19] Vincent E. Lysaght. Wilson "Indentation Hardness Testing", Mechanical Instruments Co. New York, N.Y.

[20] J. G. Swandener, E. P. George, G. M. Pharr., "The correlation of the indentation size effect measured with indenters of various shapes", Journal of the Mechanics and Physics of Solids 50, pp 681-694, (2002).

[21] http://www.salemball.com/tcmec.htm

[22] A. K. Bhattacharya and W.D. Nix, "Finite Element Simulation of Indentation Experiments", Int. J. Solids Structures, Vol. 24, No. 9, pp 881-891, (1988).

[23] "Material Hardness", CALCE Test Services and failure analysis (TSFA) Laboratory, University of Maryland, College Park, MD. See internet posting: http://www.calce.umd.edu/general/Facilities/Hardness_ad_htm\#3.2

[24] "Material Hardness", Gordon England, Independent Metallurgist and Consultant to the Thermal Spray Coating Industry, England. See internet posting: http://www.gordonengland.co.uk/hardness/vickers.htm 
[25] "Material Hardness", Gordon England, Independent Metallurgist and Consultant to the Thermal Spray Coating Industry, England. See internet posting: http://www.gordonengland.co.uk/hardness/rockwell.htm

[26] "Depth-Sensing Indentation (DSI)", Building and Fire Research Laboratory, National institutes of standards and technology. See internet posting: http://www.bfrl.nist.gov/nanoscience/DSI.htm

[27] D. Tabor, "The hardness of metals", Oxford, at the Clarendon press, (1951).

[28] Haggag, F. M., Nanstad, R. K., Hutton,J. T., Thomas, D. L., and Swain, R. L. “Use of Automated Ball Indentation Testing to Measure Flow Properties and Estimate Fracture Toughness in Metallic Materials", ASTM STP 1092, eds. Braun, Ashbaugh and Smith. ASTM, Philadelphia, Pa., pp 188-208, (1990). 


\section{DATA SHEETS}

Aluminum, E=69 GPa, $\mathrm{S}_{y}=275 \mathrm{MPa}, \mathbf{n}=\mathbf{0 . 0 9}$

\begin{tabular}{|c|c|c|}
\hline \multicolumn{3}{|c|}{ Aluminum } \\
\hline \multicolumn{3}{|c|}{$\mathrm{E}=69 \mathrm{GPa}, \mathbf{S}_{y}=275 \mathrm{MPa}, \mathbf{n}=0.09$} \\
\hline Time Increment & Load $(\mathrm{N})$ & $\mathrm{a}$, Contact Radius $(\mu \mathrm{m})$ \\
\hline 0.0299609 & 6.50424 & 49.9904 \\
\hline 0.0662982 & 17.9222 & 80.1135 \\
\hline 0.135376 & 42.996 & 120.39 \\
\hline 0.168861 & 54.8339 & 140.744 \\
\hline 0.202186 & 69.9999 & 150.865 \\
\hline 0.242179 & 83.9379 & 171.274 \\
\hline 0.277838 & 100.619 & 181.442 \\
\hline 0.313283 & 117.122 & 191.732 \\
\hline 0.350278 & 132.795 & 202.058 \\
\hline 0.388998 & 148.794 & 212.45 \\
\hline 0.440436 & 172.109 & 233.112 \\
\hline 0.47996 & 189.795 & 243.549 \\
\hline 0.514273 & 203.223 & 254.071 \\
\hline 0.560952 & 227.523 & 264.564 \\
\hline 0.600212 & 244.111 & 275.167 \\
\hline 0.646821 & 264.547 & 285.759 \\
\hline 0.703065 & 295.143 & 296.553 \\
\hline 0.751876 & 317.998 & 307.381 \\
\hline 0.79929 & 340.051 & 318.124 \\
\hline 0.868789 & 370.518 & 329.418 \\
\hline 0.920914 & 395.681 & 340.369 \\
\hline 0.97202 & 420.651 & 351.287 \\
\hline 1 & 428.409 & 352.158 \\
\hline 1.03781 & 450.542 & 362.666 \\
\hline 1.10505 & 480.9 & 374.039 \\
\hline 1.16679 & 510.186 & 385.303 \\
\hline 1.23858 & 542.64 & 396.892 \\
\hline 1.3013 & 572.917 & 408.133 \\
\hline 1.36695 & 603.289 & 419.464 \\
\hline 1.4867 & 651.743 & 432.838 \\
\hline 1.55577 & 684.562 & 444.454 \\
\hline 1.67906 & 733.88 & 466.512 \\
\hline 1.74456 & 766.492 & 469.477 \\
\hline 1.8551 & 812.226 & 482.575 \\
\hline 2 & 879.921 & 505.289 \\
\hline
\end{tabular}


Aluminum, E=69 GPa, $\mathbf{S}_{y}=275 \mathrm{MPa}, \mathbf{n}=\mathbf{0 . 1 8}$

\begin{tabular}{|c|c|c|}
\hline \multicolumn{3}{|c|}{ Aluminum } \\
\hline \multicolumn{3}{|c|}{$\mathrm{E}=69 \mathrm{GPa}, \mathbf{S}_{y}=275 \mathrm{MPa}, \mathbf{n}=0.18$} \\
\hline Time Increment & Load $(\mathrm{N})$ & a, Contact Radius $(\mu \mathrm{m})$ \\
\hline 0.08 & 23.8864 & 90.0413 \\
\hline 0.1525 & 52.9732 & 130.374 \\
\hline 0.190215 & 71.4869 & 140.451 \\
\hline 0.244554 & 96.7641 & 160.586 \\
\hline 0.303683 & 126.181 & 180.918 \\
\hline 0.395386 & 171.925 & 211.47 \\
\hline 0.458462 & 203.63 & 232.023 \\
\hline 0.513786 & 236.15 & 242.309 \\
\hline 0.553927 & 258.203 & 252.721 \\
\hline 0.641833 & 303.82 & 273.339 \\
\hline 0.714077 & 346.209 & 283.983 \\
\hline 0.786818 & 383.245 & 304.767 \\
\hline 0.836578 & 411.981 & 315.313 \\
\hline 0.900369 & 449.782 & 325.895 \\
\hline 0.994103 & 505.804 & 337.026 \\
\hline 1 & 507.99 & 337.149 \\
\hline 1.085 & 557.355 & 357.911 \\
\hline 1.175 & 613.092 & 369.137 \\
\hline 1.27249 & 664.692 & 380.724 \\
\hline 1.35114 & 709.293 & 401.296 \\
\hline 1.4375 & 762.844 & 412.428 \\
\hline 1.52289 & 815.493 & 423.66 \\
\hline 1.60683 & 865.223 & 434.899 \\
\hline 1.69352 & 915.392 & 446.197 \\
\hline 1.8185 & 986.531 & 458.586 \\
\hline 1.90628 & 1037.89 & 470.008 \\
\hline 2 & 1091.87 & 481.485 \\
\hline
\end{tabular}


Aluminum, E=69 GPa, $\mathrm{S}_{y}=275 \mathrm{MPa}, \mathbf{n}=0.27$

\begin{tabular}{|c|c|c|}
\hline \multicolumn{3}{|c|}{ Aluminum } \\
\hline \multicolumn{3}{|c|}{$\mathrm{E}=69 \mathrm{GPa}, \mathbf{S}_{y}=275 \mathrm{MPa}, \mathbf{n}=0.27$} \\
\hline Time Increment & Load $(\mathrm{N})$ & a, Contact Radius $(\mu \mathrm{m})$ \\
\hline 0.11 & 38.3793 & 99.9484 \\
\hline 0.259062 & 115.374 & 160.184 \\
\hline 0.404609 & 199.446 & 200.586 \\
\hline 0.492412 & 254.545 & 231.134 \\
\hline 0.537342 & 284.479 & 241.325 \\
\hline 0.643775 & 356.078 & 261.698 \\
\hline 0.731914 & 414.49 & 282.25 \\
\hline 0.798565 & 462.659 & 292.558 \\
\hline 0.901058 & 532.916 & 313.184 \\
\hline 0.969949 & 583.057 & 323.657 \\
\hline 1 & 600.426 & 333.986 \\
\hline 1.06445 & 646.464 & 334.515 \\
\hline 1.19438 & 740.806 & 355.409 \\
\hline 1.38659 & 884.701 & 386.755 \\
\hline 1.49547 & 961.604 & 398.084 \\
\hline 1.55777 & 1011.48 & 408.48 \\
\hline 1.69849 & 1115.16 & 429.412 \\
\hline 1.80384 & 1196.16 & 440.685 \\
\hline 1.89286 & 1262.33 & 451.46 \\
\hline 2 & 1341.58 & 462.651 \\
\hline
\end{tabular}


Aluminum, E=69 GPa, $\mathrm{S}_{y}=275 \mathrm{MPa}, \mathbf{n}=\mathbf{0 . 3 6}$

\begin{tabular}{|c|c|c|}
\hline \multicolumn{3}{|c|}{ Aluminum } \\
\hline \multicolumn{3}{|c|}{$\mathrm{E}=69 \mathrm{GPa}, \mathrm{S}_{y}=275 \mathrm{MPa}, \mathbf{n}=0.36$} \\
\hline Time Increment & Load $(\mathrm{N})$ & a, Contact Radius $(\mu \mathrm{m})$ \\
\hline 0.0875 & 30.9241 & 89.8789 \\
\hline 0.2675 & 133.222 & 159.828 \\
\hline 0.444687 & 256.464 & 210.045 \\
\hline 0.531172 & 321.998 & 230.215 \\
\hline 0.645078 & 411.335 & 250.459 \\
\hline 0.777969 & 518.892 & 280.829 \\
\hline 0.948828 & 662.769 & 311.369 \\
\hline 1 & 707.209 & 321.603 \\
\hline 1.1025 & 801.567 & 331.958 \\
\hline 1.2825 & 958.428 & 362.663 \\
\hline 1.485 & 1149.3 & 383.743 \\
\hline 1.6875 & 1334.32 & 414.567 \\
\hline 1.86469 & 1503.64 & 435.58 \\
\hline 1.97121 & 1604.77 & 446.16 \\
\hline
\end{tabular}


Aluminum, E=69 GPa, $\mathrm{S}_{y}=500 \mathrm{MPa}, \mathbf{n}=\mathbf{0 . 0 9}$

\begin{tabular}{|c|c|c|}
\hline \multicolumn{3}{|c|}{ Aluminum } \\
\hline \multicolumn{3}{|c|}{$\mathrm{E}=69 \mathrm{GPa}, \mathbf{S}_{y}=500 \mathrm{MPa}, \mathbf{n}=0.09$} \\
\hline Time Increment & Load $(\mathrm{N})$ & a, Contact Radius $(\mu \mathrm{m})$ \\
\hline 0.105625 & 42.6889 & 99.9896 \\
\hline 0.195625 & 93.2377 & 140.29 \\
\hline 0.250007 & 127.262 & 160.555 \\
\hline 0.302614 & 158.412 & 180.766 \\
\hline 0.439455 & 247.533 & 221.55 \\
\hline 0.511618 & 297.766 & 242.109 \\
\hline 0.563936 & 336.188 & 252.435 \\
\hline 0.628248 & 384.623 & 262.85 \\
\hline 0.674806 & 418.398 & 273.293 \\
\hline 0.749578 & 471.27 & 294.134 \\
\hline 0.803423 & 511.053 & 304.663 \\
\hline 0.852904 & 546.754 & 315.258 \\
\hline 0.909454 & 589.203 & 325.878 \\
\hline 0.981951 & 647.229 & 336.686 \\
\hline 1 & 656.619 & 337.018 \\
\hline 1.05719 & 700.421 & 347.838 \\
\hline 1.13108 & 752.298 & 358.906 \\
\hline 1.19215 & 799.244 & 369.82 \\
\hline 1.27915 & 859 & 390.772 \\
\hline 1.3417 & 907.532 & 401.935 \\
\hline 1.42677 & 970.793 & 413.145 \\
\hline 1.50383 & 1025.14 & 424.41 \\
\hline 1.58065 & 1081.91 & 435.808 \\
\hline 1.64648 & 1135.73 & 437.785 \\
\hline 1.72963 & 1197.32 & 449.369 \\
\hline 1.80904 & 1257.92 & 460.826 \\
\hline 1.88374 & 1315.49 & 472.222 \\
\hline 2 & 1395.01 & 484.828 \\
\hline
\end{tabular}


Aluminum, E=69 GPa, $\mathbf{S}_{y}=500 \mathrm{MPa}, \mathbf{n}=\mathbf{0 . 1 8}$

\begin{tabular}{|c|c|c|}
\hline \multicolumn{3}{|c|}{ Aluminum } \\
\hline \multicolumn{3}{|c|}{ E=69 GPa, $\mathbf{S}_{y}=\mathbf{5 0 0} \mathbf{~ M P a ,} \mathbf{n = 0 . 1 8}$} \\
\hline \multicolumn{3}{|c|}{} \\
\hline Time Increment & Load (N) & a, Contact Radius $(\mu \mathrm{m})$ \\
\hline 0.1225 & 53.3268 & 109.999 \\
\hline 0.251875 & 135.637 & 160.192 \\
\hline 0.40375 & 246.95 & 200.534 \\
\hline 0.541387 & 350.912 & 241.301 \\
\hline 0.601306 & 404.643 & 251.535 \\
\hline 0.648422 & 443.564 & 261.775 \\
\hline 0.770059 & 542.179 & 282.377 \\
\hline 0.857723 & 620.455 & 303 \\
\hline 0.920565 & 674.994 & 313.428 \\
\hline 1 & 739.979 & 334.23 \\
\hline 1.07906 & 806.862 & 344.721 \\
\hline 1.15263 & 876.945 & 355.339 \\
\hline 1.23639 & 954.141 & 366.086 \\
\hline 1.33522 & 1036.69 & 377.196 \\
\hline 1.42449 & 1112.23 & 397.835 \\
\hline 1.50753 & 1189.39 & 408.672 \\
\hline 1.59786 & 1275.13 & 419.642 \\
\hline 1.68546 & 1355.5 & 430.639 \\
\hline 1.77163 & 1433.35 & 441.656 \\
\hline 1.86161 & 1512.21 & 452.699 \\
\hline 1.97035 & 1614.2 & 464.197 \\
\hline
\end{tabular}


Aluminum, E=69 GPa, $\mathrm{S}_{y}=500 \mathrm{MPa}, \mathbf{n}=\mathbf{0 . 2 7}$

\begin{tabular}{|c|c|c|}
\hline \multicolumn{3}{|c|}{ Aluminum } \\
\hline \multicolumn{3}{|c|}{$\mathrm{E}=69 \mathrm{GPa}, \mathrm{S}_{y}=500 \mathrm{MPa}, \mathrm{n}=0.27$} \\
\hline Time Increment & Load $(\mathrm{N})$ & a, Contact Radius $(\mu \mathrm{m})$ \\
\hline 0.1025 & 44.5212 & 89.7962 \\
\hline 0.2375 & 135.652 & 149.846 \\
\hline 0.342266 & 218.7 & 179.973 \\
\hline 0.456172 & 315.248 & 210.159 \\
\hline 0.589063 & 434.303 & 240.384 \\
\hline 0.759922 & 594.068 & 270.87 \\
\hline 0.930781 & 763.363 & 311.744 \\
\hline 1 & 831.938 & 321.991 \\
\hline 1.1025 & 943.093 & 332.413 \\
\hline 1.2375 & 1084.7 & 353.119 \\
\hline 1.3725 & 1228.44 & 373.88 \\
\hline 1.44984 & 1312.96 & 384.375 \\
\hline 1.53824 & 1408.01 & 395.002 \\
\hline 1.6824 & 1560.96 & 415.788 \\
\hline 1.77551 & 1664.35 & 426.465 \\
\hline 1.86631 & 1765.25 & 437.161 \\
\hline 2 & 1910.54 & 448.466 \\
\hline
\end{tabular}

Aluminum, E=69 GPa, $\mathbf{S}_{y}=500 \mathrm{MPa}, \mathbf{n}=\mathbf{0 . 3 6}$

\begin{tabular}{|c|c|c|}
\hline \multicolumn{3}{|c|}{ Aluminum } \\
\hline \multicolumn{3}{|c|}{ E=69 $\mathbf{~ G P a ,} \mathbf{S}_{y}=\mathbf{5 0 0} \mathbf{~ M P a ,} \mathbf{n = 0 . 3 6}$} \\
\hline \multicolumn{3}{|c|}{ ' } \\
\hline Time Increment & Load (N) & a, Contact Radius $(\mu \mathrm{m})$ \\
\hline 0.1025 & 46.9819 & 89.7298 \\
\hline 0.276875 & 176.84 & 159.558 \\
\hline 0.442988 & 329.925 & 199.426 \\
\hline 0.579142 & 468.554 & 229.498 \\
\hline 0.723304 & 624.713 & 259.716 \\
\hline 0.891494 & 814.881 & 289.957 \\
\hline 1 & 942.28 & 310.287 \\
\hline 1.10125 & 1064.71 & 320.611 \\
\hline 1.30375 & 1315.56 & 351.155 \\
\hline 1.50625 & 1569.29 & 381.687 \\
\hline 1.72563 & 1857.8 & 402.769 \\
\hline 2 & 2222.14 & 433.854 \\
\hline
\end{tabular}


Steel, $\mathbf{E}=200 \mathrm{GPa}, \mathrm{S}_{y}=500 \mathrm{MPa}, \mathbf{n}=\mathbf{0 . 1}$

\begin{tabular}{|c|c|c|}
\hline \multicolumn{3}{|c|}{ Steel } \\
\hline \multicolumn{3}{|c|}{$\mathrm{E}=200 \mathrm{GPa}, \mathbf{S}_{y}=500 \mathrm{MPa}, \mathbf{n}=0.1$} \\
\hline Time Increment & Load $(\mathrm{N})$ & a, Contact Radius $(\mu \mathrm{m})$ \\
\hline 0.044375 & 21.9989 & 70.1006 \\
\hline 0.0715 & 41.0664 & 90.2563 \\
\hline 0.106665 & 67.946 & 110.415 \\
\hline 0.143835 & 96.0989 & 130.702 \\
\hline 0.165024 & 113.091 & 140.882 \\
\hline 0.186716 & 129.54 & 151.078 \\
\hline 0.20767 & 145.862 & 161.271 \\
\hline 0.234611 & 167.841 & 171.519 \\
\hline 0.264536 & 194.296 & 181.801 \\
\hline 0.290477 & 215.84 & 192.098 \\
\hline 0.32341 & 244.871 & 202.448 \\
\hline 0.350497 & 269.672 & 202.666 \\
\hline 0.380723 & 298.256 & 213.07 \\
\hline 0.405028 & 324.995 & 223.359 \\
\hline 0.430141 & 348.889 & 233.697 \\
\hline 0.466955 & 381.203 & 244.189 \\
\hline 0.501725 & 409.082 & 254.754 \\
\hline 0.542866 & 443.454 & 265.324 \\
\hline 0.588708 & 492.391 & 275.979 \\
\hline 0.629533 & 525.913 & 286.69 \\
\hline 0.680959 & 582.598 & 297.482 \\
\hline 0.736512 & 634.823 & 308.469 \\
\hline 0.78075 & 677.464 & 319.25 \\
\hline 0.826283 & 710.717 & 330.129 \\
\hline 0.876479 & 752.354 & 341.067 \\
\hline 0.928236 & 802.663 & 352.145 \\
\hline 0.968698 & 847.883 & 353.294 \\
\hline 1 & 880.139 & 363.502 \\
\hline 1.1225 & 980.852 & 385.924 \\
\hline 1.15454 & 1021.38 & 387.142 \\
\hline 1.26066 & 1111.59 & 409.056 \\
\hline 1.37103 & 1219.1 & 422.235 \\
\hline 1.46289 & 1298.39 & 434.772 \\
\hline 1.57514 & 1389.69 & 456.631 \\
\hline 1.74834 & 1543.54 & 472.662 \\
\hline 1.83649 & 1622.61 & 484.936 \\
\hline 1.96461 & 1726.89 & 506.812 \\
\hline
\end{tabular}


Steel, $\mathbf{E}=200 \mathrm{GPa}, \mathrm{S}_{y}=\mathbf{5 0 0} \mathrm{MPa}, \mathbf{n}=\mathbf{0 . 2}$

\begin{tabular}{|c|c|c|}
\hline \multicolumn{3}{|c|}{ Steel } \\
\hline \multicolumn{3}{|c|}{$\mathbf{E}=200 \mathrm{GPa}, \mathbf{S}_{y}=500 \mathrm{MPa}, \mathbf{n}=0.2$} \\
\hline Time Increment & Load $(\mathrm{N})$ & a, Contact Radius $(\mu \mathrm{m})$ \\
\hline 0.06625 & 41.6859 & 80.0184 \\
\hline 0.111825 & 79.8989 & 110.229 \\
\hline 0.141005 & 107.417 & 120.28 \\
\hline 0.174902 & 136.732 & 140.516 \\
\hline 0.20976 & 175.287 & 150.611 \\
\hline 0.260963 & 227.794 & 170.874 \\
\hline 0.298872 & 268.244 & 181.078 \\
\hline 0.350438 & 320.394 & 201.484 \\
\hline 0.38655 & 361.658 & 211.724 \\
\hline 0.419983 & 396.368 & 222.004 \\
\hline 0.490443 & 477.555 & 232.334 \\
\hline 0.525374 & 521.162 & 242.689 \\
\hline 0.562305 & 567.274 & 252.992 \\
\hline 0.613494 & 625.387 & 263.511 \\
\hline 0.655608 & 677.715 & 273.851 \\
\hline 0.697186 & 730.395 & 284.245 \\
\hline 0.73855 & 782.109 & 294.65 \\
\hline 0.817256 & 870.198 & 305.572 \\
\hline 0.864164 & 931.577 & 316.048 \\
\hline 0.902176 & 983.308 & 326.366 \\
\hline 0.974088 & 1069.97 & 337.186 \\
\hline 1 & 1091.14 & 337.745 \\
\hline 1.04797 & 1157.56 & 348.313 \\
\hline 1.14129 & 1269.27 & 369.095 \\
\hline 1.19676 & 1336.11 & 370.357 \\
\hline 1.26118 & 1419.76 & 381.169 \\
\hline 1.35441 & 1536.11 & 401.824 \\
\hline 1.43141 & 1638.23 & 412.888 \\
\hline 1.50795 & 1722.41 & 423.943 \\
\hline 1.58302 & 1817.59 & 435.079 \\
\hline 1.66914 & 1925.28 & 446.31 \\
\hline 1.76526 & 2042.27 & 457.698 \\
\hline 1.82947 & 2133.2 & 459.682 \\
\hline 1.95299 & 2274.69 & 480.67 \\
\hline 2 & 2350.32 & 482.086 \\
\hline
\end{tabular}


Steel, E=200 GPa, $\mathbf{S}_{y}=500 \mathrm{MPa}, \mathbf{n}=\mathbf{0 . 3}$

\begin{tabular}{|c|c|c|}
\hline \multicolumn{3}{|c|}{ Steel } \\
\hline \multicolumn{3}{|c|}{$\mathrm{E}=200 \mathrm{GPa}, \mathbf{S}_{y}=500 \mathrm{MPa}, \mathbf{n}=0.3$} \\
\hline Time Increment & Load $(\mathrm{N})$ & a, Contact Radius $(\mu \mathrm{m})$ \\
\hline 0.06 & 39.1234 & 69.9173 \\
\hline 0.125 & 103.058 & 109.986 \\
\hline 0.215 & 203.444 & 150.172 \\
\hline 0.305 & 315.593 & 180.415 \\
\hline 0.374375 & 409.017 & 200.626 \\
\hline 0.421836 & 480.225 & 210.724 \\
\hline 0.460398 & 535.917 & 220.905 \\
\hline 0.539612 & 646.139 & 241.179 \\
\hline 0.581663 & 707.353 & 251.466 \\
\hline 0.630047 & 780.624 & 261.667 \\
\hline 0.683989 & 868.099 & 271.88 \\
\hline 0.782241 & 1013.12 & 292.419 \\
\hline 0.827281 & 1085.79 & 302.744 \\
\hline 0.88437 & 1177.03 & 313.071 \\
\hline 0.944256 & 1273.43 & 323.404 \\
\hline 0.999727 & 1366.12 & 323.827 \\
\hline 1 & 1366.45 & 323.831 \\
\hline 1.07594 & 1485.73 & 344.192 \\
\hline 1.14169 & 1594.59 & 354.651 \\
\hline 1.21743 & 1720.18 & 365.107 \\
\hline 1.2463 & 1782.57 & 365.408 \\
\hline 1.29963 & 1869.23 & 375.694 \\
\hline 1.36852 & 1982.17 & 386.212 \\
\hline 1.45467 & 2132.33 & 396.83 \\
\hline 1.53725 & 2276.01 & 407.5 \\
\hline 1.62057 & 2417.19 & 418.187 \\
\hline 1.69763 & 2539.58 & 428.825 \\
\hline 1.78152 & 2678.69 & 439.526 \\
\hline 1.86379 & 2821.98 & 441.174 \\
\hline 1.93081 & 2947.95 & 451.448 \\
\hline
\end{tabular}


Steel, $\mathbf{E}=200 \mathrm{GPa}, \mathrm{S}_{y}=500 \mathrm{MPa}, \mathbf{n}=\mathbf{0 . 4}$

\begin{tabular}{|c|c|c|}
\hline \multicolumn{3}{|c|}{ Steel } \\
\hline \multicolumn{3}{|c|}{$\mathbf{E}=200 \mathrm{GPa}, \mathbf{S}_{y}=500 \mathrm{MPa}, \mathbf{n}=0.4$} \\
\hline Time Increment & Load $(\mathrm{N})$ & a, Contact Radius $(\mu \mathrm{m})$ \\
\hline 0.354531 & 450.133 & 179.795 \\
\hline 0.468437 & 646.866 & 209.86 \\
\hline 0.582344 & 855.637 & 240.065 \\
\hline 0.734219 & 1146.15 & 270.328 \\
\hline 0.905078 & 1491.35 & 300.723 \\
\hline 1 & 1695.35 & 311.067 \\
\hline 1.075 & 1853.4 & 321.397 \\
\hline 1.2325 & 2190.65 & 351.719 \\
\hline 1.38648 & 2534.11 & 372.198 \\
\hline 1.46758 & 2727 & 382.569 \\
\hline
\end{tabular}


Steel, $\mathbf{E}=200 \mathrm{GPa}, \mathrm{S}_{y}=750 \mathrm{MPa}, \mathbf{n}=\mathbf{0 . 1}$

\begin{tabular}{|c|c|c|}
\hline \multicolumn{3}{|c|}{ Steel } \\
\hline \multicolumn{3}{|c|}{$\mathbf{E}=200 \mathrm{GPa}, \mathbf{S}_{y}=750 \mathrm{MPa}, \mathbf{n}=0.1$} \\
\hline Time Increment & Load $(\mathrm{N})$ & a, Contact Radius $(\mu \mathrm{m})$ \\
\hline 0.035938 & 20.9589 & 60.0106 \\
\hline 0.076213 & 54.5578 & 90.1478 \\
\hline 0.110047 & 86.0401 & 110.288 \\
\hline 0.148835 & 125.017 & 130.485 \\
\hline 0.190909 & 172.055 & 140.566 \\
\hline 0.227008 & 212.747 & 160.896 \\
\hline 0.264918 & 258.4 & 171.075 \\
\hline 0.291173 & 290.07 & 181.264 \\
\hline 0.342612 & 343.346 & 201.783 \\
\hline 0.377476 & 386.987 & 212.1 \\
\hline 0.411789 & 428.693 & 222.425 \\
\hline 0.451129 & 477.774 & 232.751 \\
\hline 0.527225 & 568.992 & 253.602 \\
\hline 0.56635 & 616.118 & 264.097 \\
\hline 0.614928 & 686.255 & 274.648 \\
\hline 0.65732 & 733.38 & 285.219 \\
\hline 0.701967 & 789.19 & 295.821 \\
\hline 0.744318 & 847.867 & 296.563 \\
\hline 0.796323 & 914.345 & 317.2 \\
\hline 0.83783 & 974.816 & 317.937 \\
\hline 0.888331 & 1042.8 & 328.713 \\
\hline 0.955332 & 1124.19 & 339.955 \\
\hline 1 & 1190.41 & 350.618 \\
\hline 1.05531 & 1265.33 & 361.545 \\
\hline 1.12374 & 1351.9 & 372.879 \\
\hline 1.18096 & 1430.22 & 383.857 \\
\hline 1.25544 & 1523.78 & 395.421 \\
\hline 1.33346 & 1622.35 & 407.106 \\
\hline 1.41623 & 1724.45 & 419.033 \\
\hline 1.50365 & 1832.25 & 431.045 \\
\hline 1.5774 & 1928.94 & 442.684 \\
\hline 1.64221 & 2017.86 & 453.8 \\
\hline 1.8019 & 2204.57 & 476.971 \\
\hline 1.88896 & 2298.7 & 489.002 \\
\hline 1.97786 & 2411.99 & 501.399 \\
\hline
\end{tabular}


Steel, $\mathbf{E}=200 \mathrm{GPa}, \mathrm{S}_{y}=750 \mathrm{MPa}, \mathbf{n}=\mathbf{0 . 2}$

\begin{tabular}{|c|c|c|}
\hline \multicolumn{3}{|c|}{ Steel } \\
\hline \multicolumn{3}{|c|}{$\mathrm{E}=200 \mathrm{GPa}, \mathrm{S}_{y}=750 \mathrm{MPa}, \mathbf{n}=0.2$} \\
\hline Time Increment & Load $(\mathrm{N})$ & a, Contact Radius $(\mu \mathrm{m})$ \\
\hline 0.07 & 52.7568 & 79.9325 \\
\hline 0.16 & 150.474 & 130.22 \\
\hline 0.192842 & 195.669 & 140.267 \\
\hline 0.234556 & 245.367 & 160.482 \\
\hline 0.263592 & 283.906 & 170.593 \\
\hline 0.298538 & 330.98 & 180.728 \\
\hline 0.325937 & 369.843 & 190.861 \\
\hline 0.364039 & 421.364 & 201.03 \\
\hline 0.42364 & 514.473 & 211.124 \\
\hline 0.475301 & 584.842 & 231.613 \\
\hline 0.51508 & 645.693 & 241.855 \\
\hline 0.535767 & 686.418 & 241.828 \\
\hline 0.571218 & 739.139 & 252.145 \\
\hline 0.617747 & 811.503 & 262.437 \\
\hline 0.659233 & 872.51 & 272.778 \\
\hline 0.706414 & 942.047 & 283.134 \\
\hline 0.777578 & 1067.57 & 293.512 \\
\hline 0.863187 & 1190.78 & 314.386 \\
\hline 0.90025 & 1262.96 & 314.707 \\
\hline 0.981511 & 1386.63 & 335.411 \\
\hline 1 & 1434.59 & 335.503 \\
\hline 1.0525 & 1516.1 & 346.076 \\
\hline 1.10907 & 1602.25 & 356.68 \\
\hline 1.16313 & 1691.02 & 367.287 \\
\hline 1.2167 & 1788.79 & 368.054 \\
\hline 1.2586 & 1868.03 & 378.195 \\
\hline 1.32969 & 1986.15 & 389.01 \\
\hline 1.40338 & 2109.01 & 399.825 \\
\hline 1.48364 & 2246.55 & 410.814 \\
\hline 1.56233 & 2376.97 & 421.755 \\
\hline 1.64804 & 2523.93 & 432.86 \\
\hline 1.77106 & 2720.91 & 444.969 \\
\hline 1.83368 & 2837.25 & 455.454 \\
\hline 1.92914 & 2996.5 & 466.806 \\
\hline
\end{tabular}


Steel, E=200 GPa, $\mathrm{S}_{y}=750 \mathrm{MPa}, \mathbf{n}=\mathbf{0 . 3}$

\begin{tabular}{|c|c|c|}
\hline \multicolumn{3}{|c|}{ Steel } \\
\hline \multicolumn{3}{|c|}{ E=200 GPa, $\mathbf{S}_{y}=\mathbf{7 5 0}$ MPa, $\mathbf{n = 0 . 3}$} \\
\hline \multicolumn{3}{|c|}{} \\
\hline Time Increment & Load (N) & a, Contact Radius $(\mu \mathrm{m})$ \\
\hline \multicolumn{3}{|c|}{} \\
\hline 0.08 & 67.2827 & 79.8865 \\
\hline 0.17 & 180.996 & 129.962 \\
\hline 0.26 & 316.603 & 159.994 \\
\hline 0.365 & 487.546 & 190.098 \\
\hline 0.5 & 722.816 & 220.322 \\
\hline 0.635 & 976.096 & 250.77 \\
\hline 0.75875 & 1215.79 & 281.364 \\
\hline 0.888125 & 1482.61 & 301.862 \\
\hline 0.971182 & 1647.54 & 322.407 \\
\hline 1 & 1712.63 & 322.382 \\
\hline 1.05203 & 1817.86 & 332.788 \\
\hline 1.11446 & 1945.64 & 343.1 \\
\hline 1.18242 & 2087.31 & 353.471 \\
\hline 1.25819 & 2257.43 & 363.889 \\
\hline 1.35206 & 2467.88 & 374.471 \\
\hline 1.45545 & 2685.22 & 385.364 \\
\hline 1.54729 & 2881.07 & 405.81 \\
\hline 1.65118 & 3108.76 & 416.359 \\
\hline 1.75533 & 3353.99 & 427.216 \\
\hline 1.84654 & 3558.21 & 437.946 \\
\hline 1.94293 & 3771.24 & 448.678 \\
\hline & \\
\hline
\end{tabular}

Steel, E=200 GPa, $\mathrm{S}_{y}=750 \mathrm{MPa}, \mathbf{n}=\mathbf{0 . 4}$

\begin{tabular}{|c|c|c|}
\hline \multicolumn{3}{|c|}{ Steel } \\
\hline \multicolumn{3}{|c|}{ E=200 GPa, $_{y}=\mathbf{7 5 0} \mathbf{~ M P a}, \mathbf{n = 0 . 4}$} \\
\hline \multicolumn{3}{|c|}{} \\
\hline Time Increment & Load (N) & a, Contact Radius $(\mu \mathrm{m})$ \\
\hline \multicolumn{3}{|c|}{} \\
\hline 0.1475 & 165.559 & 109.721 \\
\hline 0.539053 & 916.379 & 219.49 \\
\hline 1.075432 & 1722.79 & 290.032 \\
\hline 1.28125 & 2152.46 & 320.425 \\
\hline & 2788.57 & 350.891 \\
\hline
\end{tabular}


Steel, E=200 GPa, $\mathrm{S}_{y}=1000 \mathrm{MPa}, \mathbf{n}=\mathbf{0 . 1}$

\begin{tabular}{|c|c|c|}
\hline \multicolumn{3}{|c|}{ Steel } \\
\hline \multicolumn{3}{|c|}{$\mathrm{E}=200 \mathrm{GPa}, \mathbf{S}_{y}=1000 \mathrm{MPa}, \mathbf{n}=0.1$} \\
\hline Time Increment & Load $(\mathrm{N})$ & a, Contact Radius $(\mu \mathrm{m})$ \\
\hline 0.499334 & 645.253 & 232.232 \\
\hline 0.546072 & 712.977 & 252.853 \\
\hline 0.585617 & 777.065 & 253.064 \\
\hline 0.646168 & 885.647 & 273.674 \\
\hline 0.715984 & 989.26 & 284.431 \\
\hline 0.783944 & 1091.7 & 305.261 \\
\hline 0.838903 & 1187.72 & 315.935 \\
\hline 0.920283 & 1323.18 & 327.007 \\
\hline 1 & 1437.39 & 348.079 \\
\hline 1.0592 & 1535.43 & 358.957 \\
\hline 1.13202 & 1663.99 & 370.029 \\
\hline 1.19897 & 1780.08 & 381.117 \\
\hline 1.27009 & 1900 & 392.311 \\
\hline 1.34926 & 2034.54 & 403.724 \\
\hline 1.4432 & 2180.11 & 415.733 \\
\hline 1.56649 & 2365.21 & 437.643 \\
\hline 1.65704 & 2521.56 & 449.448 \\
\hline 1.78274 & 2721.46 & 462.69 \\
\hline
\end{tabular}

Steel, E=200 GPa, $\mathrm{S}_{y}=1000 \mathrm{MPa}, \mathbf{n}=\mathbf{0 . 2}$

\begin{tabular}{|c|c|c|}
\hline \multicolumn{3}{|c|}{ Steel } \\
\hline \multicolumn{3}{|c|}{ E=200 $\mathbf{~ G P a , ~} \mathbf{S}_{y}=\mathbf{1 0 0 0} \mathbf{~ M P a}, \mathbf{n = 0 . 2}$} \\
\hline \multicolumn{3}{|c|}{} \\
\hline Time Increment & Load (N) & a, Contact Radius $(\mu \mathrm{m})$ \\
\hline \multicolumn{3}{|c|}{} \\
\hline 0.881567 & 1458.13 & 303.402 \\
\hline 1 & 1692.72 & 324.294 \\
\hline 1.28562 & 2278.24 & 376.608 \\
\hline 1.35075 & 2411.14 & 387.353 \\
\hline 1.4439 & 2616.94 & 398.254 \\
\hline 1.54387 & 2819.16 & 409.536 \\
\hline 1.64975 & 3024.44 & 421.042 \\
\hline 1.76083 & 3264.4 & 441.698 \\
\hline 1.87363 & 3506.73 & 453.224 \\
\hline 2 & 3756.31 & 465.26 \\
\hline
\end{tabular}


Steel, $\mathbf{E}=200 \mathrm{GPa}, \mathrm{S}_{y}=1000 \mathrm{MPa}, \mathbf{n}=\mathbf{0 . 3}$

\begin{tabular}{|c|c|c|}
\hline \multicolumn{3}{|c|}{ Steel } \\
\hline \multicolumn{3}{|c|}{} \\
\hline \multicolumn{3}{|c|}{ E=200 $\mathbf{G P a}^{\mathbf{S}} \mathbf{S}_{y}=\mathbf{1 0 0 0} \mathbf{~ M P a}, \mathbf{n}=\mathbf{0 . 3}$} \\
\hline \multicolumn{3}{|c|}{} \\
\hline Time Increment & Load (N) & a, Contact Radius $(\mu \mathrm{m})$ \\
\hline 0.1025 & 103.404 & 89.7681 \\
\hline 0.2825 & 396.239 & 159.757 \\
\hline 0.485 & 793.324 & 220.099 \\
\hline 0.636875 & 1131.02 & 250.381 \\
\hline 0.733906 & & 270.704 \\
\hline 0.885781 & 1699.38 & 301.268 \\
\hline
\end{tabular}

Steel, E=200 GPa, $\mathrm{S}_{y}=1000 \mathrm{MPa}, \mathrm{n}=0.4$

\begin{tabular}{|c|c|c|}
\hline \multicolumn{3}{|c|}{ Steel } \\
\hline \multicolumn{3}{|c|}{ E=200 GPa, $\mathbf{S}_{y}=\mathbf{1 0 0 0} \mathbf{~ M P a}, \mathbf{n = 0 . 4}$} \\
\hline \multicolumn{3}{|c|}{} \\
\hline Time Increment & Load (N) & a, Contact Radius $(\mu \mathrm{m})$ \\
\hline \multicolumn{3}{|c|}{} \\
\hline 0.645005 & 1304.34 & 239.222 \\
\hline 0.773149 & 1651.76 & 269.399 \\
\hline 0.901294 & & 289.505 \\
\hline 1 & 2301.77 & 299.712 \\
\hline 1.0575 & 2479.64 & 309.832 \\
\hline 1.20938 & 2936.72 & 340.064 \\
\hline 1.28215 & 3165.33 & 350.242 \\
\hline 1.45301 & 3708.07 & 370.553 \\
\hline 1.62387 & 4268.1 & 390.989 \\
\hline
\end{tabular}




\section{VITA}

Name: Bharath Konda

Date of Birth: August 31, 1982

Education: Master of Science in Mechanical Engineering

West Virginia University

May 2005

Bachelor of Science in Mechanical Engineering

Osmania University, India

May 2003 